WALDEN

UNIVERSITY

Walden University

$A$ higher degree. $A$ higher purpose.

ScholarWorks

\title{
Teachers' Perceptions of Differentiation and the Struggle for Consistent Implementation
}

Felicia Dawn Fordyce

Walden University

Follow this and additional works at: https://scholarworks.waldenu.edu/dissertations

Part of the Education Commons

This Dissertation is brought to you for free and open access by the Walden Dissertations and Doctoral Studies Collection at ScholarWorks. It has been accepted for inclusion in Walden Dissertations and Doctoral Studies by an authorized administrator of ScholarWorks. For more information, please contact ScholarWorks@waldenu.edu. 


\title{
Walden University
}

\author{
College of Education
}

This is to certify that the doctoral study by

\section{Felicia D. Fordyce}

has been found to be complete and satisfactory in all respects, and that any and all revisions required by the review committee have been made.

Review Committee

Dr. Michelle McCraney, Committee Chairperson, Education Faculty

Dr. Glenn Penny, Committee Member, Education Faculty

Dr. Matthew Basham, University Reviewer, Education Faculty

Chief Academic Officer and Provost

Sue Subocz, Ph.D.

Walden University

2021 


\begin{abstract}
Teachers' Perceptions of Differentiation and the Struggle for Consistent Implementation by

Felicia D. Fordyce
\end{abstract}

MS, Walden University, 2016

BA, Fairmont State University, 2014

Project Study Submitted in Partial Fulfillment

of the Requirements for the Degree of

Doctor of Education

Walden University

February 2021 


\begin{abstract}
A problem at three elementary schools in an Appalachian state was that some or all instructors were struggling to implement differentiated instruction in the classroom. Because differentiation is a research-based best practice, teachers should be consistently using this strategy to meet the varying needs found within the inclusive classroom. Therefore, the purpose of this study was to investigate perceptions of third- and fourthgrade teachers on their knowledge, implementation, and self-assessment of using differentiated instruction in classrooms in three elementary schools. A qualitative case study methodology was used with the interpretation of differentiation as the conceptual framework. The two research questions that guided this study asked how do third- and fourth-grade teachers use differentiation to support all students and what perceived opportunities and struggles do these teachers believe affect their ability to implement this strategy. Nine third and fourth grade inclusive teachers volunteered to participated in semi-structured phone interviews and lesson plan analysis. Data were hand coded and analyzed using a spreadsheet to look for reoccurring categories and themes. Six themes emerged within the collected qualitative data to include ability grouping, technology, planning for differentiated instruction, professional supports, lack of training, and instructional support. With the findings, specific professional development was created to help the teacher more consistently use differentiation in the classroom. This project study has positive social change implications because it might lead to a stronger administrator and teacher understanding of the perceived uses of differentiation as well as the perceived opportunities and struggles to fully implement the strategy.
\end{abstract}


Teachers' Perceptions of Differentiation and the Struggle for Consistent Implementation

\author{
by \\ Felicia D. Fordyce
}

MS, Walden University, 2016

BA, Fairmont State University, 2014

Project Study Submitted in Partial Fulfillment

of the Requirements for the Degree of

Doctor of Education

Walden University

February 2021 


\section{Dedication}

I would like to dedicate this work to my three children, Kaitlyn, Logan, and Austin Fordyce. Without your patience, understanding, support, and love this could not have been completed. You will always have my heart. I would also like to dedicate this to my students, past, present, and future. Know that you are the only person that holds the key to your future. Dream big, push hard, and always know that there is power in education.

Be the change you wish to see in the world! 


\section{Acknowledgments}

Again, this work could not have been completed without the patience and kindness of my own three children. You were always there as that extra push to keep me going by saying you wanted to be a Doctor of Education just like your mom. A special thanks should also be given to my home away from home. Not only did you give me my career over the past four years, but you brought friendship, heart, and drive to my neverending endeavors! I can't thank each of you enough for supporting me and having those educational talks all of you loved so much! I will forever be grateful!

I would also like to thank Dr. Michelle McCraney for her never-ending support and guidance through this process, Dr. Richard Penny for his thorough and driving feedback, the faculty at Walden University for starting this educational journey several years ago while pursuing my Master's, and my doctoral level professors for their wisdom, professional discourse, and instilling in me the drive for positive social change. 


\section{Table of Contents}

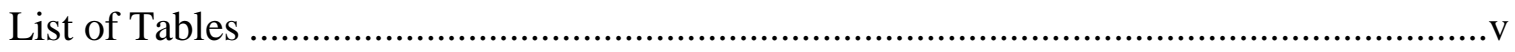

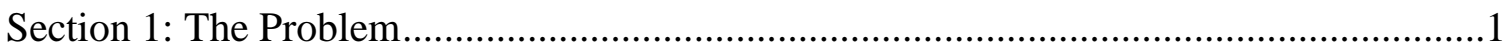

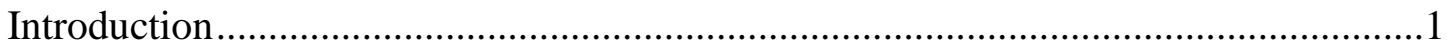

The Local Problem............................................................................................

Evidence of the Problem at the Local Level .......................................................... 6

Evidence of the Problem at the State Level .................................................. 8

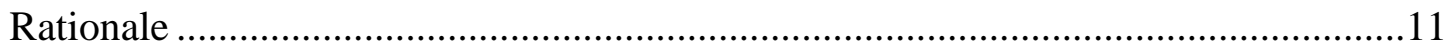

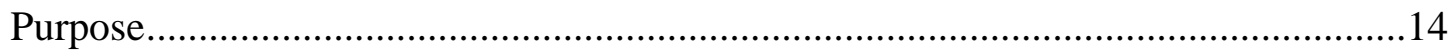

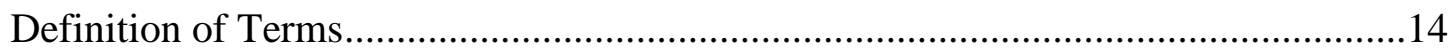

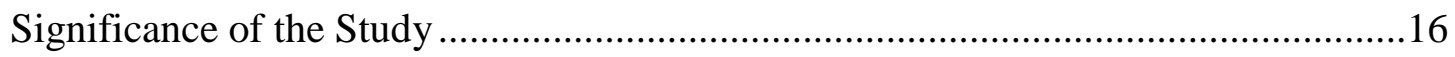

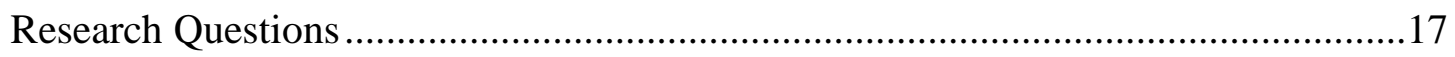

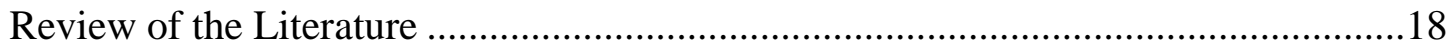

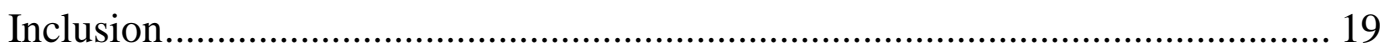

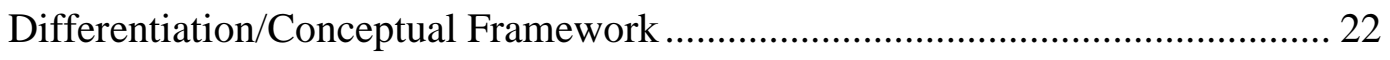

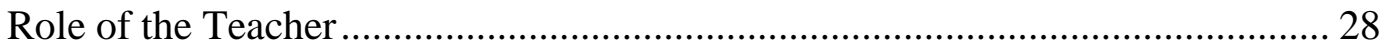

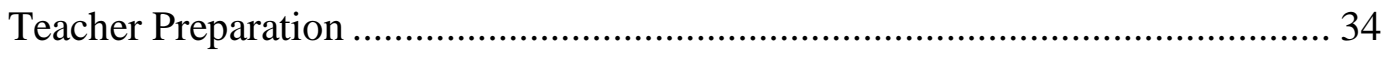

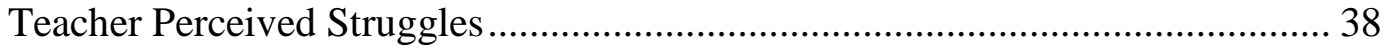

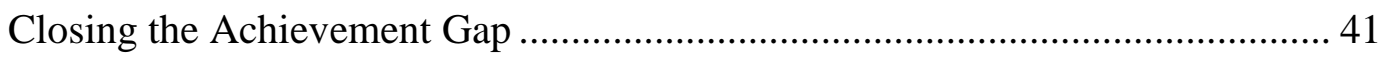

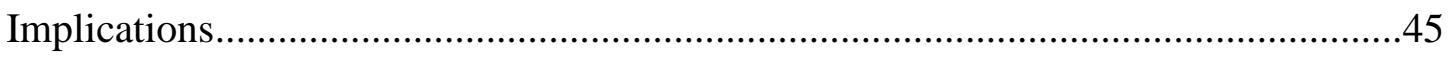

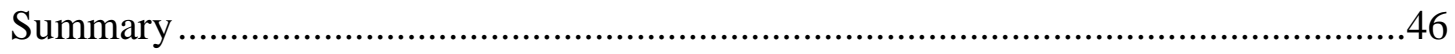

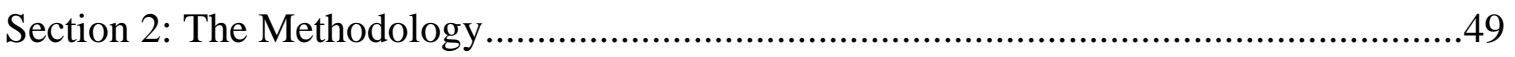




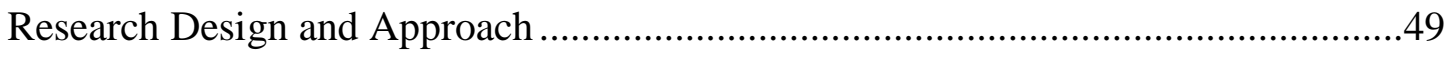

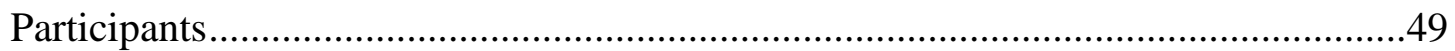

Criteria for Selecting Participants ................................................................. 53

Justification for the Number of Participants ....................................................... 53

Gaining Access to Participants .................................................................. 54

Establishing a Research-Participant Working Relationship ............................. 54

Protection of Participants' Rights ............................................................... 55

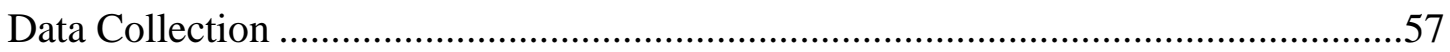

Justification for Data Collection ............................................................. 57

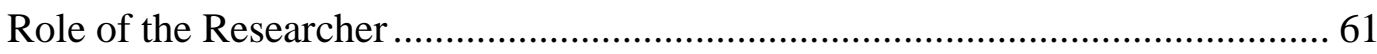

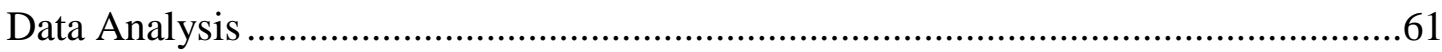

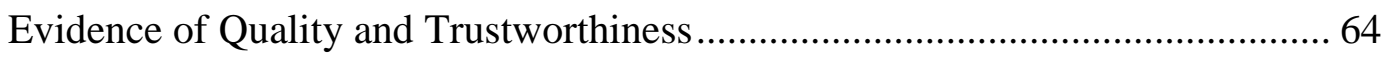

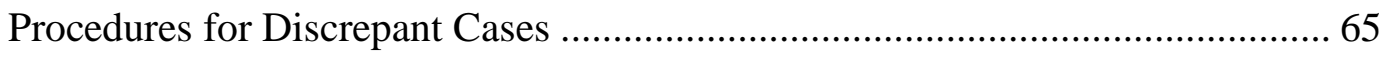

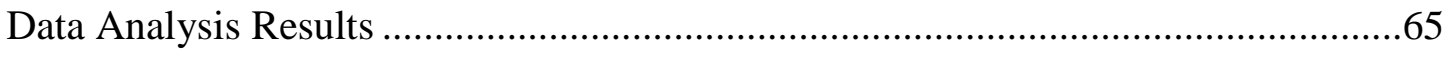

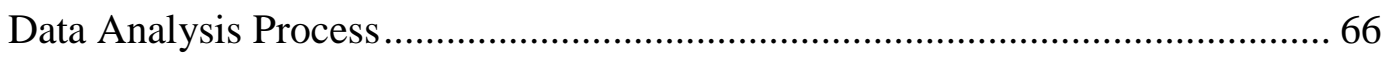

Findings from the Problem and Research Questions ........................................ 67

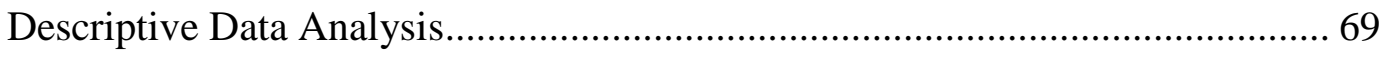

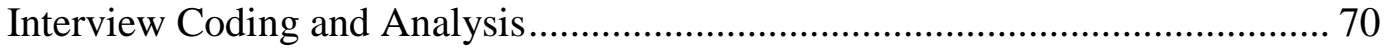

Lesson Plan Coding and Analysis........................................................... 71

Patterns, Relationships, and Themes ..................................................... 73

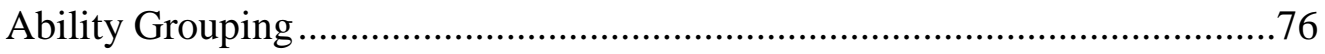

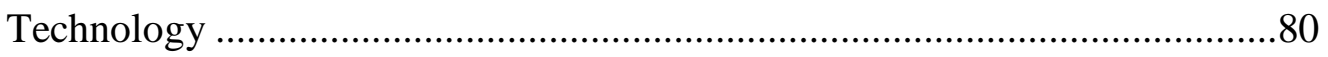




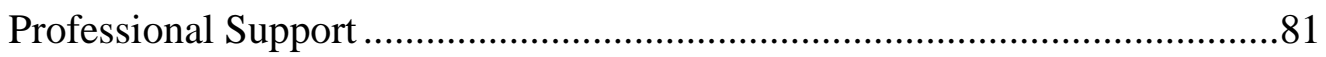

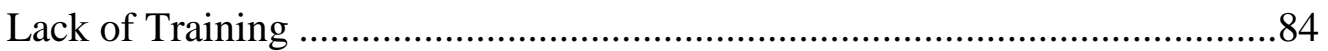

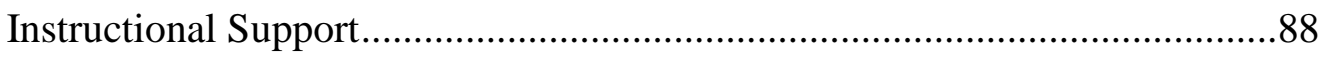

Planning for DI .......................................................................................

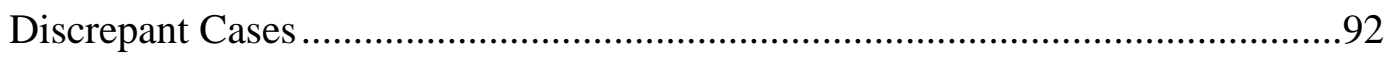

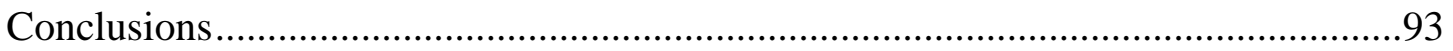

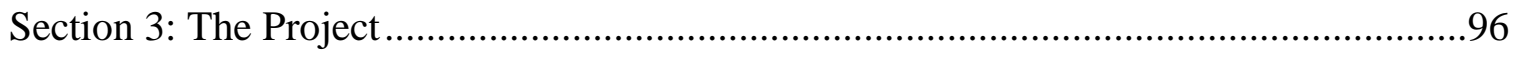

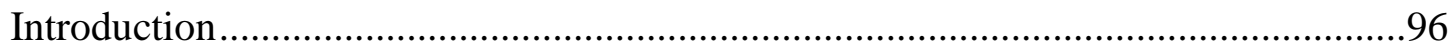

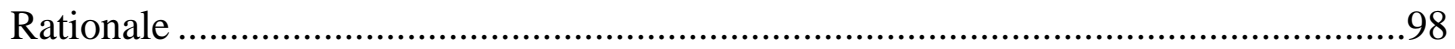

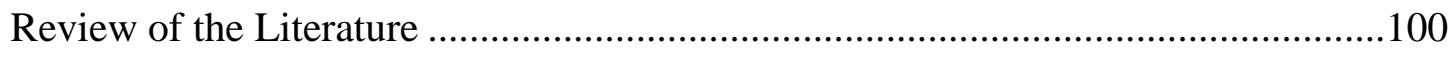

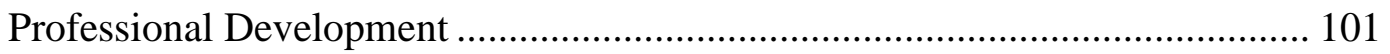

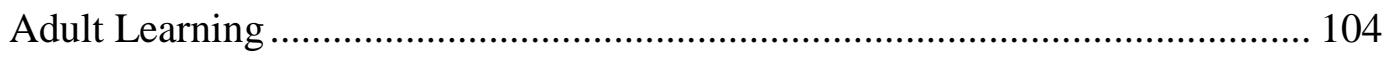

Differentiated Instruction Professional Development ...................................... 105

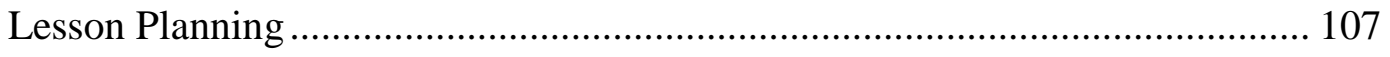

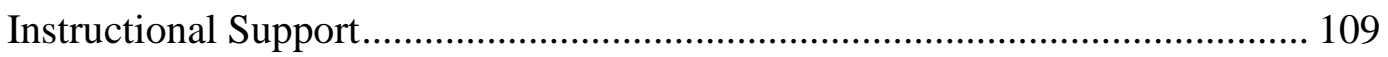

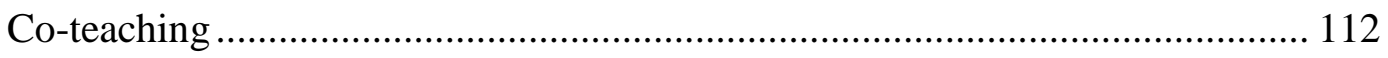

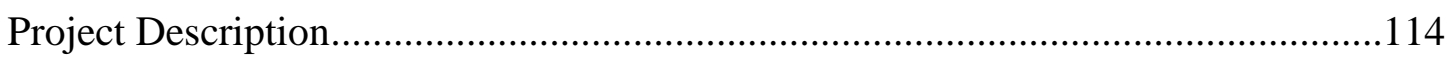

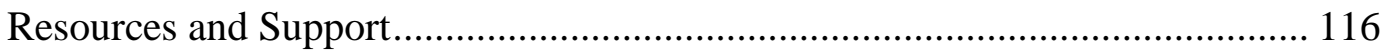

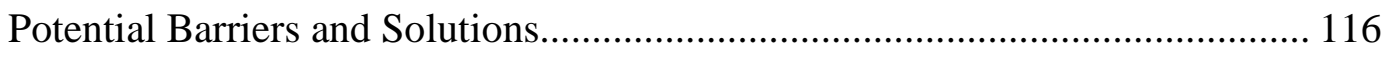

Proposal for Implementation and Project Timetable ……................................... 117

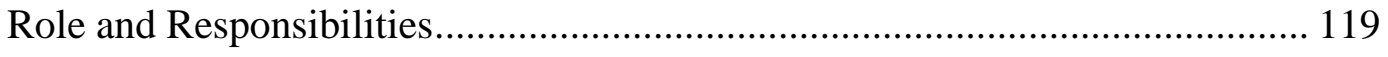

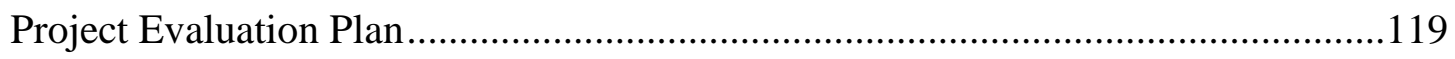


Key Stakeholders

Project Implications Including Social Change........................................................120

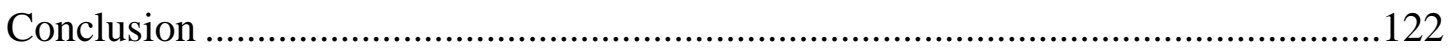

Section 4: Reflections and Conclusions.....................................................................124

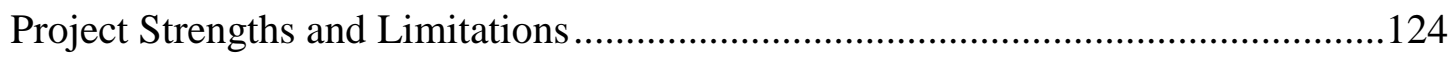

Recommendations for Alternative Approach ..........................................................127

Scholarship, Project Development, and Evaluations, and Leadership and

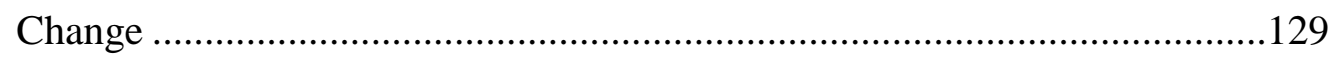

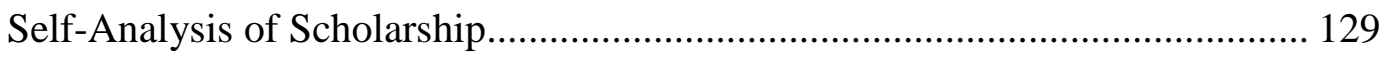

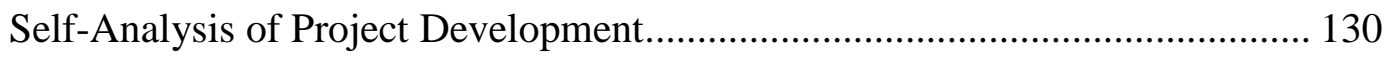

Self-Analysis of Leadership and Change ......................................................... 132

Reflection on Importance of the Work ………………......................................133

Implications, Applications, and Directions for Future Research ...............................134

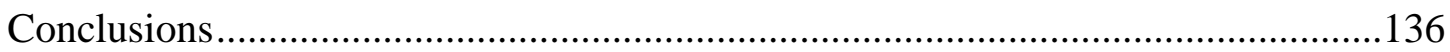

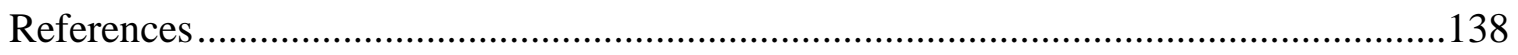

Appendix A: Professional Development on Differentiated Instruction, Co-

teaching, and Alternative Instructional Support …………….............................162

Appendix B: Research Question 1 Round 3 of Coding ...............................................199

Appendix C: Research Question 2 Round 3 of Coding ............................................217 


\section{List of Tables}

Table 1. General Summative Assessment Third Grade County Results of Students

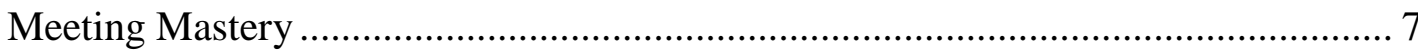

Table 2. General Summative Assessment Fourth Grade County Results of Students

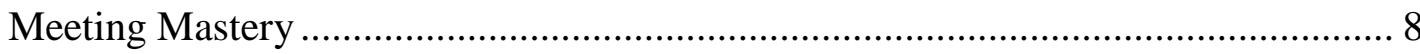

Table 3. General Summative Assessment Third and Fourth Grade Learning Gaps .......... 8

Table 4. Comparison of General Summative Assessment Mastery Results of Third

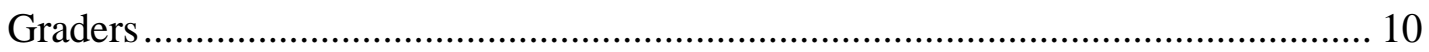

Table 5. Comparison of General Summative Assessment Master Results of Fourth

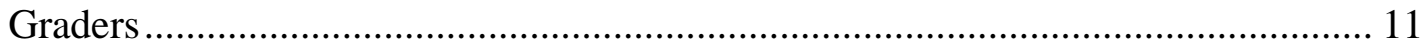

Table 6. Alignment of Interview Questions to Research Questions and Elements of

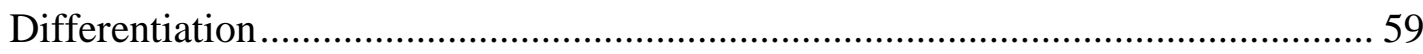

Table 7. Descriptive Data from Interviews ....................................................... 70

Table 8. Coding for Interviews ......................................................................... 70

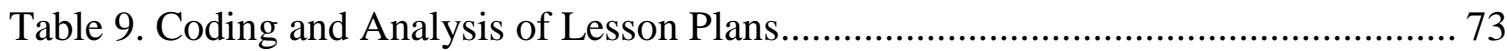

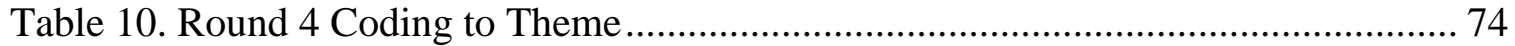


Section 1: The Problem

Introduction

Before 2004, most classrooms were teacher centered and led by direct instruction. Students who struggled were placed in remedial classes with lowered expectations. The No Child Left Behind Act enacted in 2002 provided insight into where students needed additional support (U.S. Department of Education, n.d.). But the Every Child Succeeds Act signed into law by President Barrack Obama was the first time that students were required to be prepared to standards that would help them succeed in college and careers (U.S. Department of Education, n.d.). Introduced in the Individuals with Disabilities Education Act in 2004 and reaffirmed in Every Student Succeeds Act in 2015, inclusive education ensured a free appropriate public education for all students including those with disabilities requiring students with special needs to be placed in their least restricted environment (Bicehouse \& Faieta, 2016; Boroson, 2017). The least restricted environment is known as the inclusive classroom, which includes general education and special education students led by the general education teacher teaching the state's mandated curriculum (Florian \& Beaton, 2017). Statistically, 95\% of students with disabilities (SWDs) will be placed within the inclusive setting (U.S. Department of Education, n.d.). Student disabilities can include emotional disorders, physical disabilities, and learning disabilities along with autism and hearing and visual impairments. 
Faced with new challenges and rapid changes in curriculum, some schools have turned to differentiation to meet these varying needs. Differentiated instruction (DI) is one of the most commonly used instructional strategies to help close the academic achievement gaps aiming to meet the individual learning needs of each student based on their specific academic need by providing on level instruction (Avery, 2017; Vega, 2015). For example, research has shown a positive effect of achievement scores in English language arts (ELA) and mathematics when students were grouped based on ability in each subject for small group instruction after whole group instruction had occurred (Deunk, Smale-Jacobsel, de Boer, Doolaard, \& Bosker, 2018).

DI in education is an ongoing process that takes planning, dedication, and an open mind (Bushie, 2015). It is a proactive process requiring the teacher to assess students and plan lessons with varied approaches to student differences in readiness, interest, and learning needs (Tomlinson, 2001). Thus, it is rooted in assessment and is for all students within the general education classroom (Tomlinson, 2017). The flow of instruction in a differentiated classroom can be seen by the repeated process of whole class preparation review and sharing followed by an opportunity for individualized or small group exploration, extension, and production (Tomlinson, 2017). DI is organic in nature as the teacher should be reflective of their practice and the learning of their students while accommodating the learning needs as they arise. Because differentiation is a teaching strategy used to meet the needs of all learners in the elementary general education 
classroom, teachers should hold high expectations for all learners requiring each student to meet mastery of the grade-level content (Tobin \& Tippett, 2014).

Though instructional needs are the main focus of DI because of the varied student population now in the inclusive classroom, teachers are asked to be proficient in other aspects of education including classroom management, content, communication, and assessment (Deunk et al., 2018). When teachers have an extensive background in content, experience in diagnostic, didactical and pedagogical knowledge, higher results will follow (Smeets, Ledoux, Regtvoort, Felix, \& Moi Lous, 2015). For teachers with less developed knowledge and skills, implementing differentiation can be difficult and can lead to inconsistent implementation (Prast, Van de Weijer-Bergsma, Kroesbergen, \& Van Luit, 2018). The ability to make decisions about the content being delivered, the process of delivery, and the assessment or product to show student mastery is contingent upon a successful interpretation of the curriculum and the teacher's level of comfort with the components of differentiation (Lochner, Conrad, \& Graham, 2015). For teachers to be consistent with this strategy, they should be knowledgeable of the strategy with a high sense of self-efficacy (Tomlinson, 2001). But because differentiation has many components and is embedded into already existing pedagogy (e.g., Bloom's taxonomy, learning styles, and multiple intelligences), teachers could misinterpret and unsuccessfully implement differentiation. Teachers might also face other barriers when trying to implement differentiation successfully. 
Teachers have also stated weak administrative support, low parental support and resistance, lack of time, lack of funding leading to shortages in learning resources, grading concerns, and the fear of losing control from the lack of training skills to be the main causes of unsuccessful DI in the inclusive setting (Gaitas \& Alves Martins, 2017; Siam \& Al-Natour, 2016). Research has also identified the lack of preservice and inservice training as a contributing factor to the unsuccessful implementation (Gaitas \& Alves Martins, 2017). Furthermore, current research has suggested the importance of looking deeper into barriers and teacher struggles to address the learning needs found within the inclusive classroom to help students reach their fullest potential by teachers fully and consistently implementing DI (Gumpert \& McConnell, 2019; Smets, 2019).

\section{The Local Problem}

DI is a best practice found within inclusion to help teachers meet the varying needs of all students. This instructional strategy is mandated in all classrooms within the research site as inclusion is practiced in every room as it is also statewide. Even though most teachers have had some professional development (PD) on this strategy, there seems to still be a reluctance to fully and consistently implement DI. In this study, I addressed the problem that was identified through conversations with administrators and some faculty who believe some or all third- and fourth-grade instructors may be struggling to implement DI in the classroom.

The study site used for this project consisted of three elementary schools found within one north-central county in one Appalachian state containing 14 third and fourth 
grade inclusive classrooms. Third- and fourth-grade teachers were chosen for this research study because third grade is when students first take the General Summative Assessment (GSA) and learning gaps start to become evident in the classroom. These 2 years are also the last years within the elementary school setting before students move to the middle school setting within the county.

According to the special education county coordinator, the third- and fourth-grade classrooms within the county served 351 students in which 83 students from all 14 classrooms receive special education services. These services included supports within the general education classroom and outside to specifically address more intensive learning needs. A typical inclusive classroom within the research site would include 24 to 28 students with 28 being the maximum amount by law. Legally only $30 \%$ of these students are allowed to have an individualized education plan (IEP) and receive modifications that are also oftentimes met within each classroom. With such a high special education rate within the county, one principal reported teachers expressing frustration as they were being tasked with designing and preparing lessons to meet all student needs in the elementary classroom.

To be successful and consistent when implementing DI, it is important to have student-teacher relationships, the familiarity of students' successes and interests, and repetitive formative assessment to drive differentiation (Smets, 2019). Curricular elements related to a teacher's teaching philosophy, the level of pedagogical training, and the interactional natural elements of the classroom can also impact the consistency of the 
use of differentiation (Frunză \& Petre, 2015). Although these aspects have been addressed through county-wide initiatives within the research site with greeting students at the door, writing postcards to families, implementing digital communication tools, and specific PD a lack of implementation has been documented through observational feedback and schoolwide audits.

\section{Evidence of the Problem at the Local Level}

According to the county's mission statement for the study site, schools will strive to create a safe, secure, nurturing environment that supports high expectations and success for all while preparing students to be self-directed learners who can thrive responsibly in a global society. To address these goals, the leadership team indicated that DI is a best practice for meeting the diverse needs within the school setting. The goal was closing the academic achievement gaps found between third- and fourth-grade special education and general education students in ELA and mathematics. Classroom teachers within the test area had stated the varying abilities within their third- and fourth-grade classrooms were too widely spread and believed they needed more strategies to help bridge the observed achievement gaps. Furthermore, according to a local audit report from the organization under study, teachers are struggling to differentiate within the classroom with minimal grouping styles and little to no differentiation based on interest or product.

The research site also had access to achievement data starting in third grade that can help differentiate based on ability to better remediate missing skills. The GSA is a 
summative assessment given to three through eighth graders at the end of each school year to assess their mastery of College and Career Readiness Standards set forth by the state. The results use a 1 to 4 scale with a 1 being below mastery, 2 partial mastery, 3 mastery, and 4 above mastery. The state reports the results as only 3 and 4 meeting mastery.

The 20182019 statistical school data provided by the state's GSA given to thirdand fourth-grade students showed the academic achievement gap between special education and general education students in ELA and mathematics within the county are still stagnant. Table 1 and Table 2 show third- and fourth-grade student achievement results for both general education and special education students, which were obtained from the state's reporting page over a period of 5 years. Table 3 shows the learning gaps in percentages found between these two populations of students. Overall, academic scores have room to grow in all areas, general education and special education. As a country, and therefore as a state, the U.S. Department of Education expects all students to achieve mastery as teachers should be teaching the content using effective strategies to meet individual learning needs.

\section{Table 1}

General Summative Assessment Third Grade County Results of Students Meeting Mastery

\begin{tabular}{lllllllllll}
\hline & 2015 & & 2016 & & 2017 & & 2018 & & 2019 \\
\hline & GE & SE & GE & SE & GE & SE & GE & SE & GE & SE \\
ELA & 41 & 19 & 52 & 36 & 46 & 30 & 47 & 18 & 58 & 38 \\
Mathematics & 42 & 17 & 52 & 33 & 56 & 39 & 54 & 24 & 65 & 41 \\
\hline
\end{tabular}

Note. Data given in percent. GE $=$ general education, $\mathrm{SE}=$ special education 
Table 2

General Summative Assessment Fourth Grade County Results of Students Meeting Mastery

\begin{tabular}{lllllllllll}
\hline & 2015 & & 2016 & & 2017 & & 2018 & & 2019 \\
\hline & GE & SE & GE & SE & GE & SE & GE & SE & GE & SE \\
ELA & 52 & 19 & 50 & 29 & 54 & 18 & 51 & 16 & 53 & 22 \\
Mathematics & 39 & 19 & 36 & 24 & 52 & 26 & 62 & 18 & 59 & 25 \\
\hline
\end{tabular}

Note. Data given in percent. GE = general education, $\mathrm{SE}=$ special education

Table 3

General Summative Assessment Third and Fourth Grade Learning Gaps

\begin{tabular}{lllll}
\hline & 3rd ELA & 3rd Math & 4th ELA & 4th Math \\
\hline 2015 & 22 & 25 & 33 & 20 \\
2016 & 16 & 19 & 21 & 12 \\
2017 & 16 & 17 & 36 & 26 \\
2018 & 29 & 30 & 35 & 44 \\
2019 & 20 & 24 & 31 & 34 \\
\hline
\end{tabular}

Note. Data given in percent.

\section{Evidence of the Problem at the State Level}

The National Center for Education Statistics indicated that the percentage of SWDs in the state in 2019 stood at $15.7 \%$, about three percentage points higher than the national average of $12.9 \%$ while ranking in the bottom 10 in educational academic performance. With the raised percentage of students qualifying for special education services, the state's legislators have proposed many changes to classroom organization. The law currently states that only $30 \%$ of students with an IEP can be in the inclusive classroom. In a class of 28 students, this means no more than eight students can be in special education. In a typical classroom, the remaining 20 students can still have a 504 (a legal document stating modifications or accommodations based on physical 
impairments) or be on the student assistance team that may result in more classroom accommodations and modifications. With each student needing specific adjustments made in the classroom, the workload can create a stressful and unmanageable task for the general education teacher.

To raise achievement, differentiation is a suggested best practice used statewide. According to the state's Math4Life webpage (a statewide math initiative that aims to show the way math is incorporated into everyday life), many PD opportunities are available throughout the year specifically addressing differentiation and its uses in the classroom. But although differentiation is addressed and implemented throughout all schools, academic achievement has been a struggle. Further, like many other states, the research area has a teacher shortage with hundreds of vacant positions that are never filled with a certified teacher but placed with a long-term sub (Knisely, 2020). The state's board of education has had to allow teachers already certified to skip additional classes and take a content test to become certified in high demanded areas like mathematics and special education. The state's department of education has also allowed anyone holding a high school diploma to register for being a substitute, which can lead to a full-time job in a vacant position for the school year. With uncertified teachers in high demand areas, an abundance of veteran teachers leaving the profession each year, and new teachers entering the profession unprepared to teach in inclusive classrooms, the state's department of education is struggling to address the specific needs of its teachers. 
Differentiation has been a focal point for improvement but without teacher buy-in, little progress has been made during this initiative.

Over the past 4 years (2015-2018), teachers and administrators have struggled to raise third- and fourth-grade academic achievement scores in ELA and mathematics. Examining statewide data from the 2018-2019 summative assessment, the state reported on its testing platform that $51 \%$ of third graders met mastery in mathematics and $44 \%$ mastery in ELA. Similarly, fourth graders scored $47 \%$ mastery in mathematics and $49 \%$ mastery in ELA. Furthermore, when comparing across 3 consecutive years (2015-2017), stakeholders have seen very little progress in raising achievement scores. The state's department of education showed third graders in ELA scored $46 \%$ proficient, $48 \%$ proficient, and $45 \%$ proficient in those years. Fourth graders also showed no progress with $45 \%$ proficient, $48 \%$ proficient, and $47 \%$ proficient in those consecutive years. Mathematics showed similar results. Additionally, third graders scored $44 \%$ proficient, $49 \%$, and $48 \%$ proficient in these consecutive years, and fourth grade students scored $36 \%$ proficient, $40 \%$, and $43 \%$ proficient, showing the only positive trend throughout all sets of data. Tables 3 and 4 show the lack of progress in both grades over the sequential years in ELA and mathematics.

Table 4

Comparison of General Summative Assessment Mastery Results of Third Graders

\begin{tabular}{llllll}
\hline & 2015 & 2016 & 2017 & 2018 & 2019 \\
\hline English Language Arts & 46 & 48 & 45 & 44 & 44 \\
Mathematics & 44 & 49 & 48 & 49 & 51 \\
\hline
\end{tabular}

Note. Numbers given in percentages. 
Table 5

Comparison of General Summative Assessment Master Results of Fourth Graders

\begin{tabular}{llllll}
\hline & 2015 & 2016 & 2017 & 2018 & 2019 \\
\hline English Language Arts & 45 & 48 & 47 & 47 & 49 \\
Mathematics & 36 & 40 & 43 & 45 & 47 \\
\hline Note Number
\end{tabular}

Note. Numbers given in percentages.

Looking specifically at special education students within the state, a large percent of these students take the GSA - about 91\%. According to the state's GSA reporting platform, only $18 \%$ of third graders taking the ELA assessment showed proficient results and only $16 \%$ of fourth graders. Special education students in third grade who took the mathematics portion achieved only a $24 \%$ proficient rate with fourth grade students only scoring $18 \%$ proficiency. With enrollment trends showing about one-fifth of the enrolled population qualifying for special education services (83\% general education and $17 \%$ special education), more concentration should be given to classroom adoptions that could help this disadvantaged group of students.

\section{Rationale}

The problem was identified through conversations with administrators and some faculty who believed some or all third- and fourth-grade instructors were struggling to implement DI in the classrooms. As research has shown, differentiation is a strategy that can be used by teachers to help plan instruction that meets the needs of all students within an inclusive classroom (Tomlinson, 2001). However, veteran teachers within the research site had expressed many concerns about the implementation including limited time for 
planning, an unmanageable workload, and increased behavioral concerns in the classroom. The administration had also reported the lack of documented DI during walkthrough observations and has had several conversations with the leadership team consisting of teachers and administrators to try to solve the lack of implementation.

After the state performed audit of the research site's level of differentiation, the administration of one elementary school prescribed PD provided by the state's department of education. However, at a following leadership team meeting comprised of teachers and administrators, the team vocalized the lack of impact the PD had on the teachers who still lack the motivation to use the strategy in the classroom. The team notes stated the PD merely defined differentiation without any concrete uses or examples of the strategy that could be immediately implemented within the classroom. The team then suggested that the type of differentiation that is used more in the research site was more spontaneous in nature. For example, as informal assessments were being completed during the lesson and teachers witnessed students "not getting it," they would target struggling students for answering questions during whole group instructional. Teachers would also go to these students during independent work to do a quick one-on-one session while others were working. This strategy is known as "in-flight" thinking in which teachers differentiate as a reflection of their teaching (Black, Lawson, \& Norwich, 2019).

Another strategy widely used within one elementary school in the study site is ability grouping. This strategy is one of the most implemented portions of differentiation 
but does not always have the highest gains toward achievement (Deunk et al., 2018). Teachers in the research site claimed to use ability grouping for guided reading groups and some for math groups. Guided reading is a strategy used across the research site, which allows the teacher to design four to five stations to review and practice ELA skills for the week or as a spiral review. The teacher becomes one of the stations in which they work with each group on their designated perceived level. Differentiation is most used within the content of ELA at the research site while still seeing lower achievement scores when compared to mathematics.

Although teachers claimed they were differentiating through spontaneous differentiation as they saw the need during instruction and through ability grouping, the state audit showed little to no observed differentiation being performed in the classroom. Teachers acknowledged the importance of meeting the needs of all students but seemed to lack the knowledge of how to plan for DI within the inclusive setting. One administrator in the research site stated seeing minimal DI in lesson plans. If there were any observable differentiation, it was a result of guided reading group planning. The administration within the schools offered the suggestion to use more choice boards within guided reading and morning work, which could provide more student choice and motivation. But teachers rebutted this suggestion by saying the tasks would not be meaningful and thus challenged the purpose of choice boards regarding meeting the needs of differentiation. Many teachers have also argued the minimum requirement by law and administration has stated unfamiliarity of what they are allowed to require of 
teachers. Another argument that teachers have had is that while they can plan a differentiated lesson, it is hard to determine how students will respond. A lesson is like a performance: preceded by composition (the lesson planning) but affected by the interpretation and improvisation of the teacher (Black et al., 2019). Therefore, teachers question if taking the time to preplan for differentiation is worth the investment when it could be spent designing lessons to meet the average while differentiating during instruction to meet the outliers in the classroom.

\section{Purpose}

Differentiation is a research-based best practice used across the identified Appalachian state. Administrators and teacher leaders within the research site questioned why differentiation is not being implemented consistently throughout all classrooms if teachers know this strategy increases student achievement for all learners. Therefore, the purpose of this qualitative case study was to investigate perceptions of third- and fourthgrade instructors on their knowledge, implementation, and self-assessment of using DI in classrooms in three elementary schools in the identified Appalachian state.

\section{Definition of Terms}

Differentiation or differentiated instruction (DI): "Differentiation is a combination of careful progress monitoring and adapting instruction in response. It is an approach to teaching in which teachers proactively modify curricula, teaching methods, resources, learning activities, and student products to address the diverse needs of 
individual students and small groups of students to maximize the learning opportunity for each student in a classroom" (Deunk et al., 2018, p. 1).

English Language Arts (ELA): As determined by College and Career Readiness Standards, ELA consists of 11 components within three clusters: fundamental literacy, model building, and application (Deane et al., 2015). The key practices include (a) communicate by speaking and listening (oral language); (b) read silently and aloud (early reading); (c) write down words and ideas (early writing); (d) develop and share stories and other social understandings; (e) build and share knowledge from text; (f) draft, revise, edit, and publish text; (g) analyze craft and literary elements; (h) build and justify interpretations; (i) discuss and debate ideas; (j) conduct inquiry and research; and (k) propose, revise, recommend, and evaluate (Deane et al., 2015).

General education student: A student who spends $100 \%$ of their time in the general education classroom (Hunt et al., 2020).

General Summative Assessment (GSA): The Department of Education for the study site describes the GSA for students Grades 3-8 as an online cumulative test given toward the end of the school year to measure student performance on the state's content standards, which provide clear consistent guidelines for what students should know and be able to do at each grade level. Students in Grades 3-8 are assessed in ELA and mathematics. Students in Grades 5 and 8 also are assessed in science.

Inclusion: "Inclusive education is defined as educators and schools ensuring that children can access the curriculum by not only being physically into the educational 
setting but also by ensuring that the curricular materials are being appropriately modified and used by educators to allow all children to access them" (Gregory, 2018, p. 128).

Professional development (PD): Training opportunities that aim to teach new skills and alter teacher beliefs on current teaching strategies (Gaines et al., 2019).

Pull-out services: Used as a special education program, students are taken out of the regular general education classroom during the typical school day and placed in an alternative education environment (Archibald, 2017).

Students with disabilities (SWD): Individuals with unique academic and social needs (Bemiller, 2019)

Special education student: A student who receives pull-out services through special education or receives accommodations/modifications within the inclusive setting (Hunt et al., 2020).

\section{Significance of the Study}

This study investigated the perceptions of third- and fourth-grade instructors on their knowledge, implementation, and self-assessment of using DI in classrooms in three elementary schools in one Appalachian state. This study makes an original contribution to the existing body of knowledge on differentiation, a key component of inclusion to which teachers have indicated struggling to implement fully within the inclusive classroom (Arnaiz Sánchez, de Haro Rodríguez, \& Maldonado Martínez, 2019). As a result of the study, teachers and administrators may become more knowledgeable of the perceived barriers within the research site found within the implementation of DI, thus 
becoming able to address these needs through specific PD. Teachers will then be more prepared and knowledgeable of the strategy and can better implement the teaching style within the classroom. As such, all teachers within the site will have differentiated PD and can more consistently use DI in the classroom, helping to meet all student needs with the intent to help close the achievement gap between general education and special education students. The findings for this study have the potential to promote positive social change by promoting best instructional practices and therefore equity in learning for all students.

\section{Research Questions}

To gather information to further understand why some or all third- and fourthgrade instructors have been struggling to implement DI in the classrooms, this qualitative case study investigated the perceptions of third- and fourth-grade instructors on their knowledge, implementation, and self-assessment of using DI in classrooms in three elementary schools in one Appalachian state. The following research questions provided further guidance to district and local leaders about how teachers perceive their use of differentiation and if any perceived implementation barriers exist:

Research Question 1: How do third and fourth grade teachers use differentiation to support all students?

Research Question 2: What perceived opportunities and struggles do third and fourth grade teachers believe affect their ability to implement differentiation? 


\section{Review of the Literature}

The peer-reviewed articles used for this literature review on inclusive practices and differentiation were retrieved from the Walden University Library using Education Source, ERIC, SAGE Journals, ScienceDirect, Taylor and Francis Online, and Academic Search Complete. The key terms used for the search have been used to divide the literature review into comprehensive sections. Other terms include differentiation, differentiated instruction, inclusion, special education, achievement gap, teacher preparation, advantages of DI, successes of DI, teacher perception, differentiation struggles, and individualized instruction. I also explored the reference section of current articles and studies to locate additional research on this topic.

Inclusive practices have been implemented across the United States after educational legislation known as the Individuals with Disabilities Education Act was passed in 2004 mandating the least restrictive environment. As a result, approximately $47 \%$ of SWDs spend $80 \%$ or more of their day in an inclusive setting (National Center for Education Statistics, 2017). As inclusion is found within all schools, teachers look for ways to meet each individual student's needs to ensure a fair and equal public education. Differentiation has been identified as one of those strategies.

The first part of this literature review focuses on inclusion and how it has affected the general education classroom. Differentiation is followed as it is the conceptual framework for the study and was the focal point for the study. I examine Tomlinson's (2001) definition of differentiation and how it can be implemented in the classroom. 
Next, I look at the role of the teacher in this strategy, teacher preparation for DI, and implementation barriers for successful and consistent implementation. Lastly, I discuss the effects of DI on student achievement. Each section elaborates on the development of differentiation, definition, uses, and perceived struggles of the strategy.

\section{Inclusion}

Due to the implementation of inclusion as found within the Individuals with Disabilities Act, schools are tasked with finding ways to meet all instructional needs within the classroom and provide SWDs access to the same opportunities as their nondisabled peers (Gilmour, 2018). But the interpretation of inclusion varies within schools throughout the United States (Haug, 2016). However, a common interpretation of inclusive practices suggests that SWDs should be fully included in the general education classroom with typical students (Bemiller, 2019). The idea is that all students should be exposed to material that is on their level and related to their interests (Anastasiou, Kauffman, \& Di Nuovo, 2015). However, no legislation has determined what the least restrictive environment entails, leaving a wide variety of uses. For example, some schools implement partial inclusion where students with special needs spend part of their time in the general education classroom and part of their day in a special education classroom. Statistically, more than $60 \%$ of all SWD spend $80 \%$ or more of their school day in regular classrooms (Gilmour, 2018). Other districts use reverse mainstreaming in which students without disabilities enter the special education classroom to socially engage with 
SWDs (Ozaydin, 2015). Regardless of interpretation, all stakeholders in education can agree that some level of inclusion is beneficial for students.

With these mandates, teachers are tasked with designing lessons to meet varying needs, but they have a multitude of strategies they can employ. DI and other multifaceted teaching practices can be used to address student needs (Coubergs, Stryven, Vanthournout, \& Engels, 2017). Using an inquiry-based lesson with a pre-assessment to determine baseline data, teachers can differentiate the lesson based on the student's needs (Gumpert \& McConnell, 2019). Other alternative forms teachers can use to meet varying academic needs include a flipped classroom, universal design for learning, alternative discussion strategies, and innovative homework. Peer collaboration is another popular strategy in which students in an inclusive classroom are given tasks in groups to not only develop academic development but social as well (Ncube, 2011). Research also suggests teaching with "big questions" can help students think and relate materials to existing knowledge. Centers allow groups of students to work on different tasks at the same time which then allows the teacher to work with students as needed. Goal setting can also be used to help students meet IEP mandates while creating a unique learning experience for each student. Lastly, teachers can include diverse content, materials, and ideas into the classroom while also encouraging a growth mindset. It is important to be data-driven but notice other differences such as language, culture, and personal interests as factors that could influence instructional needs (Tomlinson, 2001). 
Further, instructional needs are only one component of meeting the needs of all students in the inclusive classroom. Successful inclusion is made up of supportive environments, positive relationships, feelings of competence, and opportunities to participate (Freer, 2018). But students diagnosed with autism show a lack of empathy, social communication struggles, difficulties in joint attention, and impairment in routine interaction as in cooperation, helping, and sharing (Miller, 2017). Furthermore, research has shown that fewer than $5 \%$ of students create meaningful friendships as typical peers tend to group themselves with like peers (Silveira-Zaldivar \& Curtis, 2019). These students are at risk of bullying, peer rejection, and stigma. While there are risks, benefits include an increased opportunity for social interactions, exposure to typical peer models or behavior, and higher academic expectations (Silveira-Zaldivar \& Curtis, 2019).

Despite the importance of inclusion, studies have found both positive and negative attitudes toward inclusion, and teacher beliefs toward SWDs can affect the teacher attitude and expectations for this group of students (Rakap, Parlak-Rakap, \& Aydın, 2016). Many things can influence a teacher's perception of inclusive practices including past experiences with these students, the level of training in this area, years of experience in education, age, and gender (Ozokcu, 2018). Attitude and expertise in the application are also key components in the successful implementation of inclusion as well as school climate and culture and systematic support from leadership (Woodcock \& Woolfson, 2018). General education teachers have also been accepting of SWDs in their classrooms but only under certain conditions - if additional supports were provided and if 
the SWDs were not a constant behavior issue within the classroom (Gilmour, 2018). Similarly, teachers have shown more favoritism to students with a milder disability (Khan, Hashmi, \& Khanum, 2017). Additionally, though students have shown a positive overall rating of inclusion, some saw inclusion as dampening the overall intensity of learning (Schwab, Sharma, \& Loreman, 2018). Parental perspectives are mixed, both supporting and rejecting inclusion, which can bring into question if these perspectives are influential to student perspectives and thus the classroom learning environment (Sofwan et al., 2019).

Other barriers to successful inclusion include lack of training, lack of staff, prioritization concerns, and lack of time (Silveira-Zaldivar \& Curtis, 2019). Teachers and parents have also reported the unwillingness of general education teachers to want to be trained in this area where most trainings were mandated (Silveira-Zaldivar \& Curtis, 2019). Even though teachers know the benefits of inclusion, teachers have reported having limited resources, difficulties in individualizing the curriculum and therefore rated their own perceived attitudes and performance with inclusion low (Yu, 2019).

\section{Differentiation/Conceptual Framework}

Used as the conceptual framework for this study, differentiation is described as maximizing learning through meeting individual learning needs through various means as part of inclusive education (Tomlinson, 2015). DI is a targeted process that involves forward planning, programming, and instruction. Carol Tomlinson's (2001) definition is used widely defining DI as adjusting the content, process, product, and the physical 
learning environment according to the teacher's perception of student readiness, learning profile, and interest. However, Renzulli also defined it as a triad model serving gifted students to extend their skills, foster creative thinking, and supporting their commitment to their tasks (Bondie, Dahnke, \& Zusho, 2019). Differentiation uses teaching, learning, and assessment strategies that are flexible and reoccurring to provide an appropriate level of challenge and engagement for students in meaningful ways (Cooney, 2019). The practice of differentiation acknowledges student's differences in readiness, interests, and learning style (Civitillo, Denessen, \& Molenaar, 2016). Differentiation is a teacher's proactive response to a learner's needs that is shaped by mindset (Tomlinson, 2014). Differentiation opens up creativity for students and allows the student to make choices and be in charge of their learning, work with various peers, receive instruction at their individual level while forming a trusting relationship with their teacher (Conderman \& Hedin, 2015).

Although differentiation is not considered a theory on its own, it is seen as a group of common theories and practices. For instance, it builds on the zone of proximal development introduced by Vygotsky in which differentiation aims to assess and teach at each student's actual developmental stage (Civitillo et al., 2016) and the constructivist theory that implies the active participation by the student as they negotiate meaning during instruction (Taole, 2019). Constructivism in education is based on Piaget's concept of cognitive development (Juvova, Chudy, Neumeister, Plischke, \& Kvintova, 2015). Bruner later worked on the theory, stating that learning was a process in which the 
student should actively engage and process the information. Constructivists encourage social communication and the importance of student engagement (Juvova et al., 2015). Furthermore, constructivism can be characterized by the emphasis on the activity to increase the student's motivation, the systematic approach to problem solving, the individualized approach to the student based on development needs, and the analysis and interpretation of error (Juvova et al., 2015). With the overlying similarities, these foundational aspects play an important part in laying the foundation for DI.

Also encompassed within DI are many different teaching methods teachers already utilize such as Bloom's taxonomy, learning inventories, small group and whole group instruction, as well as project-based learning. Small group instruction can specifically be used to enhance student learning and engagement through grouping students based on interest or ability (Mainini \& Banes, 2017). With many different interpretations, differentiation can be implemented in various ways.

Recommended as a best practice throughout the United States, differentiation is founded on five existing principles found within any classroom: (a) an environment that encourages and supports learning, (b) quality curriculum, (c) assessment that informs teaching and learning, (d) instruction that responds to student variance, and (e) leading students and managing routines (Tomlinson, 2014). By examining current practices and adapting these five principles, a teacher sets the foundation for productive differentiation. Once the foundation is set, teachers can differentiate through four means: content, process, product, and affect or environment (Tomlinson, 2014). To differentiate based on 
content, the teacher designs lessons using relevant content that might interest students. Content is described by Tomlinson (1999) as what learners should know (facts), understand (concepts/principles), and be able to do (skills) as a result of the assignment. When students are interested in their work, they are more motivated and can relate preexisting knowledge to aid in their understanding. Teachers can differentiate the process by allowing the student to take in and make sense of the content in various ways (Tomlinson, 2014). Small group instruction is utilized in this aspect as well as station work, technology, and other grouping techniques. Teachers can differentiate based on product by allowing the student to show what they have learned in various ways. This can look different in many classrooms but can include skits, written explanations, pictures, and discussions. Lastly, teachers can differentiate the environment in which learning occurs such as flexible seating or working outdoors (Tomlinson, 2014).

Once teachers acknowledge the areas in which they can differentiate, they then can examine how to differentiate based on student needs. Teachers should continuously examine student readiness, interests, and learning profile (Tomlinson, 2014). To differentiate based on student readiness, teachers can analyze pre-existing data as well as continuous data to successfully group students based on their ability (Benders \& Craft, 2016). This can help the teacher identify specific areas of weaknesses and strengths that can be supported or enhanced within the small group setting. Teachers can also differentiate based on student interest through interest surveys, conferencing with the student, and being present in the classroom during conversations (Tomlinson, 2014), 
which can motivate the student to learn more about the topic. Lastly, the learning profile of the student is another way teachers can differentiate (Tomlinson, 2014). This is typically done through teacher observations of the student, but surveys can also be used. Though new research suggests that differentiation should not occur in this manner due to the fear of limiting the student to one learning style (Malacapay, 2019), differentiation can be productively used as a starting point of instruction that will boost student selfefficacy as well as allowing more complex situations seem more approachable.

Analyzing a pupil's learning style can also help enhance the learning environment for all students and is an important part of DI. To increase motivation and improve student performance, the student's preferred learning style should be considered and continuously evaluated (Malacapay, 2019). Using components of differentiation, teachers can meet these varying learning styles with the use of visual aids, audiotapes, and manipulatives striving to meet different learning styles as some students learn best through seeing, hearing, reflection, action, thought, analysis, or imagination (Malacapay, 2019). Teachers should also be aware of not the varying ways to differentiate based on the needs of each student. Several different strategies can be used to meet these needs including learning centers, graphic organizers, tiered assignments, learning contracts, and choice boards (Tomlinson, 2014). These strategies can be utilized to differentiate based on varying needs to ensure all students are successful in mastering the content.

To address differentiation, most teachers prefer a co-teacher to collaborate within a heterogeneous classroom to help plan for varied learning needs. Ideally, the teacher has 
a co-teacher who is another licensed professional such as a special educator. In theory, each teacher has equal decision-making in the classroom while bringing different skills and perspectives to the planned instruction (Conderman \& Hedin, 2015). Because of the collaboration and extra support, co-taught classrooms have had a small to moderate positive effect on reading and math scores of SWDs (Conderman \& Hedin, 2015). As teachers work toward differentiation, the use of collaboration can also ease the extra planning burdens some teachers claim as a disadvantage. Collaboration has been shown to lead to a perceived increase in teacher competency to differentiate as well as a growth in student learning (Mofield, 2020).

Differentiation also requires a lot of organization and engagement with the students' characteristics. While aiming to meet the demands of the inclusive classroom and designated learning outcomes, teachers should conduct ongoing assessments in response to student readiness, interest, and learning profile (Tomlinson, 2001). One way to get to know students is through surveys or questionnaires, which can allow the teacher to differentiate more meaningfully (Conderman \& Hedin, 2015). With this knowledge, teachers can use flexible grouping to best meet the needs of students during different learning activities, small group, and whole-group work while ensuring each assigned task is a respectable task still meeting the learning objective (Tomlinson, 2001). Furthermore, both the teacher and student should have a growth mindset rather than a fixed mindset (Tomlinson, 2014). A growth mindset is important to note differentiation be planned, and instructional decisions should be based on the analysis of student data. Moreover, to 
observe differentiation in the classroom, the observer should be able to see the variation in learning goals, instructional content, instructional time, assignments, and learning materials aimed at addressing varying learning needs (Faber, Glas, \& Visscher, 2018).

Similar to the opinions of inclusion, differentiation is a strategy with mixed reviews. Teachers who have been properly trained in the classroom see the benefits as all students have higher achievement. However, teachers who are new to the profession lack resources and management strategies to consistently implement the strategy (Wan, 2017). Administrators also see the importance of full implementation but lack the time to enforce policy (Shepherd \& Devers, 2017). Students in the elementary setting start to see a learning gap form with their peers in later elementary years as behavior issues also arise as a result. In later years of schooling, students question the validity of inclusion as education becomes more meaningful and serious to those with an educational drive (Schwab et al., 2018). Parents of general education students question if the classroom distractions associated with inclusion inhibit learning for their child or takes away time from their child to spend with special education students. Parents of special education students question if learning needs are truly being met in the general education classroom and worry about bullying as their child is academically behind others (Sofwan et al., 2019).

\section{Role of the Teacher}

Current teachers face three present-day challenges. First, teachers answer the continued call for more differentiation in education to meet the needs of both low 
achieving and high achieving students (Haelermans, Ghysels, \& Prince, 2015). In past classrooms, teachers taught to the average population with a current shift to bridge the learning gaps between these two groups. Second, as the population decreases in rural regions, classroom sizes increase leading to lower quality instruction and less differentiation (Haelermans et al., 2015). This is stated by many research articles as the main concern for educators. Lastly, schools are turning more toward a technology-based curriculum to encourage student motivation and engagement (Haelermans et al., 2015). If teachers are not familiar with their roles in this system of learning, they may be reluctant to implement the change or not implement the program effectively. Knowing that differentiation can take on many forms and as technology advances, teachers can utilize these tools to more easily differentiate to meet varying needs.

The teacher plays the main role in the process of differentiation in which they create the learning opportunities to meet the needs of each student based on assessment data taking the role as the facilitator. To differentiate, teachers should know their students in three main ways: readiness level, interest, and learning profile (Gaitas \& Alves Martins, 2017). Then, three general principles should guide the differentiation process: designing challenging tasks, flexible groupings, and classroom arrangements, and ongoing assessments and appropriate scaffolding (Gaitas \& Alves Martins, 2017). The teacher should encourage students to question, challenge, and guide student investigations by exploring their ideas, opinions, and conclusions (Wan, 2017). These designed tasks should challenge the student to learn while challenging students to 
question what they know and to stretch their knowledge while providing feedback to help students consolidate and review what they have learned (Cooney, 2019).

For differentiation to be effective, teachers should reflect on their own practices asking themselves what needs do the students have, what differentiation will they require, how are they preparing themselves to differentiate for their students, how knowledgeable are they on the topic, and how can the passion from the teacher be used as a tool in their classroom (Bagot \& Latham, 2019). Instructional leaders (teachers, instructional coaches, or administration) should be determined to monitor, mentor, and model effective teaching and learning practices for teachers in the classroom (Lang, 2019; Lindner, Alnahdi, Wahl, \& Schwab, 2019). As new legislation is passed stressing student accountability, teachers need instructional guidance and feedback to implement differentiation successfully. While some teachers might be reluctant to implement differentiation, generating awareness of instructional leadership practices can better direct administrative support to where it is needed (Lang, 2019).

Tomlinson (2014), the leading developer for this strategy, argues differentiation can occur in five instructional dimensions. These include the curriculum such as grouping styles, process, resources, learning activities, and student outcomes. Every teacher will have different ideas about how to deliver differentiation in their classroom (Bagot \& Latham, 2019). Because of this, principals might consider the possibility to have collaborative time for teachers to share their ideas while extending their own knowledge and creativity with others. 
Similar to differentiation, individualized learning is a step toward ensuring each student is examined and prescribed an individualized learning path. The Bush Foundation believes individualized learning makes education more relevant for students in terms of who they are (cultural relevance), how they learn (instructional relevance), and what they aspire to do (career relevance) (Leshnick, Allen, \& Berman, 2019). To create this type of experience, teachers should be aware, understanding, and enthusiastic about the new learning experience that might occur as a result while utilizing the in-depth support provided by leadership. Leshnick et al. (2019) further explain teachers might need more information about how to do individualized learning well to include more specific PD.

The opportunity to observe the practice, creating community engagement and buy-in, creating thoughtful assessments, reimagining the role of the educator, and being flexible in instruction can all help teachers create a more student-centered classroom where differentiation is used successfully (Leshnick et al., 2019). To differentiate, teachers should know their students in three main ways: readiness level, interest, and learning profile (Gaitas \& Alves Martins, 2017). Then, three general principles should guide the differentiation process: designing challenging tasks, flexible groupings and classroom arrangements, and ongoing assessments and appropriate scaffolding (Gaitas \& Alves Martins, 2017). However, Tomlinson (2014) found both novice and veteran teachers feel the need to only cater instruction to only low-achieving students and are more likely to differentiate to this group of students if they are differentiating at all. When differentiation strategies are applied to instruction, the most likely change is at the 
content level such as more drill and practices for low-achieving students and more advanced content for higher achievers (Brevik, Gunnulfsen, \& Renzulli, 2018).

One tool teachers can use to drive differentiation is formative assessments. Formative assessments are informal assessments used to check for student understanding to adjust instruction to meet individual needs (McGlynn \& Kelly, 2017), thus differentiating. Because these assessments are informal, they should not be graded and because they are used to inform, students should be allowed to be assessed in the best manner to show understanding. For example, a kinesthetic learner might best show their understanding with hands-on learning and a visual learner might show learning best through a diagram. Also, differentiating by product can increase motivation and engagement showing a greater increase in learning (McGlynn \& Kelly, 2017). While a quiz is a typical assessment, teachers can also use other means of assessment like four corners, whiteboards, Socrative, and 3-2-1 (McGlynn \& Kelly, 2017). Collecting this data is the start of differentiation as teachers have a starting point of student learning.

In a heterogeneous classroom, student ability will vary greatly and continue to expand as the grade levels increase. McGlynn and Kelly (2017) state students typically fall within three categories: students who fully understand the skill or concept you are teaching and are ready to move on, students who have a basic understanding but could use a little review, and students who are totally lost and need the lesson to be retaught to address their specific understanding. By grouping students based on ability, these needs can be addressed in a small group setting. This would allow your advanced learners to 
think more deeply about the content, your intermediate learners more time to reinforce skills and more practice, and struggling students reteach opportunities with corresponding lessons and supplemental materials (McGlynn \& Kelly, 2017).

When implementing DI, teachers can choose from several different strategies. Tiered learning or lessons are designed to meet varied learning abilities. These lessons aim to teach the same standard but are created to meet the student at their individual learning level (King-Sears, Brawand, Jenkins, \& Preston-Smith, 2014). To utilize this strategy teachers should be knowledgeable of where their students are academically with the content and should realize the importance of not "dumbing down" the content or “adding more work" for advanced learners (Cash, 2017). DI is meeting the student at their readiness level and encouraging them to stretch their understanding through these tiered assignments.

Flexible grouping as discussed earlier is another strategy teachers can utilize to create a successful DI environment. Teachers can choose to group students on likeability during small group instruction and station rotations. Teachers can also use mixed ability groupings to ensure collaborative learning. Rachmawati, Nu'Man, Widiasmara, and Wibisono (2016) acknowledges the importance of grouping students and the advantages of flexible grouping but cautions that this strategy should be revolving and always based on current student data.

Co-teaching is an approach schools can take to meet the instructional needs of students and relieve instructional strain on inclusive teachers (King-Sears et al., 2014). 
Co-teaching is defined as two or more educators, typically a general education and a special education teacher, working collaboratively to deliver instruction to the inclusive classroom (Cash, 2017). One method of co-teaching involved one teacher, usually the general education teacher teaching while the other is observing and supporting students by circulating the room (Friend \& Bursuck, 2014). Another popular model uses both teachers as primary teachers in stations where students are grouped and rotated throughout each station (Friend \& Bursuck, 2014). The most common approach to coteaching is the team teach method which involved collaborative planning and instructional delivery by both teachers (Friend \& Bursuck, 2014). This is the most productive form of DI as both teachers aid in student understanding while maximizing instruction for special education students by providing additional supports within the general education classroom (King-Sears et al., 2014; Tomlinson, 1999).

\section{Teacher Preparation}

Learning to teach does not stop after a teacher earns their degree but is an ongoing developmental process that occurs in multiple settings over multiple years (Dack, 2019). Pre-service teachers learn pedagogy and teaching strategies in the university setting, but research has found a disconnect between pedagogical practices within the schools and suggests the complexity and interpretation of differentiation may be the cause (Dack, 2019). Dack (2019) also found teaching programs should be constructed to be coherent in reinforcing learning in other courses while addressing misconceptions and concerns arising from pre-service teachers. Many teachers exiting the profession still only claim 
minimal exposure to teaching strategies like differentiation and report little observed differentiation during clinical experiences. When novice teachers are then placed in their own classroom, teachers are tasked with learning differentiation on their own: a complex topic with many components used to meet the varying needs within the classroom. Brevik et al. (2018) explained in addition to providing student teachers with theories about differentiation, teacher educators should be offered practical training on campus under supervision while helping these preservice teachers relate their knowledge within their own practices. This idea is supported throughout the country in Chile, Cuba, Finland, Norway, and the United States suggesting the most effective teacher education programs integrate both theory and practice (Jenset, Klette, \& Hammerness, 2018; Klette \& Hammerness, 2016).

Preservice teachers have many opportunities throughout their higher education experience to connect educational theory to practice as they look for a pedagogical practice that blends with their own personal styles in the attempt to create meaningful learning opportunities for all students (Parks, 2019). During field experiences, preservice teachers move to conceptual understanding focusing on student learning and individual needs to keep students engaged and motivated (Aschbacher \& Ing, 2017). During field experience discussions, teachers were able to articulate the importance of DI but struggled to identify differentiation in action and to create lessons that provided meaningful learning opportunities for all students (Parks, 2019). Without being able to 
articulate and identify differentiation in the setting, teacher preparation programs are not fully preparing teachers for successful classroom implementation.

The quality of teacher preparation programs is a good indicator as to how teachers will perform in the classroom. As a result, the performance of the teacher indicates the quality of education (Sunthonkanokpong \& Murphy, 2019). Teachers should be taught to value diversity while learning about inclusive practices through modeling (Florian \& Pratt, 2015). While teacher education programs teach about inclusion, there still seems to be a disconnect between the implications and applications in the classroom. Sunthonkanokpong and Murphy (2019) suggest even though reform efforts have been made within many programs, there is evidence that teachers from urban areas and high socio-economic backgrounds have better access to quality teacher-education programs and therefore, are better performing with the implementation of inclusion. As inclusion is the foundation of DI, teachers should be knowledgeable of the impact of inclusion and the strategies associated with meeting student needs.

Differentiation is a complex teaching strategy that incorporates many aspects of teacher discretion. Teacher training before teaching in the inclusive classroom can greatly impact the success of differentiation. Manrique, Dirani, Frere, Moreira, and Arezes (2019) utilized a questionnaire with 48 questions both open and closed formats where 197 participants replied to seek knowledge on pedogeological work in the inclusive classroom. Manrique et al. (2019) revealed teachers need further training on inclusive practices that take into consideration teacher profile and potential biases. Manrique et al. 
(2019) also revealed the need for support in developing materials for differentiation including games, software, devices, and assistive technology. After ensuring instructional needs are met, student social emotional needs should also be addressed.

For a complete integration of students with educational needs, Manrique et al. (2019) suggest ensuring all needs of the students are met that could contain emotional support along with unique instructional needs. Stites, Rakes, Noggle, and Shah (2018) noted preservice teachers stated a lack of understanding of inclusion and how to support students with learning needs. The teachers perceived themselves as needing additional support in both social emotional and instructional strategies to be prepared to teach diverse students in the inclusive setting. Stites et al. (2018) suggest teacher preparation programs should provide a more coherent conceptual framework that could include fieldwork and course work to ensure a better understanding of both inclusive practices and effective differentiation by meeting all the needs of inclusive students.

Notably, pre-service teachers also need direction and instruction of special education training. Teachers who receive little to no special education training can develop negative attitudes towards inclusive students, or those with learning disabilities (Deason, 2017). As teachers are serving all students in an inclusive setting, special education training will lessen the frustration of working with SWDs as well as aid in the understanding of sustainable expectations and effective instruction techniques for these students (Deason, 2017). 
Teacher preparedness does not stop at the university setting. In a recent study, Shepherd and Devers (2017) asked 423 principals in Indiana how satisfied they were with newly graduated and hired teachers within their buildings. The results suggested principals were only satisfied with the teacher's attitude and approach toward assignments and only moderately satisfied with general instructional abilities and content knowledge (Shepherd \& Devers, 2017). Principals were less than satisfied in five areas: (1) classroom management, (2) DI, (3) professional development, (4) parent communication, and (5) effective assessment (Shepherd \& Devers, 2017). Education is a revolving door that is always changing creating an environment where teachers, too, should be life-long learners to continue best practices. Both novice and veteran teachers struggle with the implementation of differentiation. DI is proven to enhance student performance by catering to a student's specific learning need but is contingent on the teacher's ability to use the approach effectively (Sabb-Cordes, 2016). Teachers, therefore, should be guaranteed quality PD and feedback within the setting to strengthen these practices and interpretations.

\section{Teacher Perceived Struggles}

Many different factors have been identified as to why teachers struggle to use DI in an inclusive setting. Wan (2017) identified four critical factors influencing the implementation of DI in schools which include: teacher preparation, teaching beliefs, school support, and team collaboration. Teacher mindset toward differentiation and the impact on learning can also hinder the successes found in the classroom (Coubergs et al., 
2017). Bodovski, Byun, Chykina, and Chung (2017) found differentiation as an early intervention was more beneficial than differentiation at the later stages of education. If teachers feel this strategy is irrelevant and not important, they are less likely to fully implement the strategy within their instruction.

Other commonly cited barriers to the implementation include lack of time, heavy workload, large class sizes in regular schools, lack of resource materials, and lack of skills in differentiating instruction (Civitillo et al., 2016; Taole, 2019). Teachers also report the stress associated with high stakes testing. Serving SWDs and general education students, teachers should find a way to present information to all learners through differentiation to meet adequate progress (Gonzalez, Orange, \& Grisby, 2016). With these mounting struggles, teachers tend to leave the profession resulting in newer, less experienced teachers in their place (Glazer, 2018). This is also true for special education teachers exiting the profession when there is already a nationwide shortage of highly qualified teachers leaving the school and teachers with a lack of resources and services for their SWDs (Hagaman \& Casey, 2018).

It is important to note DI should be utilized in the classroom to help all students learn. General education students who are meeting academic expectations should still be receiving instruction on their development stage. SWD should be receiving instruction on their level but also working toward the same educational objectives as their peers. Lastly, gifted students should also be given meaningful assignments while also still developing their understanding of the same learning concept more deeply. Brigandi, Gilson, and 
Miller (2019) found teachers believed gifted learners were the group of students most often left behind stating little to no training had been provided during preservice teaching experiences and little PD specifically for this group once in a teaching position. Teachers also stated that even if PD was given, concentration on struggling students often took priority due to a lack of time and resources for gifted students (Brigandi et al., 2019). Despite the research-based associated positive outcomes, $83 \%$ of surveyed teachers reported differentiating instruction daily as being somewhat too very difficult and $73 \%$ stated the gifted students were bored and under-challenged in schools (Brigandi et al., 2019). Tobin and Tippett (2014) found teachers often refuse to differentiate for this group of learners because of teacher fears and insecurities, misconceptions, lack of time, and their current contextual needs. Similarly, Wan (2017) in his two-factor quantitative analysis found teachers are ready to differentiate using the student center model but seem to be more ready to use the teacher center model when first entering the profession. Teachers stated three obstacles toward DI: class size and diversity, time, and understanding of teaching strategies (Wan, 2017). Similarly, Siam and Al-Natour (2016) in their mixed methodology study of 194 teachers found the mean scores of the six domains of differentiation (content, process, resources, product, assessment, and learning environment) were low for the preparedness of DI. This study suggested there was no correlation between experience and the overall implementation of differentiation finding the main challenges were weak administrative support, low parental support, lack of time, and shortages in learning resources for all educators (Siam \& Al-Natour, 2016). 
As most teachers are willing to differentiate, many barriers hinder a more positive outlook. These motives include a lack of planning time, inadequate time blocks in the schedule, lack of funding appropriate materials and resources, parental resistance, grading concerns, fear of loss of control, and lack of training skills (Gaitas \& Alves Martins, 2017). Further research has shown teachers feel the training they received in preservice and in-service do not prepare them to meet the diverse needs within everyday classrooms (Gaitas \& Alves Martins, 2017; Siam \& Al-Natour, 2016).

Teachers need both material support and psychological support to make DI effective (Bondie et al., 2019). Bondie et al. (2019) found teachers who worked in schools with encouraging and supportive administrators who helped provide resources such as incentives for staff development opportunities and extra planning time were more likely to differentiate their instruction. This indicated teachers should be motivated to change their practice and supported for differentiation to happen.

\section{Closing the Achievement Gap}

Many research studies have been divided on the benefits of differentiation. This teaching strategy provides instructional support for those struggling learners while also enhancing the rigor of other students' learning experiences (Brigandi et al., 2019). These studies stating differentiation makes a significant effect on academic achievement range from many disciplines throughout elementary education including reading (ShaunessyDedrick, Evans, Ferron, \& Lindo, 2015). language arts (Callahan, Moon, Oh, Azano, \& Hailey, 2015) and mathematics (Casa, Firmender, Gavin, \& Carroll, 2017; Gavin, Casa, 
Firmender, \& Carroll, 2013). Some research has found a negative effect on student achievement when comparing learning achievement gaps between special education and general education students as well as a learning decline for general education students in general. On the other hand, other research shows an improvement with all students (Prast et al., 2018). In examining this phenomenon, Deunk et al., (2018) in their literature review, found only 16 studies met the inclusion criteria even though most were too narrow only including ability grouping or too broad including only interventions.

Using technology is another popular way teachers can differentiate in the classroom. Beasley and Beck (2017) found most teachers who utilized technology often asked why a student needs differentiation and what needs to be differentiated to prescribe a technology component to the classroom. Because most current programs are ability based, teachers assign the student a placement test on the program and the program prescribes lessons based on gaps in learning, student ability, and the sequence the content should be taught. Technology can easily differentiate content while the teacher works in small group sessions with students. Technology can also assist teachers to differentiate the product as a way for students to show their learning. Students in the $21^{\text {st }}$ century should have access to technology and should be able to use programs fluently as they enter the workforce. Teachers should allow students to explore programs such as Word@ for typing documents, Excel@ for charts and diagrams, and PowerPoint $@$ for presentation. Technology can also be used to help with the delivery of content. For example, students can listen to stories instead of reading them. As teachers look toward 
differentiation, technology has been shown to be utilized accurately and efficiently to better implement differentiation in the classroom.

Schools are also moving toward blended classrooms in which teachers are expecting students to be more self-driven in which they assign materials to be completed at home to then be discussed and analyzed in class. Little direct instruction during this time is given as it is seen more as practice time to reinforce the skills with the learning of concepts at home. With the blended classroom, students are now receiving tablets they carry with them throughout the school year. This provides access to technology throughout the school day and instant connection to the content. In examining student perspectives of the use of tablets in classrooms and for assignments, Gokcearslan (2017) found significant positive feedback on having the readiness of technology as well as the ability to extend learning at home.

Ability grouping is one of the most common differentiation practices in primary education. This tool can be used for fitting instruction to the needs of individual students in academically diverse classrooms (Deunk, et al., 2018). Researchers, Benders and Craft, (2016) and Deunk et al. (2018) have proven a positive effect of small group instruction following whole group instruction which also increases if grouped differently based on the subject. However, in their quantitative study, Faber et al., (2018) examined the relationship between differentiation and mathematical achievement in second and fifth graders. By observing classrooms, the researchers found no significant positive effects on achievement and found the low-ability groups profited less than the average or 
high-ability groups. Because these groups were based on ability, one could question if heterogeneous small group instruction is of more importance when academic achievement is of concern.

Some differentiation has been successful in raising achievement scores. For differentiation to be successful, teachers should be knowledgeable of the strategy and have a positive perspective on this technique. Valiandes and Neophytou (2018) examined specific PD on differentiation and the impact DI could have on attitudes, practices, and student achievement. Scholars seem to agree teacher education has little effect on altering teacher beliefs and attitudes (Valiandes \& Neophytou, 2018). Most influential as to how a teacher teaches is their own experiences as a pupil, apprenticeships, observations, and schools' organization and culture (Valiandes \& Neophytou, 2018). As teachers witnessed increased student achievement, teacher attitudes toward the continued use of DI increased. Consequently, as teachers struggled with implementation their motivation to use the strategy decreased (Valiandes \& Neophytou, 2018). Lastly, student achievement did slightly increase during the study with the support of PD on DI arguing teachers were still learning the strategy, but researchers could already see the positive impact differentiation had created. Professional development on differentiating could ultimately help teachers understand the process. Once teachers see the impact, positive results will occur. 


\section{Implications}

Brigandi et al. (2019), Casa et al. (2017), Gavin et al. (2013), and ShaunessyDedrick et al. (2015) have acknowledged DI is one of many best practices that can be used to increase student engagement and achievement Therefore, the purpose of this case study was to investigate perceptions of third and fourth grade instructors on their knowledge, implementation, and self-assessment of using DI in classrooms in three elementary schools in one Appalachian state. Consequently, this project study has the potential to have a positive social impact, for a professional development training curriculum and materials plan will be developed on how third and fourth grade teachers can consistently implement DI in the inclusive classroom. The professional development plan will also provide strategies for teachers that will address differentiation concerns and stated barriers.

Throughout the literature, teachers have stated the lack of training on differentiation throughout preservice and in-service teacher training and how it has hindered their ability to effectively use the strategy in the classroom (Brevik et al., 2018; Dack, 2019). As stated in the leadership meetings at the study site and state conducted audit, teachers are still not consistently implementing the strategy even with the emphasis at the state and local level. This research could impact social change by providing the county and school site administrations with tools needed to support DI in the inclusive setting for all teachers. This could lead to higher student engagement and achievement. 
This project study will include professional development training that will consist of a three-day informative workshop providing third and fourth grade teachers an opportunity to collaborate with other teachers. They will be given an opportunity to discuss ways to differentiate in both ELA and mathematics in whole group and small group instruction. Deunk et al. (2018) has shown ability grouping to be the most common form of differentiation teachers might be unaware of other forms and their values. This project study will improve administrator and teacher understanding of observable differentiation and how it can be used in the classroom in all its forms. Furthermore, teachers will be provided guidance on lesson planning for DI and how to include the components with their curriculum to support all learners in the inclusive setting.

\section{Summary}

The problem for this project study was identified through conversations with administrators and some faculty who believe some or all instructors may be struggling to implement DI in the classrooms. Therefore, the purpose was to investigate perceptions of third and fourth grade teachers on their knowledge, implementation, and self-assessment of using DI in classrooms in three elementary schools in one Appalachian state. The local goal is for teachers to recognize the observable differentiation already being implemented while seeing other forms that could also be implemented successfully in the classroom. By acknowledging the barriers teachers indicated during the project study, school leadership should take the initiative to start to address these concerns to further 
differentiation within the system. Section 1 showed the development and research-based need for differentiation throughout the country, but specifically within the research site.

A large achievement gap can be found between general education and special education students. Research has indicated differentiation as a successful strategy to help close this gap in achievement (Prast et al., 2018). This study should clarify what differentiation is already being implemented in the classroom and the struggles teachers see as a result of full implementation by using the two created research questions. The two research questions that guided this study asked how third and fourth grade teachers use differentiation to support all students and what perceived opportunities and struggles these teachers believe affect their ability to implement this strategy.

The terms related to this project study were also identified. The literature review identified inclusion to be the founding reason for differentiation as before this implementation, classrooms were mostly teacher-led. Differentiation was intricately defined as Tomlinson's definition was used as the conceptual framework. The role of the teacher within differentiation was examined and explained. A deeper look at teacher preparation experiences and programs was given as to how it pertained to teacher perception and implementation of differentiation. Teachers perceived struggles with differentiation and how differentiation can be used to close the academic achievement gap concluded the literature review process.

To close Section 1, implications for the results of this project study were stated aiming to meet the needs of the local area and similar communities. Specific PD will be 
created to address third and fourth grade teachers' concerns on using DI in the inclusive setting and reasons for inconsistent implementation. In the next section, I detail the methodology of this study. This includes details on the qualitative process and research design, the data collection process, participants, the interview procedures, and the data analysis process. 
Section 2: The Methodology

\section{Research Design and Approach}

This study used a qualitative case study approach. Qualitative research is an approach that researchers can take to analyze an individual's experience along with that individual's interpretation (Ravitch \& Carl, 2016). Qualitative case studies are designed to help the researcher to understand individuals and groups in their natural settings by providing an opportunity to reflect on these experiences in-depth and over a period (Ledford, Barton, Severini, \& Zimmerman, 2019). Using this approach, I investigated perceptions of third- and fourth-grade instructors on their knowledge, implementation, and self-assessment of using DI in classrooms in three elementary schools in one Appalachian state.

A conceptual framework is used in a qualitative study to provide the focus of an idea (Tracy, 2013). The conceptual framework for this study is Tomlinson's (2015) interpretation of differentiation. Tomlinson described differentiation as a teaching strategy in which the teacher creates opportunities to learn that meets each individual's needs. These opportunities can be created based on student interests, learning styles, and ability as well as through levels of difficulty (Tomlinson, 2015). Using formative assessment regularly, teachers can also modify instruction based on student readiness using different grouping strategies to meet differentiated needs (Tomlinson, 2015). Lastly, differentiation can occur through the modification of content, process, or product (Tomlinson, 2015). This conceptual framework helped focus this qualitative study as the 
perception of differentiational use and perceived struggles in third- and fourth-grade teachers were examined.

Because qualitative research seeks to understand the behaviors and views of the participants in a study (Creswell, 2015), third- and fourth-grade teachers were interviewed using a semi-structured phone interview to help build a better understanding of how they are using DI currently in the classroom. Using guiding questions, teachers were asked to describe their struggle to consistently implement the strategy. One week of lesson plans were also collected from each participant as archival data to look for varying forms of planned differentiation.

By using the methodology of a qualitative case study, the project study can further understand teachers' perceived struggles in the research site. Qualitative research answers what or how something happens (Thomas, 2017). Guiding this qualitative study were the following research questions: "How do third and fourth grade teachers use differentiation to support all students?" and "What perceived opportunities and struggles do third and fourth grade teachers believe affect their ability to implement differentiation?” By answering these questions, the project study provided a deeper understanding of this small set of cases, which is indicative of a qualitative case study (see Thomas, 2017). As quantitative research refers to the analysis of numerical data such as statistics while looking for trends set between two or more variables (Thomas, 2017), this research utilized only a qualitative approach. Again, the purpose was to investigate perceptions of third- and fourth-grade instructors on their knowledge, implementation, and self- 
assessment of using DI in classrooms in three elementary schools in one Appalachian state. The quantitative approach was inapplicable to this methodology and design. To answer the research questions and provide insight into teacher perspectives of differentiation and implementation struggles, qualitative means were required. Statistical relationships and data trends would not provide the type of data necessary to provide insight and understanding of differentiation struggles and perceived barriers. As such, a mixed methods design using both qualitative and quantitative data was also inapplicable (see Creswell, 2015).

What qualitative methodologists' study, how they study it, and how they interpret it all depends on their theoretical perspective (Taylor, Bogdan, \& DeVault, 2016). Qualitative theoretical perspectives used in educational research are centered around phenomenological, ethnography, grounded theory, and case study. The phenomenological perspective emphasizes how a participant experiences a specific event while attempting to see things from other people's points of view (Taylor et al., 2016). This methodology did not fit this project study as meaning was not sought from the experience of differentiation but rather perspectives on the topic in general. Ethnography refers to the study of culture and learning from people within that culture by examining differences and documenting evidence in field notes during fieldwork (Thomas, 2017). The purpose of this study was not to study how different cultures respond to differentiation but to gather an overall perspective. The grounded theory method analyses large sample populations to explain why something happened the way it did and to build theory 
(Taylor et al., 2016). The use of phenomenological research methodology, ethnography methodology, and grounded theory methodology would create misalignment to every aspect of the framework. After considering each methodology approach, the case study methodology was chosen and determined to be appropriate as it is a qualitative design and aligns with this research framework.

A case study design best fits this study due to its approach of examining the perspectives and experiences of humans in their natural surroundings (Burkholder, Cox, Crawford, \& Hitchcock, 2019). A case study aims to gain a rich, detailed understanding by examining aspects of the case in detail (Thomas, 2017). It provides an in-depth understanding of a real-life phenomenon (Kaur, Noman, \& Awang-Hashim, 2016). It is an approach where researchers investigate a bounded system or systems (i.e., cases) through multiple sources of data (Creswell \& Poth, 2017). This case study was bounded in the third- and fourth-grade inclusive classroom by examining nine teachers' perceptions in one county in the identified Appalachian state by using semi-structured interviews and lesson plan reviews. The interview protocol (see Table 6) was approved by the research committee, indicating no need to pilot test the research tool. The data collected were analyzed, grouped into themes, and then compiled into a detailed report.

\section{Participants}

The purpose of this qualitative study was to investigate perceptions of third- and fourth-grade instructors on their knowledge, implementation, and self-assessment of using DI in classrooms in three elementary schools in one Appalachian state. The study 
site was in a small county containing three elementary schools, one middle school, and one high school. The elementary school setting served grades prekindergarten to fourth grade. All third- and fourth-grade teachers were recruited as participants within the three elementary schools.

\section{Criteria for Selecting Participants}

Of the 14 third- and fourth-grade classrooms, all were inclusive, and all teachers were certified in the area holding a valid teaching certificate. Because all teachers experience the inclusive setting and were certified, and a deeper understanding of perceived opportunities and struggles was the goal of the study, all third- and fourthgrade teachers were invited to participate. Regardless of the participants' perceived comfort and mastery of DI, all were invited and allowed to participate in the research. Inviting all 14 of the teachers for the study increased the possible number of participants and allowed for generalization of the data collected (see Leedy \& Ormond, 2015).

\section{Justification for the Number of Participants}

Qualitative research generally consists of eight to 12 participants (Thomas, 2017), where saturation of data is met generally by the ninth interview (Hennink, Kaiser, \& Marconi, 2017). Saturation occurs when the analysis of data begins to reveal repetitive and redundant data and therefore, no new information can be gathered. Using the method of convenience sampling, 14 teachers for Grades 3 and 4 from three area elementary schools were invited to participate in this research project. The final sample included nine of the 14 who volunteered to participate. This small sample size aligns with the 
recommendation for qualitative research and met saturation as well as provided an opportunity for a deeper inquiry for each individual with an emphasis on more time on each interview examination and document review which led to a stronger data analysis.

\section{Gaining Access to Participants}

Prior to beginning data collection for this research study, I sought approval from Walden University's Institutional Review Board (IRB) to ensure all ethical concerns have been addressed. After approval (09-08-20-0437172), I presented a letter of introduction to the local superintendent and principals at each of the three elementary schools requesting permission to conduct the research with the third- and fourth-grade teachers. After obtaining permission to conduct the study, I planned to gain access to participants by asking the three elementary school administrators for third- and fourth-grade teachers' e-mail addresses. I then contacted the teachers through a recruitment e-mail detailing the research project and process as well as informed consent information on their rights as research participants. The respondents were asked to respond "I agree" if they chose to willingly participate in this study and to also provide a time an after-school phone interview would be convenient for them. A confirmation e-mail was then sent to participants verifying the time, reminding participants that 1 week of lesson plans were due by the interview and thanking them for their participation.

\section{Establishing a Research-Participant Working Relationship}

Establishing a research-participant working relationship is important to the reliability and quality of the research output. The researcher should strive to create a 
trusting relationship that will make the participant feel at ease, respected, and valued throughout the research procedures (Ravitch \& Carl, 2016). After receiving permission to conduct the study from the superintendent and principals, I e-mailed third- and fourth grade teachers' information about the study being descriptive and thorough with my explanation. By being transparent within the research process, the researcher can build trust with the participants which can aid in more honest and open communication during the process (Rubin \& Rubin, 2012).

All 14 third- and fourth-grade teachers were invited to participate in the study via e-mail and were provided with an informed consent. The research process outline was used to help ease any hesitation to participate while also opening lines of communication between me and the participants. Reaffirming the research process, being transparent of the purpose, and being trustworthy during the planning stages of implementation help create a working relationship between participant and researcher (see Tracy, 2013).

\section{Protection of Participants' Rights}

The protection of participants' rights was guided by the Walden University Center for Research Support and the IRB. Researchers should always consider the welfare of participants while ensuring no harm is done physically, mentally, or emotionally (Thomas, 2017). Obtaining approval from the IRB process helped indicate that the research project to be safe and compliant with ethical concerns, which also helped protect the rights of all participants. 
Confidentiality is a right that should be protected throughout the process. To ensure validity and confidentiality in results, the participants should feel they can speak openly during interviews. To provide reassurance to participants and to follow research ethics, all participants received an informed consent through e-mail and were reminded they may save or print a copy for their records.

Teachers were asked to participate in phone interviews that were audio recorded. During the interview, the participants were asked to state their assigned number rather than their real name to strengthen confidentiality. No identifying characteristics were revealed, place of employment, or date and time of the interview. Lastly, interviews occurred over the telephone after school hours to ensure the teachers were comfortable in their surroundings and also to ensure privacy that addressed any concerns of someone hearing the interview. Teachers were reminded at the beginning of the interview they could stop the interview at any time or refuse to answer any question.

Throughout the data collection process, participants were given the opportunity to verify the collected information and revise, edit, or remove any details they deemed necessary to strengthen confidentiality concerns. Once data were gathered and to avoid confidentiality concerns, security measures were put in place to protect confidential information. All information such as data, interview transcripts, audio recording, and lesson plans, were placed in a locked filing cabinet or on a secure password-protected laptop where only I will have access. These measures ensured confidentiality and therefore protection from harm in accordance with privacy concerns with this study. 


\section{Data Collection}

The data collection occurred in two phases of gathering lesson plans and interviews. The collection and analysis occurred over a 2-week period where common themes emerged. The validity of the data was ensured through transcript review and member checks.

\section{Justification for Data Collection}

Qualitative research involves verbal descriptions of events in a setting (Thomas, 2017). To gather qualitative evidence, a researcher can use interviews, observations, field notes, and archival document reviews as a source of data (Rubin \& Rubin, 2012). To meet saturation, I asked third- and fourth-grade teachers when volunteering to recommend a time they were available for an after school semi-structured phone interview lasting 45 to 60 minutes and to provide a copy of 1 week's lesson plans before their interview.

The semi-structured interview consisted of 13 researcher produced interview questions and lasted between 20 to 30 minutes for each participant. This form of qualitative data is readily used within qualitative research as it provides an opportunity to look closely at an individual's experiences with a comparison lens to others (Rubin \& Rubin, 2012). This data provided individual third- and fourth-grade teacher perspectives on their knowledge, implementation, and self-assessment of using DI in the inclusive classroom. 
The questions stated in Table 6 were used to guide the semi-structured interview to answer both research questions. These questions provided a starting point of conversation on each topic and led to sub-questions that were transcribed and documented later. Along with these questions, I also followed an interview protocol to set the parameters of the structured interview. 
Table 6

Alignment of Interview Questions to Research Questions and Elements of Differentiation

\begin{tabular}{|c|c|}
\hline Interview Questions & Research Questions or Element \\
\hline $\begin{array}{l}\text { 1. How do you currently use differentiation in the } \\
\text { mathematics classroom? Give an example of process, } \\
\text { product, and content. }\end{array}$ & $\begin{array}{l}\text { RQ1: How do third and fourth grade } \\
\text { teachers use differentiation to support } \\
\text { all students? }\end{array}$ \\
\hline $\begin{array}{l}\text { 2. How do you currently use differentiation in the } \\
\text { ELA classrooms? Give an example of process, } \\
\text { product, and content. }\end{array}$ & RQ1 \\
\hline $\begin{array}{l}\text { 3. How is your classroom arranged to promote student } \\
\text { centered learning and differentiation? }\end{array}$ & RQ1 \\
\hline $\begin{array}{l}\text { 4. What forms of assessments do you use in the } \\
\text { classroom to help you differentiate? }\end{array}$ & RQ1 \\
\hline $\begin{array}{l}\text { 5. How do you provide student choice in the } \\
\text { classroom? }\end{array}$ & RQ1 \\
\hline $\begin{array}{l}\text { 6. How do you differentiate differently for high } \\
\text { achieving students in comparison to students with } \\
\text { learning disabilities? }\end{array}$ & RQ1 \\
\hline $\begin{array}{l}\text { 8. In your opinion, how can differentiation be used to } \\
\text { help close the academic achievement gap between } \\
\text { special education and general education students? }\end{array}$ & RQ1 \\
\hline 9. What practices and procedures does the school have & RQ1 \\
\hline in place to help make differentiation be successful? & $\begin{array}{l}\text { RQ2: What perceived opportunities and } \\
\text { struggles do third and fourth grade } \\
\text { teachers believe affect their ability to } \\
\text { implement differentiation? }\end{array}$ \\
\hline $\begin{array}{l}\text { 10. What do you feel hinders your ability to } \\
\text { consistently implement differentiation in the inclusive } \\
\text { classroom? }\end{array}$ & RQ2 \\
\hline $\begin{array}{l}\text { a. How often do you feel behavior hinders your } \\
\text { ability? }\end{array}$ & \\
\hline $\begin{array}{l}\text { b. How often do you feel pull out services hinder } \\
\text { your ability? }\end{array}$ & \\
\hline c. .... time for planning? & \\
\hline $\begin{array}{l}\text { d. ... previous training, lack of training? } \\
\text { e. ... supplies? }\end{array}$ & \\
\hline $\begin{array}{l}\text { 11. What experiences do you have with } \\
\text { differentiation? (training, and education) }\end{array}$ & RQ2 \\
\hline $\begin{array}{l}\text { 12. In your opinion is differentiation a useful tool in } \\
\text { the classroom? Why or Why not }\end{array}$ & RQ2 \\
\hline $\begin{array}{l}\text { 13. What is needed, if anything, to help teachers } \\
\text { consistently use differentiation in the inclusive } \\
\text { setting? }\end{array}$ & RQ2 \\
\hline
\end{tabular}


Participants were reminded at the start of the interview their participation was voluntary, and they could refuse to answer any question at any point as well as leave the study. A classroom context was also documented to better understand the classroom dynamics when referring to teachers' perceived struggles. The interviews were audiorecorded and immediately transcribed using Microsoft Office transcription software and Microsoft Word. The transcripts from the interviews were then hand-coded and analyzed for common themes. Once the audio recording was transcribed into a narrative, a copy of both the transcription and summary was reviewed with the participant for accuracy through means requested by the participant such as email, telephone, or in person. This provided further feedback to ensure accuracy.

A similar process occurred with the review of teacher lesson plans. The lesson plans collected through email given by each participant were used as a form of archival data for each subject to look for existing planning for differentiation. Findings were indicated as field notes and reflective note taking. Specific components of differentiation were notated in field notes which were then triangulated to the interview data. These components included ongoing assessments, a variety of instructional strategies, evidence of groupings, and student choice in each subject area. Both forms of qualitative data provided insight into the use of differentiation in the classroom and possible barriers teachers are facing when trying to implement the strategy. The timeline of data collection and analysis included a total of one interview, one lesson plan review, and one follow-up meeting with each of the participants over a one-month period. 


\section{Role of the Researcher}

I am a current fourth grade teacher at one of the elementary schools within the research site. I have also taught third grade at the research site prior to this placement. Of the potential other 14 third and fourth grade teachers, 8 are teachers within the research site in which I teach. I do not hold any administrative or leadership roles over my colleagues. As I do not wish to gain any personal benefits from this investigation, my role as a researcher will not affect data collection. The role of the researcher should be approached with as little bias as possible. To ensure minimal influences and to better identify potential personal biasness, I consistently documented and reflected on my own past experiences relating to the topic study. I also shared my notes with my committee chair, as needed, and sought advice as needed.

\section{Data Analysis}

Data analysis is a process of systematically organizing interview transcripts, notes, field notes, and other forms of data that are gathered to look for similar categories and themes that represent the findings (Thomas, 2017). In this study, the goal was to identify emerging themes and categories through the analysis of two sources of data. The sources were limited to third and fourth grade lesson plan reviews and semi-structured phone interviews. A goal of implementation was to have all interviews complete within a three-week time period with transcription and analysis of both interviews and lesson plans to be completed within another three weeks. 
An inductive analysis of data involves examining data, transcribing, transferring, analyzing, and interpreting commonalities into thematic relationships and patterns (Creswell, 2015; Yin, 2014). This type of analysis can be completed following the five steps for analysis and interpretation of qualitative data provided by Creswell (2015). These steps include: (a) collecting the data, (b) preparing data for analysis, (c) reading through data, (d) coding and labeling data into segments, (e) coding text for themes to be used in research reports. Data for this research study consisted of semi-structured phone interviews, and artifact review to which both were designed to help answer the two research questions: (1) How do third and fourth grade teachers use differentiation to support all students? (2) What perceived opportunities and struggles do third and fourth grade teachers believe affect their ability to implement differentiation?

The interview protocol created was grouped into sections. First, participants described their classroom setting and their experience in the inclusive setting. Then, the first set of questions were used to answer the first research question pertaining to the current uses of DI in the inclusive setting. The last group of questions pertain to research question 2, asking, "what opportunities or barriers do teachers see towards full implementation of DI?" The interview data were immediately transcribed as it was obtained to ensure accuracy as it was still fresh with the researcher to allow for easier coding into categories and themes (Lodico, Spaulding, \& Voegtle, 2010). I read over the transcriptions and made corrections to the inaccuracies while listening to the recordings 
again. The updated and corrected transcriptions were sent to the participant for accuracy verification.

The data collection process occurred over two different phases. The first round of participants was interviewed and coding occurred along with lesson plan analysis. Once more participants were recruited, the process was repeated.

I used open coding and memos created during the bracketing process. Tufford and Newman (2010) describe three methods of bracketing in which one was used within this study. "One method of bracketing is writing memos throughout data collection and analysis as a means of examining and reflecting upon the researcher's engagement with the data" (Tufford \& Newman, 2010, p.80). The memos in this case took the form of observational comments that allowed me to explore my feelings about the research and the process.

I broke down the data into first level concepts, or master headings, and second level categories or subheading (Ravitch \& Carl, 2016). Using highlighting tools within the document, I noted similarities in phrases or words used by each participant. Using different colors for these similarities helped me see emerging themes. Lesson plans were analyzed and then compared to the interview findings concerning the level of use in the classroom.

A spreadsheet was used to organize the qualitative data into common themes. After the interview data were transcribed into a document and color coded with similarities, common colors were copied and pasted into cells under reoccurring themes. 
As reoccurring phases occur, codes were assigned and recategorized to identify themes within the data. The transcripts were then reread to ensure all the ideas were captured. Once completed, the codes were organized into categories and developed themes that were addressing each research question (See Yin, 2014). A total of four rounds of coding were completed. Discrepant data was noted during the analysis.

The use of transcript review and member checking provided accuracy to the study data. First, each participant received a copy of their transcribed interview through email to confirm the transcription. At this time, confidentiality was reviewed by the participant as well as the validity of the transcribed results. Participants were asked to provide additional feedback after reviewing the data for accuracy. Once finalized, the overall findings of the study will be written in narrative form to provide the participants with third and fourth grade inclusive teachers' perspectives on differentiation that is being implemented to help close the academic achievement gap and on possible reasons for their struggles to implement the strategy consistently.

\section{Evidence of Quality and Trustworthiness}

Trustworthiness in qualitative research is expectant upon the successful implementation of transferability, dependability, confirmability, and credibility upon which both researcher and participant should be involved. Method triangulation and data source triangulation was used to ensure credibility as it relates to the validity of the study (Ravitch \& Carl, 2016). These research strategies refer to the use of multiple data sources and participants to develop a comprehensive understanding of a phenomenon (Ravitch \& 
Carl, 2016). Two data sources were used to support the collected results which included lesson plan reviews and interviews. Teachers of varying experiences and education comprised the sample leading to multiple viewpoints to compare data.

To ensure validity throughout the study, thorough alignment and close review of results took place to ensure dependability. Reflexivity was used to self-reflect on potential bias and potential assumptions that could affect the investigation. Reflexivity helped strengthen the trustworthiness of the study design. Transferability can be achieved by providing detailed descriptions of the findings (Thomas, 2017). The results involved specific quotes from the participants to support specific themes that arose within the study.

\section{Procedures for Discrepant Cases}

Discrepant cases are cases that contradict other findings in a research study (Thomas, 2017) which can lead to validity concerns. Using different sources of data will aid in the constant comparison of data to look for deviant cases (Flick, 2018). If deviant cases are found within the analysis of results, contradictions will be discussed in detail in the research findings. By explaining these cases, the analysis will also be strengthened (Brikci, 2007).

\section{Data Analysis Results}

Data analysis followed a five-step process: collecting data, preparing data, reading through the data, coding and labeling data, and coding into themes. One data was 
collected through semi-structured phone interviews and the retrieval of lesson plans, the interviews were transcribed and coded. Six themes emerged.

\section{Data Analysis Process}

Data for this study was generated using third and fourth grade teachers from three elementary schools in one county in one Appalachian state. Permission was requested and granted from the county superintendent and then principals were informed of the study. Principals supplied email addresses for their third and fourth grade teachers to which a recruitment email was sent regarding volunteering for the study. Initially, five third and fourth grade teachers responded with an interview time that worked for them after school and attached their lesson plans. These phone interviews followed the interview protocol and lasted between 20 to 30 minutes that took place over three days. They were recorded using Microsoft Word@ transcription software and as a result, were transcribed simultaneously with the interview. The interviews needed major revisions due to transcriptioning errors and once revised, were sent to the participant for accuracy verification. The transcriptions and audio recordings were securely stored on a locked computer.

Needing more participants, I resent the recruitment email acknowledging the time restraints potential participants could be facing due to the opening of schools and COVID-19. With the second attempt at recruiting participants, four more volunteered by sending an interview time and lesson plans. These phone interviews occurred over a twoday period following the same structure as the five previous interviews. Once all data 
were collected, analysis began within Microsoft Excel@ by organizing key phrases and terms for each interview question and for each participant. I then started to compare responses grouping together similar responses from the interviews.

Saturation was achieved by the sixth interview. After the first round of participants were interviewed, transcribed, and data were coded, saturation was not apparent. I then recruited four more participants and conducted semi-structured interviews and lesson plan retrieval. After transcription and the start of additional coding, it became apparent no new information was being added. Therefore, it was concluded due to the small participate pool and the lack of gaining new information, saturation had been met.

Once the interviews were coded, I reviewed each participants' submitted lesson plans looking to see if the lesson plans corresponded to the interview data collected. I specifically was looking for forms of differentiation of content, process, and product along with small group instruction was planned for. Notes were taken in the margin and then organized within Excel.

\section{Findings from the Problem and Research Questions}

The problem for this research study was identified through conversations with administrators and some faculty who feel some or all third and fourth grade instructors may be struggling to implement DI in the classrooms. To gain insight into the teacher's perspective of differentiation and possible barriers to implementation, two research 
questions were created to drive the study. The two research questions created to investigate these concerns include:

Research Question 1: How do third and fourth grade teachers use differentiation to support all students?

Research Question 2: What perceived opportunities and struggles do third and fourth grade teachers believe affect their ability to implement differentiation?

The interview questions were divided into two sections, one pertaining to question one and section two pertaining to questions two. Teachers were asked how they use DI to support all students in ELA and mathematics that specifically indicated special education students, general education students, and gifted students. Specific examples of the process, product, and content were also of interest during the interview process. Data analysis of lesson plans and interviews revealed teachers do not plan for differentiation but use it as a tool to remediate low learners based on immediate informal feedback. The analysis also revealed teachers use other professionals in the building to differentiate. For example, teachers stated the use of Title 1 teachers and retired tutors for meeting their differentiation component for low learners in both ELA and mathematics.

The analysis of Research Question 2 data revealed teachers believed they are not prepared to differentiate effectively within the inclusive classroom due to several issues: not enough training in education or training by the county, not having enough instructional time, feeling restrained by the curriculum mandates, and not feeling supported through specific instructional feedback from evaluations and walkthroughs. 
Teachers expressed they had enough time to plan for DI and had materials that could be used if they were knowledgeable of how to use them to reinforce learning. Teachers also expressed hindered by the number of pull-out services the students receive, taking them away from the general education classroom, and missing important direct instruction. Six themes emerged within the collected qualitative data to include ability grouping, technology, planning for DI, professional supports, lack of training, and instructional support.

\section{Descriptive Data Analysis}

Data were derived through semi-structured phone interviews lasting between 20 to 30 minutes. Table 7 shows descriptive data of the teachers and classroom context. The nine teacher participants were all highly qualified having taught for four or more years with at least a bachelor's degree in elementary education. The interviews revealed all classrooms having a wide range of abilities ranging from 20 to 28 students and each classroom consisting of several students who qualified for special education services, title services, math support, speech services, and counseling. The county is unique in which two of the three elementary schools are title one schools. This means students who are identified as needing support in reading language arts will receive remedial services with a certified teacher outside of the classroom setting. These students will have not qualified for special education services due to not having a learning disorder but will be low in the area of reading. These schools receive additional funds to cover the costs of these 
professional positions through federal funds aimed at schools in low socio-economic status due to research that has proven low educational proficiency in these areas.

Table 7

Descriptive Data from Interviews

\begin{tabular}{lllll}
\hline & $\begin{array}{l}\text { Years' } \\
\text { experience }\end{array}$ & Education level & Grade taught & Number of students \\
\hline P1 & 5 & Masters & 3rd & 21 \\
P2 & 6 & Bachelors & 4th & $23-28$ \\
P3 & 18 & Bachelors & 3rd & 20 \\
P4 & 5 & Masters plus 45 hours & 3rd & 20 \\
P5 & 4 & Masters plus 15 hours & 4th & 21 \\
P6 & 10 & Maters plus 45 hours & 3rd & 22 \\
P7 & 5 & Bachelors & 4th & 25 \\
P8 & 6 & Masters & 4th & 24 \\
P9 & 6 & Masters plus 45 hours & 3rd and 4th & 20-28 \\
\hline
\end{tabular}

\section{Interview Coding and Analysis}

Four rounds of open coding with In Vivo coding were used to narrow 455 codes to six themes. Open coding refers to codes driven by the data whereas In Vivo coding is a form of qualitative data analysis that emphasizes the actual spoken words of the participant (Manning, 2017). Table 8 shows the process of coding from each round and how 6 themes were derived from the data.

Table 8

Coding for Interviews

\begin{tabular}{lll}
\hline & Codes & In Vivo \\
\hline Round 1 & 414 & 41 \\
Round 2 & 173 & 12 \\
Round 3 & 44 & 0 \\
Round 4 & 6 & 0 \\
\hline
\end{tabular}


After the interviews were transcribed, 455 pieces of interviews were coded into Excel. Round 2 of the coding process revealed similar codes as the staff felt similar on many of the topics presented in the interview. For example, participants mentioned Title One and Tutoring Services over 20 times. Other key terms that were common include manipulatives, whole group to small group instruction, technology, lack of time, common goals and expectations, lack of support, and behavior to name a few. Further condensing the codes into categories, I started to see that teachers were aware of the benefits of differentiation and could verbalize what they saw as barriers to implementation. I then categorized the codes into how teachers were currently using DI (Research Question 1) and perceived barriers of DI (Research Question 2). Round 3 of coding further condensed the data into 44 codes. Round 4 resulted in the final 6 themes presented in the research findings. Three codes, ability grouping, technology, and professional supports accurately depict how third and fourth grade teachers are currently meeting the diverse needs of students. Planning for DI, lack of training and instructional support indicated the three main barriers as perceived by third and fourth grade teachers towards full implementation of DI.

\section{Lesson Plan Coding and Analysis}

Third and fourth grade teachers were asked to submit one week's lesson plan for review no later than their interview date. All teachers submitted their lesson plans for review. Each lesson plan was labeled with the participants number to triangulate data from the interview. 
The review of the lesson plan consisted of looking for specific concepts associated with DI. These included proof of differentiated process, product, and content, evidence of informal assessment to guide instruction, and lists of accommodations/modifications. Acceptable process differentiation could have consisted of instructional techniques like small group instruction, cooperative learning, projectbased learning, technology-integrated lessons, or other best practices. Product differentiation could have included interest-based assessments, project-based assessments based on ability, technology-driven assessments, or any kind of product to reflect the individualized student learning. Lastly, teachers could have shown the differentiation of content through the description of ability-based instruction, technology based, tiered assignments, or interests based to name a few.

The analysis of lesson plans showed little to no differentiation across all lesson plans. A few teachers showed some differentiation based on planning for small group instruction, but there was no provided proof of differentiation based on product. All teachers organized their lesson plans into instruction blocks of time and listed SAT and IEP accommodations for each qualifying student. Table 9 shows the overall depicture of differentiation in lesson plans leading to the overall theme of Planning for DI and adding to support the theme of Instructional Support. 
Table 9

Coding and Analysis of Lesson Plans

\begin{tabular}{|c|c|c|c|c|c|c|c|c|c|}
\hline & $\begin{array}{l}\text { Accomm- } \\
\text { odations } \\
\text { List }\end{array}$ & $\begin{array}{l}\text { Planned } \\
\text { into } \\
\text { blocks } \\
\text { of time }\end{array}$ & $\begin{array}{l}\text { Process } \\
\text { ELA }\end{array}$ & $\begin{array}{l}\text { Product } \\
\text { ELA }\end{array}$ & $\begin{array}{l}\text { Content } \\
\text { ELA }\end{array}$ & $\begin{array}{l}\text { Process } \\
\text { Math }\end{array}$ & $\begin{array}{l}\text { Product } \\
\text { Math }\end{array}$ & $\begin{array}{l}\text { Content } \\
\text { Math }\end{array}$ & Other \\
\hline P1 & $X$ & $X$ & & & & & & & \\
\hline P2 & $X$ & $X$ & & & & & & & \\
\hline P3 & $X$ & $X$ & $X$ & & $X$ & $X$ & & $X$ & \\
\hline P4 & $X$ & $X$ & $X$ & & $X$ & & & & \\
\hline P5 & X & $X$ & & & & & & & \\
\hline P6 & $X$ & $X$ & & & & & & & \\
\hline P7 & $X$ & $X$ & & & & & & & \\
\hline P8 & $X$ & $X$ & & & & & & & \\
\hline P9 & $X$ & $X$ & $X$ & & $X$ & $X$ & & $X$ & $X$ \\
\hline
\end{tabular}

The analysis of the lesson plans showed teachers were unaware of how to plan for differentiation in all components of differentiation. While teachers stated in their interviews that they did differentiate by using guided reading groups, the lesson was not planned for or notated in a way for instructional support to occur. There was no documented evidence for product in either ELA or mathematics. Teachers who showed evidence of differentiating process through small group instruction also showed differentiation of content through ability grouping students and using the time to remediate lower-leveled learners. Lastly, Participant 9 was the only teacher who showed any other form of differentiation through the planning and implementation of choice board during station rotations.

\section{Patterns, Relationships, and Themes}

Because of the uniqueness of the county and the extra support that is received during the school day, teachers felt grateful but were also hindered by the additional 
support. This research study aimed at exploring teacher's perceptions of DI and potential barriers to full implementation. The qualitative data derived through semi-structured phone interviews and lesson plan analysis revealed six themes within the data: ability grouping, technology, planning for DI, professional supports, lack of training, and instructional support. Table 10 shows Level Four coding analysis into themes. Level three analysis has been included as Appendices B and C for further analysis support. Appendix B includes the interpretation of the data as it pertains to Research Question One, the current implementation strategies in the inclusive classroom. Appendix $\mathrm{C}$ shows Level Three coding as it pertains to Research Question Two, perceived barriers to the implementation of differentiation.

Table 10

\begin{tabular}{|c|c|c|c|c|c|}
\hline $\begin{array}{l}\text { Professional } \\
\text { Supports }\end{array}$ & $\begin{array}{l}\text { Ability } \\
\text { Grouping }\end{array}$ & Planning for DI & Technology & Lack of Training & $\begin{array}{l}\text { Instructional } \\
\text { Support }\end{array}$ \\
\hline Title and tutors & Grouping & Goal Setting & Technology & Importance of DI & $\begin{array}{l}\text { Instructional } \\
\text { Support }\end{array}$ \\
\hline $\begin{array}{l}\text { Teacher } \\
\text { Collaboration }\end{array}$ & $\begin{array}{l}\text { Different } \\
\text { Instruction }\end{array}$ & Learner Inventory & $\begin{array}{l}\text { Data driven } \\
\text { instruction }\end{array}$ & Training & Student Needs \\
\hline Identifying & Choice & Accommodations & Programs & Choice & Interruptions \\
\hline Pull out services & $\begin{array}{l}\text { Student } \\
\text { Collaboration }\end{array}$ & $\begin{array}{l}\text { Student } \\
\text { Collaboration }\end{array}$ & $\begin{array}{l}\text { Student } \\
\text { Tracking }\end{array}$ & Lack of time & Behavior \\
\hline Interruptions & Instruction & Instruction & & Lack of time & Scheduling \\
\hline Scheduling & $\begin{array}{l}\text { Differentiated } \\
\text { materials }\end{array}$ & assessment & & $\begin{array}{l}\text { No DI for } \\
\text { Product }\end{array}$ & More Planning \\
\hline $\begin{array}{l}\text { Losing } \\
\text { instruction }\end{array}$ & $\begin{array}{l}\text { Differentiated } \\
\text { work }\end{array}$ & Expectations & & $\begin{array}{l}\text { Teacher } \\
\text { expectations }\end{array}$ & $\begin{array}{l}\text { Administrative } \\
\text { help }\end{array}$ \\
\hline More support & & $\begin{array}{l}\text { Curriculum } \\
\text { Diverse Activities } \\
\text { Differentiated } \\
\text { materials } \\
\text { Differentiated work } \\
\text { Supplies } \\
\text { Classroom DI } \\
\text { Classroom } \\
\text { Accommodations } \\
\text { Curriculum } \\
\text { More Planning }\end{array}$ & & $\begin{array}{l}\text { Misconceptions } \\
\text { Choice }\end{array}$ & $\begin{array}{l}\text { More support } \\
\text { No Supplies }\end{array}$ \\
\hline
\end{tabular}


The six identified themes were identified in both current implementation and barriers. Pertaining to Research Question One, participants were asked how do you currently differentiate for both ELA and mathematics. Participants mentioned Title 1 services and tutoring within the research site as the main source of differentiation. This led to the theme of professional supports. Throughout this portion of the interview, participants also had a hard time explaining a way that product could be differentiated in their classroom which led to the theme of "lack of training." Technology was used throughout the interview process as a way of current implementation through abilitybased programs that automatically differentiate content and naturally the process of instruction. Due to the lack of time stated by teachers, ability grouping was used in the majority of ELA blocks with only two teachers finding time to use small group instruction as a form of differentiation in the mathematics time allotment. Lastly, I analyzed current ways high and low achieving students' needs were met in the inclusive classroom. Again, Title services were mentioned along with giving students extra work and having lower expectations for struggling students. Technology and professional supports became the main focus on how teachers currently differentiate in the inclusive classroom with an emphasis on when differentiation occurred, it was through the use of ability grouping predominately in ELA.

Research Question 2 asked participants about barriers to full implementation of differentiation. Teachers primarily indicated professional supports as being a hinderance resulting from multiple class disruptions and students missing core content time. 
Teachers also indicated a lack of training with differentiation and a lack of support from observations and associated instructional feedback. Experiences with DI was similar in which teachers indicated a lack of training at the worksite and limited training during teacher preparation. With the process of reflection during the interview process, teachers were able to indicate what they need to be successful when implementing DI. More time to plan for differentiation and to implement stations in mathematics was a common response along with more training and more instructional feedback from instructional coaches. Coteaching was a commonly mentioned solution among teachers which was indicated to keep unplanned interruptions to a minimum. As being student centered is a large component of differentiation, teachers were asked how they perceived their own classrooms. Teachers were unfamiliar with the term and stated seating as a way to be student centered with the counter that the county had a mandated curriculum which enabled them to use a student-centered form in instruction.

Ability grouping. Ability grouping is a main component of differentiation that a teacher can use to create instruction that is relevant to the student's ability. This grouping task allows for organized leveled content delivery and differentiation of both content and process. Ability grouping was a common theme that arose from both Research Question One and Research Question Two. Participants were asked how they currently use DI in the mathematics and ELA classroom. Because of the range of ability found in all classrooms, all participants similarly stated regularly using ability grouping to differentiate the process of instruction in ELA. Participant Two said, "the school has 
mandated all teachers to use Guided Reading Groups as a form of reading intervention. Students are to be placed in ability groups and then our little books are matched to their abilities." Tomlinson (2014) states this is the most used form of differentiation as it provides on level instruction to students in a small group format.

To gather data to form ability groups, teachers can use an assortment of data. The study site used mandated benchmarking testing to group students based on ability and then shares these groups with support staff including Title 1 teachers and retiree tutors. All nine teachers stated using ability grouping for ELA within the classroom setting under guided reading groups with only two stating the use of small groups for math remediation. Participant Five stated, "students would receive math remediation through pull-out tutoring services, but I lack instructional time to incorporate math stations into my daily schedule." Participant Four similarly said, "the school has really pushed for guided reading groups and has provided training to ensure they happen. We haven't had any training on how to differentiate math and there really isn't a push for it."

Differentiation provides flexibility in the process of instruction. Teachers can decide when it is appropriate to differentiate or alternatively use whole group direct instruction. Eight out of nine teachers stated they started their core on level instruction using whole group direct instruction for both ELA and mathematics. Direct instruction is a common way to provide modeling of new content to students which also allows for informal feedback to differentiate further. They would differentiate their process by using 
small groups based on ability in ELA during guided reading times. Participant Three stated that

Our county has been really fortunate to not have a lot of teachers leave and we've all come together to do very similar things based on the same trainings we've received. Because I want all of my students to receive the grade level curriculum, I start every day with whole group grade level content.

The participant furthers the explanation to say, "after whole group instruction, we move into our groups based on quarterly benchmark scores. This is where we do 15-minute rotations of four stations, me as the teacher, silent reading, word study, and technology." During small group instruction, Participant Seven stated, "I would teach the groups based on ability meeting the needs of below level, on level, and above level students. During guided reading, the materials would be targeted to the state of development each student was at." In the remaining stations, the students would be rotating through the skills that needed reinforcing for the lessons of the week.

The same eight teachers also said they started all math lessons with whole group instruction and would use informal feedback during the lesson to decide which students needed more help with the content. They would do quick remediate segments at the student's desks instead of small group instruction. Participant One shared,

I really don't have time to do small group instruction during my hour math block I start off the lesson whole group and just observe how the students are doing. If 
they need more help, I will call on them throughout the lesson or visit their desk during the student independent work time.

The two teachers who stated using small groups for math still used ability grouping to group the students. "Just like in ELA, I use the quarterly benchmark scores to group based on ability. I set up four stations around the room; Me as the teacher center, math with a partner, multiplication center, and technology," Participant Three explained. When asked how the participant found time within their schedule, they replied:

I understand that students need different things to learn, and sometimes it's just that little bit of one-on-one time. I refuse to leave this important part out even if it means I'm not moving through the content as fast as my colleagues.

When asking the second teacher how they found time to use stations within mathematics and why they thought it was important, they replied:

I would meet with each group remediating, reinforcing, and extending the skills being taught in class that week. I love this time and think it's really important as it allows for the kids to collaborate with one another and for me to spend one on one time with my kiddos.

With significant gaps found within both ELA and mathematical achievement data, teachers presented to differentiate more for ELA in comparison to mathematics especially through ability grouping which was the only indicated way of differentiating. Discussed later, teachers disclose their lack of mathematical groups and remediation due to the lack of time, lack of training in this area, and push for mathematical differentiation groups. 
Technology. Technology was addressed throughout the interview and observed through lesson plan analysis. Pertaining specifically to Research Question One, teachers were asked how they use technology to differentiate in the ELA and mathematics classroom as technology can enhance and lessen the burden of classroom differentiation. Technology has been addressed throughout current research to easily differentiate the content, process, and product of learning. All nine participants acknowledged the use of technology. "The county has supplied all elementary students with an iPad and before this implementation, all third and fourth grade classrooms were supplied with a laptop cart that stayed within the classroom," explained Participant One. Each elementary school has several different subscription programs that are ability based. These programs include Mobymax, Spellingcity, Thinkcentral, iReady, and ReadingEggs. These programs are ability based and content is assigned by the program based on the progress students are making and their individual placement exams. "Each student also has a free Office365 account," Participant One stated. "This allows me to communicate with the students more easily and share material.”

All teachers stated using technology to differentiation their content and process. Participant Four said that

The county has done a great job in providing the students the equipment needed like the iPads and laptops. They also purchase several subscriptions that are ability based which helps us track progress and assign lessons we know will benefit the student. 
Because of the technology use, all students would have content specific to their learning level. Technology also changes the process by which students are receiving instruction. Participant Five stated:

I always start my math lessons off whole group on level instruction, but technology has allowed me to use different apps for assessments. For example, I can use Kahoot which projects a question and the kids have to pick the right answer on their iPads which is projected as a bar graph on the board after each question. This gives me a great sense of where the class is with their understanding and it's fun.

Participant Three stated:

The only downfall to all of the technology is the mandated time set by the principal students are required to log per week. This sometimes takes place of teacher instruction and it's hard to get behind the idea that technology can easily replace what I do in the classroom.

Professional supports. The theme professional supports were present in both research questions. Teachers were asked, "how do you currently use DI in the mathematics and ELA classroom; how do you differentiate differently for high and low achieving students; and what practices and procedures does the school have in place to help make DI be successful?" In all instances, Title 1 teachers and tutors were mentioned. Participant Seven stated, "Title 1 is used for reading intervention, retired teachers known as tutors in our building are specifically for math. We also have special education 
teachers, speech teachers, occupational therapists, and counseling services that support students." The study site is unique in that two of the three schools are Title 1 schools and use retired teachers as additional supports. Based on benchmark assessments, students are grouped based on their abilities. Students who are below level are tracked to be placed into special education but up until qualification are placed with a Title 1 teacher for reading support and retired teachers (tutors) for math support. Six of the nine teachers, all from a Title One school replied depending heavily on these extra supports for differentiation services. Participant Two stated, "a lot of our lower students are pulled out of the classroom for remediation services. In math, because I don't have time to use stations, I depend on the interventionists to help." The student would spend time within the general education classroom to receive their grade level content and then would be pulled from the classroom for additional supports. "Students would typically be pulled during Guided reading times for reading support and during the math time block for math support," stated Participant One.

Teachers were also asked, "what do you feel hinders your ability to consistently implement DI in the inclusive setting and what is needed, if anything to help teachers consistently use DI?" In both questions, the same teachers who stated the usefulness of the support staff also stated the hindrance. Teacher Three claimed, "because of the varied population in each classroom, students were constantly coming and going from the classroom.” Participant Eight stated: 
On a typical day, I would have my full class for the first 30 minutes of the day and then my special education students would leave for their time for ELA. When they would return, my designated bubble kids would leave for their Title services, my speech kids would be pulled out for services, OT and PT would take their kids. We would all be there for 30 minutes of math together before special education students would be pulled out for their time, math tutors would pull their kids. There isn't enough time in the day to make sure all students are receiving the instruction they need.

Five of the nine participants stated pull out services being an obstacle for differentiation in the classroom but recommended the need for coteaching instead of pull-out services. Participant Five said, "if we could adopt a co-teaching format where we push these support services in the room instead of pulling students out, more students would benefit and there would be fewer classroom distractions." Participant 7 also stated:

We need to come up with a new way, a new idea, that allows students to be successful on content level stuff while still receiving their remediation. Our school hasn't looked at coteaching strategies, but it would be something I would be interested in.

Five teachers also stated they needed administration to keep unplanned interruptions from occurring during instructional times and would like meetings such as IEP, 504, and SATs to occur on a limited basis. Participant Three stated, "I am pulled out of the classroom so much for meetings involving my students. On top of students coming and going, subs 
coming into my room to cover my meetings, and unscheduled drills, it's overwhelming and frustrating at times."

Professional supports were repeatedly addressed during the interview process as both a hindrance and differentiation support. Teachers saw the benefits of having the specialized support to help struggling learners but also recognized the downfall of the students always leaving the classroom. If the students were not in the room to receive the on-level instruction, they were ultimately missing the valuable direct instruction of the day that they would not get anywhere else. This was found to occur in both ELA and mathematics. Because of the expansive range of ability in the classroom, mandated remediation times stated in student progress plans, and progress monitoring of struggling students, teachers found these supports should burdensome when trying to teach the core content.

Lack of training. The theme lack of training was found within both research questions. Teachers were asked how they currently use DI in the mathematics and ELA classroom, how they differentiated differently for high and low achieving students, what practices and procedures are in place to help make DI be successful, what hinders your ability to consistently implement DI, and what experiences do you have with DI (education and training). Throughout the interview process, teachers verbalized their lack of workplace training and their desire for more. As differentiation is developing along with the recognized struggles associated with inclusion, schools should provide current and relevant PD for their teachers. 
For differentiation to be successful, teachers should realize the importance and impact differentiation can have on student learning. All teachers saw the importance of using DI to meet the needs of all of their students. Teacher One explained, "when you differentiate to their abilities, it's going to help close the achievement gap because they are getting the skills, they are missing in a way that makes sense to them."

The teachers in the study seemed to understand the importance of differentiation but lacked the knowledge to determine the components and their meanings. Six of the nine teachers participating in the study asked me to clarify what product meant towards differentiation. Participant Nine asked, "that means how I grade, right?” All but one teacher stated learning about differentiation in their undergraduate degree, the one having gone through school over 10 years ago. Participant Eight specifically said, "I started teacher training 20 years ago and differentiation wasn't really a thing. I took a break from teaching and came back and I've maybe had one training at the school." Teachers who had furthered their education into their master's degree also claimed to have had to differentiate lessons more thoroughly within their educational training. For example, Participant Two explained that

As a student-teacher they expect you to differentiate your lessons, and you really don't have a curriculum to follow. As a teacher now, I know how to differentiate but have little time or knowledge on how to differentiate our specific mandated curriculum. 
All teachers recalled the training provided by the state department the previous year and all teachers stated they could use more PD to consistently implement DI within the inclusive setting.

In discussing how teachers differentiate for high achieving and low achieving students, five of the nine teachers stated they gave the more advanced students more work because they finished their work early and did not want them to get bored. When differentiating for gifted or advanced learners, it is important not to just give them more work to keep them busy, but one should ensure all tasks are meaningful and relevant to the student's learning (Cash, 2017). Participant One said, "I usually give my higher achieving students more problems and my lower achieving students less work." Teachers also stated they felt "stuck" teaching to the middle of the group because of the "mandated curriculum and standards set by the county office." Participant Four said, "I know I have to use the county's curriculum and it's geared towards the on-level kids. We really don't have much supplemental materials that will allow us to teach up or down." However, in all cases during the interview, teachers needed clarification of some term basic to differentiation furthering the findings that PD is needed within the site. Participant Seven asked, “is product how I grade?” Participant Four asked, “content is what I'm teaching, process is how I'm teaching it, but what is product?" There seemed to be a big misunderstanding of not being able to differentiate the curriculum because it was mandated in the county which also leads to a lack of training in the area. Teachers can 
still base their instruction on the mandated curriculum but use a variety of tools to ensure it is on level and relevant to student learning.

In discussing key components of differentiation such as being student centered, using assessments to guide instruction, and providing choice, teachers struggled with explaining how they use these options in the classroom. Teachers should be able to identify and vocalize what these best practices are in order to be able to plan for these experiences in the classroom. For example, Participant Three said, "I don't know how my room is student-centered. I just feel really dumb when it comes to all of this." Participant Six said, "I know I should provide choice, and I'm not sure why I don't. I guess that is something I should really work on." The lack of competency in the area was evident within participants but also was the acknowledgment of the need for training and the willingness to learn more about differentiation.

All teachers described a classroom that is, for some of the day, led by direct instruction. Participant One said:

I always start reading and math with direct instruction. All students need the content on level. It is from here that I break off into my reading groups to help students reteach the skills they may have missed earlier on.

All teachers also explained grouping students into pods for seating and providing additional tables or library corners for station options. All teachers stated they used the end of unit tests supplied by the curriculum and did not differentiate base on product within the classroom. This all tends to go back to the feeling of not being able to venture 
away from the county mandated curriculum. Student choice was also a struggle as teachers stated seating options as one of the only ways they differentiated based on choice. Participant Five said, “I don't use choice boards and I don't usually move away from the county curriculum. I do, however, do an interest inventory at the beginning of the year."

Instructional support. Instructional support came up regularly within the second research question. Teachers were asked what practices and procedures does the school have in place to help make DI be successful and what is needed if anything to better DI within the school. Teachers expressed the need for more PD that was discussed earlier along with the desire to use coteaching instead of pull-out services. Participant Nine said, "there are constant distractions throughout the day. I would love for the school to adopt a push in policy like coteaching that would allow teachers to help all students in the room and reinforce skills that I am teaching."

Six of the nine participants expressed the need for more instructional support within their classrooms. The supports would help teachers address student attention, assist in teaching, helping during stations, among other things like behavior concerns. Three teachers explained behavior has been an issue in the past with students of varied abilities, specifically students who had qualified for special education services.

Participant Seven said, "I believe that students with learning disabilities get distracted more easily in the classroom because they don't understand what I am doing. It's hard to teach a class of 28 kids when five of them are being a class distraction." With the varied 
abilities within the general education classroom, co-teaching has been an identified strategy to help manage these inclusive related hindrances and help support student learning. Some teachers believed they needed strategies and instructional support to help these struggling students be productive in the general education classroom. Participant Five explained:

I know it's hard to provide teachers with classroom support but strategies and ideas would really be helpful to decrease classroom discipline referrals. I want someone to watch me teach for a day and tell me what I can be doing better! All teachers also indicated the use of observational feedback as a way to develop their differentiated strategies. Observational feedback should be actionable feedback leaving teachers with two to three ideas to better their instructional practices. However, teachers indicated these walkthroughs were not as thorough as they should be and seldom included actionable feedback. Participant Two said, "we all are swamped with work overload right now. I kinda feel like we have the required observations for the paperwork and it's never for the purpose to further my instructional pedagogy." Participant Four also explained, "I'm at the point in my career where I feel stuck in my ways. I'm open to new ideas and what I can be doing better but I'm not sure where I can turn to for that information." Seven of the nine teachers wanted specific feedback from their administrators to help develop their weaknesses in instructional approaches but also realized time was an issue. 
Instructional feedback can help teachers be more reflective in their practice. It helps identify what is working successfully in the classroom and areas of improvement which helps a teacher continue developing their craft. The feedback is important especially in the inclusive classroom as teachers are facing new challenges and are always looking for ways to better than instruction for their wide range of learners. Administrators can also take this time to identify specific school-wide PD to enrich all teachers' instructional practices.

Planning for differentiated instruction. Teachers were asked what practices and procedures does the school have in place to help make DI be successful and what do you feel hinders your ability to consistently implement DI in the inclusive classroom? Planning for differentiation and the process of planning was mentioned throughout interviews and observed through lesson plans. Teachers within this setting have the same planning time each day as their grade level to encourage team planning. This specific allotment of time allows teachers to discuss plans for lesson delivery and share creative lesson plans. Teachers can also discuss classroom issues and pacing with colleagues All teachers stated having enough planning time to consistently plan for differentiation but little to no differentiation was discussed within the interview process. Participant Seven said:

The school has arranged our schedule so that we could have the same planning time as our grade level. This is a time for us to team plan and keep pace with one 
another. We can share ideas at this time or talk with the special education teachers to ensure they need for the week.

When specifically asked, "do you think you have enough time to plan for differentiation," Participant Three responded like all others, “yes, I believe I do.” The assumption from this statement would indicate a further lack of training on how to use planning successfully while also learning more about the observable and useful components within differentiation.

The lesson plan review for all nine participants showed very minimal differentiation. All participants used Planbook to document their daily/weekly lesson plans which are purchased through county funds. Each participant also noted the daily accommodations students needed set forth by their IEP, 504, and SAT plans. These accommodations and modifications included adult supervisory aid, assignments read aloud, redirection to task, rephrase and repeat directions, extended time on assignments, text to speech, preferential seating, modified spelling lists, use of manipulatives, alphabet strip for handwriting, behavior charts, and multiplication charts. All participants also broke their day into blocks of time per each subject.

The blocked time for ELA stated only whole group skills that were being introduced and the activities correlated to the content. While all teachers stated they used guided reading groups, only three teachers depicted this within their lesson plans by stating "Guided reading groups from 1-1:30." Two of these teachers broke the time block 
down further by stating which students went to each group and the activity assigned to each station: reading with the teacher, silent reading, word work, and technology.

In the area of mathematics, all teachers designated a time block and listed the math skills or lessons for the day. However, no teachers depicted math groups within their lesson plans. No other signs of differentiation could be found within the planning documents pertaining specifically to mathematics.

\section{Discrepant Cases}

When data were analyzed, there may be some data that has nothing to do with the rest of the collected data. This data is referred to as discrepant data. Discrepant case analysis is another strategy that can increase the credibility of a study (Merriam, 2009). As I coded the data, I looked for discrepant data that emerged between the interviews and lesson plan analysis. I also examined responses between participants for discrepancies.

Participants were consistent with their responses with one exception during the interview process. Eight participants responded they needed more time to plan for consistent differentiation for various reasons. One participant said they had enough time, and that code could not be coded with the rest of the data and was left out.

Another discrepancy was found when comparing the interview responses to the lesson plan review. One theme that emerged from the document analysis was planning for DI. During the lesson plan analysis, there was little to no evidence of planning for DI. Several participants voiced their concern that they differentiated by using small groups 
and with technology, but this was also not indicated within the lesson plans viewed during analysis.

Also, only two participants used ability grouping for mathematics whereas all participants used ability grouping for ELA. This creates the question of why teachers differentiate into small groups for one subject instead of for both core content areas. The data from the interview supports the idea that teachers see the value in differentiation. Therefore, more information could be gathered as to why teachers are not differentiating in all content areas as needed.

\section{Conclusions}

A qualitative case study was used to explore third and fourth grade instructors' perceptions on their knowledge, implementation, and self-assessment of using DI in classrooms in three elementary schools in one Appalachian state. Grounding the study is the interpretation of differentiation described as maximizing learning through meeting each individual learning need through various means which is found embedded in inclusive education (Tomlinson, 2015). Specifically stated, DI is a targeted process that involves forward planning, programming, and instruction. It uses teaching, learning, and assessment strategies that are flexible and reoccurring to provide an appropriate level of challenge and engagement for students in meaningful ways (Cooney, 2019). Teachers can differentiate in the classroom setting by modifying the content, process, or product during instruction. 
To gather data for this study, individual phone interviews and lesson plan reviews were conducted. The data from the interviews, field notes, and the document reviews were hand coded to help identify possible relationships within the data. Teachers were asked to review their transcripts for accuracy as well as a summary of each individual interview. All identifying characteristics were removed and all data were stored on a locked computer. Six themes emerged from the data in this study: (a) ability grouping, (b) technology (c) planning for DI, (d) professional supports (e) lack of training, and (f) instructional supports.

The findings showed an overall agreement amongst participants that differentiation was a useful tool to help all students be successful in the inclusive classroom. Also, teachers believed it was easy and relevant to use ability grouping and was the dominant way the county DI in both ELA and mathematics. Ability grouping is a way to differentiate the process of instruction and is most widely used by teachers across all grade levels (Tomlinson, 2014). Technology was discussed throughout each interview as it is a tool used for easier differentiation. This technique to differentiate could affect the process, content, or product towards meeting unique needs. Teachers expressed the county provided adequate support and programs they could choose which could lead towards more differentiation. However, participants believed certain things could be implemented to better enable teachers to fully implement the strategy. These suggestions included more training on how to use DI in the classroom, having more instructional support, and requested more uninterrupted time during the day. Through data analysis, 
another key factor uncovered was the lack of actual planning for differentiation to occur within the instructional day.

The following section will discuss the recommended three-day professional development (PD) project as an outcome of the results. The PD will discuss the foundational terms and applications of differentiation allowing teachers time to preplan for DI by practicing the skill of differentiating tasks. Teachers will be advised on alternative instructional support models that can be implemented within the school to help advance the use of DI as an instructional strategy. Lastly, teachers will be introduced to coteaching strategies that could also be used within the research site to further support general education teachers and the use of productive and effective differentiation strategies. 
Section 3: The Project

\section{Introduction}

The purpose of this qualitative case study was to explore third- and fourth-grade instructors' perceptions on their knowledge, implementation, and self-assessment of using DI in classrooms in three elementary schools in one Appalachian state. The findings from this study provide insight into the PD needs of third- and fourth-grade inclusive teachers. The following program has been designed to meet these specific needs.

Teachers within the research site are knowledgeable of the positive outcomes that are associated with successful inclusive differentiation and readily differentiate using ability groupings and the use of technology. But as stated within the findings, teachers need guidance and support on how to preplan for differentiation and feel they need more training on how to differentiate the process, product, and content in the ELA and mathematics classroom. Because instructional support from administration cannot be guaranteed, alternative strategies such as peer observations, video analysis, and collaboration will be discussed within the development. Lastly, teachers will be guided through co-teacher techniques and strategies to support more push in services to aid in fewer classroom interruptions and more inclusive teaching practices conducive to student success.

With these findings and concerns in mind, I created a 3-day professional development training that focuses on enhancing third- and fourth-grade teachers' 
understanding of the components of DI and how their knowledge can be extended to both areas of ELA and mathematics. First, teachers will receive a clear understanding of what DI is and the foundation set forth by the findings of Tomlinson (2001). Next, teachers will learn how to modify their curriculum by focusing on content, process, and product while still teaching the state mandated standards. Documentation of these planned activities and the benefits of preplanning these activities will also be addressed. Then, teachers will be introduced to instructional support strategies that they can implement within their school that could provide observational feedback and additional learning opportunities toward differentiation. Finally, teachers will be introduced to coteaching strategies and implementation suggestions to better aid in unnecessary classroom disruptions. The PD will close with collaboration time for teachers to discuss the next steps, share differentiation ideas, and how best to incorporate these ideas into their school setting.

The goal of this professional development workshop is to increase DI use within the inclusive classroom by enhancing teacher knowledge of the different ways to differentiate as well as provide insight on alternative strategies for instructional support and coteaching. Overall, if teachers become more consistent with the use of DI within both ELA and mathematics, more students will be successful working toward mastery of content in these core areas. 


\section{Rationale}

Six themes emerged from the data in this study: (a) ability grouping, (b) technology (c) planning for DI, (d) professional supports (e) lack of training, and (f) instructional supports. Participants believed that they were adequately differentiating for students in both areas of ELA and mathematics, but further research showed they were just ability grouping for ELA and little for mathematics. Teachers also indicated the use of technology throughout both content areas by using ability-based programs that automatically differentiated based on placement exams. Participants expressed a need for more DI training specifically in mathematics and how to differentiate the content and products within ELA. Teachers indicated being provided little instructional support or feedback during observations and feel their instructional development has not progressed much within the classroom setting. Within this area of concern, lesson plan analysis also showed minimal to no stated differentiation within planned instruction or content. Further, all participants indicated that the number of pull-out services hindered their ability to effectively differentiate for their varied classrooms as they depended on the remedial services provided through Title 1, tutors, and the special education department.

Teachers also indicated that they received training in preservice teacher education and minimal PD within the job setting. Specifically, teachers remembered one training a year ago in which the definition of DI was discussed with little applicable knowledge received. This only pertained to ELA with teachers claiming they have received no DI 
training for mathematics. All participants expressed the need and want for more PD on the topic with actionable ideas to take back to the classroom.

This PD program is based on current literature. For instance, according to Gupta and Guang-Lea (2020), teacher and teaching quality are the most powerful predictors of student success, and PD is important for teacher retention. Effective PD can be characterized by being relevant to the teachers and their students, teacher collaboration, support from the school leadership, exploration and reflection with attention to practices and beliefs, job-embeddedness, and valuing teachers' experience and knowledge (Canaran \& Mirici, 2019).

Additionally, the PD was designed for third- and fourth-grade teachers in mind but could be easily used within any grade band. The PD was also designed for the adult learner keeping key characteristics in mind: Adults need self-directed PD, they learn by doing, and they should know the relevance. They need to draw on experience, have multi-sensory learning, practice what they are learning, have personal development, and therefore have involvement within the activities of the training (Svendsen, 2020). Additionally, it is important to have PD that is job-embedded and designed to meet individual participant needs (Jordan, 2016).

The key findings from this study provided the framework for a 3-day professional development program to support third- and fourth-grade inclusive classroom teachers. Day 1 of training will review the key components of DI and how to apply these components to the county wide mandated curriculum. Teachers will have the opportunity 
to collaborate with colleagues by sharing ideas and implementation plans. On Day 2, teachers will be introduced to co-teaching strategies and suggestive ways it can be implemented within the research setting. Day 3 will consist of how to further DI understanding by observing and evaluating colleagues on their implementation of DI. Teachers will be introduced to alternative instructional feedback with different suggested strategies for actionable feedback. By addressing three main themes found within the research findings, teachers may develop a further understanding of the implementation of DI and other ways to strengthen their daily function as educators by addressing the obstacles that were revealed.

\section{Review of the Literature}

I conducted an exhaustive search and analysis of peer-reviewed research articles using Walden University library, searching Education Source, ERIC, SAGE Journals, ScienceDirect, Taylor and Francis Online, and Academic Search Complete. The key terms used for the search have been used to divide the literature review into comprehensive sections. These terms include effective professional development, adult learning, DI, instructional support, importance of lesson planning, and co-teaching. The literature review supported a 3-day professional development workshop that incorporates DI components in creating opportunities for teachers to actively work together creating units that include differentiation. Teachers will also be introduced to alternative instructional support models and suggestions on coteaching strategies that could be implemented. 


\section{Professional Development}

The program I created for this study was a professional development program with three goals: increase teacher understanding and effective incorporation of all components of DI (content, process, and product) in the areas of ELA and mathematics, increase teacher knowledge of instructional support models they can implement to further understand DI through teacher observations and introduce teachers to coteaching strategies to further enable uninterrupted time with more in class time to differentiate for all students. School systems and county administrators implement PD programs to provide teachers with a way to develop skills and stay informed of changing educational trends. This allows for the opportunity for PD to be connected to the teacher's interests and identified needs (Dennis \& Hemmings, 2019; Kennedy, 2016).

PD refers to both formal and informal learning activities specifically designed to enhance teachers' professional knowledge, capabilities, competence, motivation, selfefficacy, and beliefs (Coldwell, 2017). Successful PD requires thought and planning on the developer side. Seven elements for successful PD include being content focused, incorporating active learning, supporting collaboration, using models of effective practice, providing coaching and expert support, offering feedback and reflection, and being sustained (Darling-Hammond, Hyler, \& Gardner, 2017). Additionally, by making the training relevant to the teachers' needs and eliminating the unnecessary content, teachers are more likely to find the information relevant and useful in their classrooms, thus helping them develop their practice (Kennedy, 2016) Furthermore, teachers want PD 
from professionals in the field, who have experience with problems teachers face and base programs on their own experiences and expertise (Minor, Desimone, Lee, \& Hochberg, 2016). With these development programs, teachers also need visual models, opportunities, and support during and after the implementation to advance their teaching styles over an extended period as they use their curriculum (Lunsford, 2017). The overall goal of PD, however, is to change instructional practices. When PD is embedded in teachers' work lives and allows for practice, discussion, and feedback, teachers are most willing and able to make these changes (Minor et al., 2016).

Professional development creators should also take into account the context and culture of the schools when developing the programs (Campbell, Lieberman, \& Yashkina, 2016). This can be done by following a theory of action or negotiation between the teacher or school and the provider (Kennedy, 2016). This two-part negotiation is identifying a central program of practice and then prescribing a pedagogy that will help teachers enact ideas into the context of their own practice (Kennedy, 2016). A welldeveloped theory of action will engage teachers in their learning while encouraging them to take risks and be resilient as they work towards developing their expertise (Drew, Priestley, \& Michael, 2016).

Professional development is needed for both novice and veteran teachers, but both have different needs. Novice teachers lack experience within the teaching profession and the knowledge of what is missing in their current placement (Martin, Kragler, Quatroche, \& Bauserman, 2019). Veteran teachers need to stay up to date on current teaching 
literature and practices while renewing new strategies within their pedagogy (Avery, 2017). In both instances, if teachers feel supported, valued, and adequate in their teaching placement, they are more likely to remain in that position and grow into expert teachers (Fer Coenders \& Nellie Verhoef, 2019). Further discussing the difference in needs between the two, novice teachers tend to use observations and informal discussions with peers to improve their practice, whereas more experienced teachers tend to participate in more formal meetings for their PD (Tantawy, 2020). Furthermore, teachers in their earlier years report more problems with classroom management and effective teaching approaches, whereas older teachers gain more professional knowledge in subject content, pedagogy, teaching methods, and performance standards through formal activities such as conferences, workshops, and training courses (Tantawy, 2020)

School systems spend a large amount of money on PD each year, which supports the need for effective designing of these programs. The federal government spends 2.6 billion dollars each year on PD allotting 8 to 12 thousand dollars for each teacher (Calvert, 2016). Although a substantial amount of money is placed toward these advances, a survey conducted by the Bill Gates Foundation in 2014 found more than 1,600 teachers characterized their PD as irrelevant, ineffective, and not connected to their core work of helping students learn (Calvert, 2016). Ineffective PD is a result of not understanding the needs of adult learners (Gore et al., 2017). Moreover, many studies suggest that quality PD can increase teachers' content knowledge and improve their enacted instructional practices which could increase student achievement (Pehmer, 
Gröschner, \& Seidel, 2015; Polly et al., 2015; Tantawy, 2020). To address the inconsistency in research findings related to the effectiveness of PD, a bottom-up approach can be used to address teacher needs (Brigandi et al., 2019). This approach, also known as professional learning, is active, uses collaboration, and is a long-term, sustained approach to teacher learning (Brigandi et al., 2019).

\section{Adult Learning}

Adult learning begins with andragogy. Malcolm Knowles first recognized adult learners as both self-directed and autonomous and saw teachers as facilitators rather than presenters. Knowles suggested that as a person matures, they move from being dependent to self- directed. Next, an adult learns from experiences, and the readiness for an adult to learn relied on their social role. An adult is also more problem centered than subject centered in learning. Lastly, adults are more internally motivated, and they need to know why they need to learn something new (McCray, 2016).

Adults think and act according to a set of values and experiences, which accumulate and become reference points to help adults understand, shape, and interpret new experiences and feelings (Martin et al., 2019). Transformation or creating and understanding for these new experiences always starts with a problem or conflict that is not aligned with the person's frames of reference or is not within the person's current belief system (Mezirow, 2003). In this social constructive theoretical model, there are three ways an adult transforms their learning: Adults examine their beliefs and experiences, adults use critical reflective assessment either individually or with peers, and 
reflective rational discourse leads adults to take action and a transformation of beliefs and behaviors (Mezirow, 1995). With this process, teachers should be willing to change their belief systems and teaching techniques over time. However, for adults to experience transformative learning, they should experience something different from the learning associated with children (Mezirow, 1997). The ideal condition in which an adult learns requires the participant to be free to engage in various roles of discourse, including becoming critically reflective of assumptions and free from coercion (Calvert, 2016). For real learning to take place, the adult learner should be both the decision maker and the subjects of their own learning (Calvert, 2016; Vella, 2002). Transformative learning places greater emphasis on the process of meaning-making from an adult learner's perspective and studies how adult learners change as a result of the significant shift in personal beliefs (McCray, 2016).

\section{Differentiated Instruction Professional Development}

Teachers within the research site used ability grouping to differentiated ELA with only two teachers using math groupings to remediate math learners. All teachers, for most of their instructional time, used whole group direct instruction. Although teachers stated that they were aware of the benefits of DI, students still receive the same instruction (see Vlachou \& Fyssa, 2016). But when teachers modify the curriculum, the engagement of SWDs increases, and challenging behaviors decrease (Lee, Wehmeyer, Soukup, \& Palmer, 2010). 
Within this section of the literature review, I examined different forms of DI that can be introduced to teachers including different grouping styles. For example, Bates (2013) suggests groups should be fluid, meaning groups should change based on the needs of the students. Students could be grouped based on interest or based on the daily skill that they might have struggled with. Students can also be grouped heterogeneously and be called to work one on one with the teacher. Though this approach allows for flexibility with grouping practices and managing the classroom more difficult, it allows the student to interact with others with different strengths. Teachers have many options when forming their groups. By not being a part of the center rotation, the teacher can be free to differentiate for a variety of skills and interests. Additionally, teachers can adjust group formations more easily and the amount of time needed per each group when they are not directly involved with instruction. Flexible grouping is essentially for meeting all student's needs (Bates, 2013).

Also found within the research was the lack of DI for gifted students with participants explaining they gave these students more work to keep them occupied or "not bored". Students with high academic ability benefit when a teacher is trained in gifted education pedagogy allowing the teacher to be better prepared to meet the advanced student's needs (Brigandi, Weiner, Siegle, Gubbins, \& Little, 2018). To meet these advanced needs, teachers implementing DI should create an emotionally safe learning environment in conjunction with a rigorous curriculum that is academically challenging. Teachers should be readily using discovery, inquiry-based, and hands-on 
methods with these students (Brigandi et al., 2019). Tiered assignments could also be used to meet varying instructional demands.

Tiered assignments are assignments that are most simple to most difficult. Roberts (2019) suggests all students have access to tiered assignments, and they work up to their capacity. Students should not be limited by data based on previous findings (Roberts, 2019). Teachers can also use stations, centers, choice boards, and discussion circles to help meet varying needs. Morningstar, Shogren, Lee, and Born (2015) found within their study that the most frequent modifications for SWD in almost half of classrooms was a reduction of rigor or cognitive demands of work, changes in how materials were presented in $31 \%$ of classrooms, environmental adjustments (23\%) and response alterations $(25 \%)$.

The overall purpose of DI is to meet the student where they are currently learning. Roberts (2019) further describes this teaching style as teaching to the whole student through the development of a growth mindset and being a self-directed learner. Students should be able to articulate what they both want and need from their education to be successful.

\section{Lesson Planning}

Teachers across the world use lesson plans to preplan for student activities and is a key component of initial teacher training. As this process has changed throughout the decades, teachers now are preplanning for a wide variety of skill sets working towards personalization due to inclusion. The process of lesson planning reflects continuing 
challenges and dilemmas in teaching that have been recognized for some time such as the balance between subject content demands and learner needs (Black et al., 2019).

While it is best practice to use lesson planning to prepare and plan for daily lessons, little is required by law to implement these plans. In the identified Appalachian state teachers are required to turn in weekly lesson plans and the principals are required to make quarterly comments aimed at supporting instructional practices. Planbook.com ( is an online lesson planning format that allows a teacher to customize their schedule with time blocks and add content as necessary. Lesson plans, according to state code, cannot require standards to be in place, individualized, or in any particular format. OfSTED (2015) furthered this thought in suggesting principals are more interested in the effectiveness of planning rather than the form it takes.

The concept of universal design for learning is a planning program that can help teachers create learning opportunities for everyone (Black et al., 2019). This process extends what is available for all learners instead of finding additional or different materials for struggling or advanced students. Universal by design (UBD) involves starting at the end rather than at the beginning of the planning process (Sumrall \& Sumrall, 2018). This can help teachers plan appropriate lessons for all learners to ensure the standard is being addressed. The assessment and learning objectives should also be identified at the beginning of planning (Sumrall \& Sumrall, 2018). By knowing the end result, teachers can align learning activities for each learner. As some teachers use a county wide curriculum not only for convenience but also to stay consistent with other 
teachers, UBD could still be used. Teachers should pull the end of unit assessment and identify the learning objectives within the unit. The materials supplied within the curriculum should align with the general norm and at this point, teachers should find materials for lower level and upper-level students. To differentiate for all students, teachers cannot just teach to the average norm which also means, they should plan for high, average, and low achieving students.

Although student abilities vary within the classroom, a separate lesson plan is not needed for each student (Birnie, 2015). For example, teachers can use a three instructional model which includes direct instruction followed by cooperative learning groups and wrapped up by a highly individualized computer-based program (Chubb, 2012). In this instance, the students are receiving differentiation through grouping based on their collaborative groups and through intense remediation if needed through the technology program. This would create an instance where very little differentiation would need notating in lesson plans. Teachers can also use stations, centers, tiered activities, small group instruction, choice boards, and discussion circles that would not require a plan for each student.

\section{Instructional Support}

Professional development is one-way teachers can advance their competency as educators. Teachers can also look to one another for instructional support. Instructional support is defined as providing feedback to teachers that provide insight on strengths and weaknesses with steps to improve instructional practices (Feldman, 2016). While this is 
one of the main responsibilities of a principal within a school setting, principals can become bogged down with other administrative tasks. Teachers can implement instructional support strategies to further develop their teaching skills in addition to principal feedback.

Feldman (2016) suggests seven different structures that teachers can use to provide instructional support and feedback. Teachers can use learning walks which include a group of 4 to 8 teachers that observe their peers for 20 minutes using an observation checklist. Not only does this provide feedback to the teacher that is being observed but it also provides an opportunity for the observers to think about what good practice looks like, have an opportunity to see good instructional practice to take back to their classroom, and share their experiences with the observed teacher.

Teachers can use a peer-to-peer structure where teachers choose a partner and observe the teacher for 20 to 30 minutes. Using an observation form, teachers can receive informal feedback and have productive professional learning community conversations grounded in concrete experience (Feldman, 2016). There are benefits to this structure over the learning walks as teachers might be more comfortable with teachers they invite within their room.

Teachers can use video feedback to help develop their understanding of excellent instructional practices (Feldman, 2016). Feldman (2016) suggests teachers start with watching videos of other teachers found within expert teaching channels and move to self-observations. Teachers should then share videos with trusted partners for additional 
feedback. This provides teachers an opportunity to reflect on their practices if they are not quite ready or comfortable to allow others to provide critical feedback.

Expert coaching is another instructional feedback structure. This strategy uses district or school-based coaches to provide observation and feedback as well as covering the classroom so a teacher can observe a particularly skilled colleague focused on an area of professional need (Feldman, 2016). This is dependent on the area in which the participant works, however, can be very beneficial for the teacher to have one expert in the field to confide in for advice and support. Principal Walkthrough brief observations, usually lasting 5 to 10 minutes. Principals should aim to provide two to three specific pieces of actionable feedback for teachers (Feldman, 2016). Both of these options are dependent on positions, time restraints, and money within the county.

Co-planning is another instructional support tool teachers can use to develop their instructional practices. Working in professional learning communities or grade level teams allows teachers to plan specific lessons together based on incorporating key strategies or practices tied to the feedback they have received to improve instruction (Feldman, 2016). This is a valuable teaching tool that allows teachers to collaborate with their colleagues that are facing the same challenges specific to the school and grade level. Teachers can evaluate weaknesses found within the grade level and assessment data and work together to build strategies that could work to increase achievement.

Interviews and student surveys are the last suggested teaching support that is recommended by Feldman (2016). This teaching strategy gives students a voice in the 
school improvement project. After learning walks or observations, it can be very revealing to ask students about the lesson, their perceptions of how the lesson went, what they liked, or disliked about the lesson. They are also able to articulate what instructional practices best work for them which can be compared to the observed instructional practices. Each instructional support practice presented provides insight into teacher strengths and weaknesses and can ultimately help teachers be more reflective practitioners.

\section{Co-teaching}

Coteaching has been suggested as a promising approach to foster the transition from a dual to a more blended and up to date educational practice for students with and without disabilities who are educated in the same physical space (Friend, Cook, HurleyChamberlain, \& Shamberger, 2010). In a co-teaching system, teachers are sharing roles and responsibilities, including DI methods, in an attempt to blend their expertise for students with and without disabilities (Friend et al., 2010). Both students benefit from this strategy as there are two people instead of one supporting student learning.

There are six approaches or variations of coteaching that can be implemented based on student needs: (1) one teach, one assist (2) station teaching, (3) parallel teaching, (4) alternative teaching, (5) teaming, (6) one teach, one observes (Strogilos, Avramidis, Voulagka, \& Tragoulia, 2020). In the one teach-one observes approach one teacher is the primary teacher while the other teacher circulates among the students to support learning (Willard, 2019). The team-teaching approach allows both teachers to 
share the instructional lead in delivering content to the class (Willard, 2019). The students are divided into two groups with both teachers simultaneously instructing one of the groups using similar instructional materials in parallel teaching. Station teaching requires students to be divided into small groups and learning tasks are separated into segments. Each teacher instructs a segment in a station and students then rotate amongst the stations (Willard, 2019). Alternative teaching allows for one co-teacher to instruct the majority of the class with the other teacher teaching a small group of students through intensive strategies (Willard, 2019). Lastly, the one-teach one-observe strategy allows for one teacher to lead the instruction while the other partner observes students, teachers, and other paraprofessionals (Willard, 2019). Teachers and special educators should evaluate the need within the classroom and choose a model that best helps teachers meet the need within the classroom. However, it is important to consider the use of a co-teacher over pull-out services as co-teachers have the potential to create a classroom community that provides engaging learning tasks to help all students achieve (Willard, 2019).

Coteaching can be used throughout all grade levels where specialized support is needed. Willard (2019) found the conditions within a high school are conducive to coteaching. Also, the type of coteaching approach chosen should reflect the objective of the lesson. Coteaching is a professional partnership and could be used as a tool for ongoing PD (Willard, 2019). Because of the blocked scheduling and designated content, coteaching can be most beneficial within the high school setting. 
Not only can coteaching be beneficial for students in the classroom by receiving extra support when being allowed to stay in the general education classroom, but it also provides professional learning for teachers: "It enables the participating teachers to have real learning opportunities in the classroom and develop pedagogical practices benefitting all students" (Shaffer \& Thomas-Brown, 2015, p. 117). Coteaching allows for teachers to have reflective dialogues about teaching practices, the field of education, and their PD (Willard, 2019). Also driving differentiation is the now numerous opportunities to observe and collect data on student engagement, achievement, and response to instructional practice. This allows for both teachers to reflect on their strengths and weaknesses and seek specific PD to grow as teachers and partners (Willard, 2019).

\section{Project Description}

PD refers to both formal and informal learning activities specifically designed to enhance teachers' professional knowledge, capabilities, competence, motivation, selfefficacy, and beliefs (Coldwell, 2017). The goal of this PD program is to increase third and fourth grade teachers' understanding of DI and provide strategies that could impact instruction supporting DI use such as coteaching and alternative instructional supports. The project consists of three 8-hour day trainings to work towards the training's goal.

On the first day of the program, teachers will do a self-reflection on their current uses of DI and what they feel they need to be more successful with the strategy. This should closely align with the findings of this research. Findings from the research will be shared with the goal of the program. Teachers will focus on what DI is and the different 
learning strategies that can be used within the upper elementary classrooms. This session will include modeling of the strategies so teachers can see what DI looks like within the areas of ELA and mathematics. Teachers will also have an opportunity to collaborate with their colleagues on how they can specifically use the strategies within their classrooms and content.

The second day of the program will focus on coteaching. Teachers within the research site overwhelmingly expressed the need to limit the amount of classroom interruptions and pull-out services. Teachers will be introduced to coteaching models by observing videos of this strategy. Teachers will then again reflect on their personal schedules and classroom interruptions to come up with a plan that utilizes coteaching instead of pull-out services. Teachers will also incorporate DI strategies within their plans using the co teacher.

The final day of the program will discuss alternate options for instructional support. Teachers expressed wanting instructional feedback to strengthen their instructional pedagogy but finding time was an issue with the administration. Teachers will be introduced to teacher observation techniques that could be used within the school setting to strengthen teacher understanding of DI and the uses of this strategy. Teachers will come up with a plan to use DI in their school setting and a unified observation checklist that will be used during the observations specifically looking at DI in the classroom. 


\section{Resources and Support}

The county in which the research was conducted has many of the resources needed for this project to be implemented. The county has a unified learning center that would allow space for the 14 third and fourth grade teachers to gather. This space has internet access, smartboards, and a projector available to use if needed. Teachers would need to bring their school-issued laptops to access planbook.com () (a digital lesson planning tool used by the county), the curriculum (also online), and state standards. Teachers would receive a copy of the handouts along with a digital copy of the presentation which would both be provided.

\section{Potential Barriers and Solutions}

This project has been designed to be presented to third and fourth grade teachers but could easily be adapted to be presented to all grades, special education teachers, and title/ tutors within the county. Two potential barriers to this project implementation are funding and the availability of substitutes. The county would need to supply substitute teachers for three days during this training. Substitutes within the county are sparse and funding could be an issue. However, one solution the county could utilize is the implementation of this project during scheduled PD days. This would occur during the first two weeks of school when teachers are only present or during three of the five scheduled days during the school year. This solution would eliminate the need for substitute teachers while providing a time that is specific to teacher PD. 
Another potential barrier could be the lack of support from county wide administration and teachers. If teachers are reluctant to participate in a local countywide PD initiative, teacher buy-in could be affected. A solution to this possible barrier would include disclosure of the research findings that insisted on more PD on DI and strategies to lesson teacher stated barriers. Because this project is a direct result of the findings, teacher and administrative buy-in should not be an issue.

\section{Proposal for Implementation and Project Timetable}

The findings of this study will be shared with local school administrators and community stakeholders. Once shared and buy-in increased, the project will be proposed to the local school board. The proposed project is a three- day program (Appendix A) that will occur sometime during the first two weeks of school at the "Teacher Academy." This is a time set aside for teachers to emerge themselves back into new educational research and thought. The anticipated dates for the project will fall between Wednesday, August 11- Friday, August 13, 2021. Each session will take place from 8:00 am to 3:00 pm.

On the first day, teachers will focus on what DI is and how it can be incorporated into ELA and mathematics. The workshop will include video clips of observable DI exampling different ways teachers can differentiate the process, product, and content of ELA and mathematics. The teachers will use a reflection at the beginning of the program to gauge their current uses and collaboration throughout the first day to discuss with colleagues' different ways to incorporate the strategy. The presenter will suggest strategies to differentiate the process, product, and content on the current county-wide 
curriculum and allow time for teachers to work with colleagues to create their own lesson plans. The first day will close with another self-reflection done with the teachers to gauge their new understanding of DI and its components within the inclusive classroom.

The second day will focus on coteaching strategies. Teachers will reflect on their current struggles to successfully differentiate within the inclusive classrooms. A topic that was revealed during the research was the amount of pull-out services students receive throughout the day. Therefore, during the second day of training, teachers will discover coteaching strategies by watching successful coteaching videos and practicing models through role play. Teachers will talk with their teams to discuss where and how this strategy can be implemented within their current schedule. Teachers will have time to create lesson plans incorporating DI and coteaching as well as create new schedules as needed to reflect changes within their instructional day.

On Day Three, teachers will discuss and reflect on current instructional feedback provided within the school setting. After reflection, teachers will be provided with research that indicates the importance of actionable instructional support feedback. Teachers will be provided instructional support observation models that can be used to help themselves and fellow colleagues develop their instructional skills by concentrating on DI. Teachers will work together to create an observation checklist that will be used to do observations with their colleagues. Teachers will spend the rest of their day, collaborating with their colleagues, creating lesson plans, and finding ways to utilize all 
components of DI, coteaching, and instructional supports to further their implementation of differentiation.

\section{Role and Responsibilities}

The county curriculum, instruction, and assessment coordinator will be approached with the PD program to approve the dates and times selected as well as the developed program. As the facilitator, I will oversee the implementation of the program, ensuring the participants have everything they need to be successful within the program. I will ensure participants see the value in the program by addressing the goals and intent of the PD with them which should increase teacher buy-in. Teachers, facilitators, and county leaders should work together for the program to be successful.

\section{Project Evaluation Plan}

At the end of each day, the participants will be asked to provide feedback through a survey to assess the effectiveness of each topic addressed: DI, coteaching, and instructional support strategies. The evaluations will help the facilitator determine the strengths and weaknesses of each individual topic under discussion so that further implementations can be adjusted to best meet participant needs. Four weeks after the training, teachers will be sent a summative evaluation asking teachers if they were able to incorporate more DI within their lessons in both ELA and mathematics, if they were able to use coteaching as an instructional strategy, and if they were able to use the alternative instructional support feedback strategies. This information will be valuable for the 
facilitator to make changes for future training sessions and also to administrators within the sites to acknowledge the growth or lack thereof within the developing staff.

\section{Key Stakeholders}

The primary stakeholders within this project are teachers, administrators, and district personnel. This PD program will help teachers more consistently use DI in the inclusive classroom incorporating strategies into both ELA and mathematics. Teachers will also become more knowledgeable of coteaching strategies and instructional support strategies that will also help develop DI use in the classroom and, as a result, raise student achievement. Administrators will provide support to teachers experimenting with these new strategies within the classroom, answering questions, and giving suggestions as needed. Teachers could need things like substitutes for observations, a meeting with a mentor teacher for support, or team planning time to work on classroom schedules with tutors, title personnel, speech, and special educators now used as a push in service rather than pull out. All stakeholders can monitor student achievement and learning as a result of the project.

\section{Project Implications Including Social Change}

This PD program will have both local and extended social change implications as it will address the need that third and fourth grade inclusive teachers are struggling to consistently implement DI within the inclusive setting. Therefore, the study will be most beneficial to third and fourth grade teachers within the inclusive setting and as a result to third and fourth grade students. Incorporating the components of DI to support all 
learners in the inclusive classroom in the areas of ELA and mathematics could potentially increase students' academic achievement, excitement for learning, and classroom engagement.

The PD program also addresses coteaching strategies and alternative instructional approach strategies. These strategies require a strong sense of collaboration and trust within the staff which could increase the overall school climate and culture. Teachers will learn to work together, trust one another, and rely on one another for support, creating a positive work environment.

This could also raise teacher self-efficacy. The more teachers practice DI within their classrooms and the more teachers are observing other teacher's craft, teachers will become more comfortable with the implementation. Teachers will start to believe they are being successful in the classroom which will also create a more positive classroom culture. Professional development helps teachers develop their skills and craft and in doing so, students directly benefit. By improving instructional practices concerning the implementation of DI and providing information on how teachers can overcome stated barriers within their county setting, school climate and culture will be enhanced, teacher's level of knowledge and accountability will be raised, and all students will start seeing raised academic achievement scores.

The results of this study could have far-reaching possibilities beyond one county in the identified Appalachian state. This PD program will present DI strategies in both ELA and mathematics, coteaching strategies, and alternative instructional support 
strategies. While this PD was designed specifically for third and fourth grade teaches, it could be applied to all other elementary grades who serve in an inclusive classroom. This PD could serve as a model for other counties that see a lack of DI and face similar barriers to constant disruptions and lack of support. Social change could occur if counties across the Appalachian state adopted this PD program, leading to an increase in teaching knowledge of DI and therefore, an increase of student achievement across a larger area.

\section{Conclusion}

The purpose of this qualitative case study was to investigate perceptions of third and fourth grade instructors on their knowledge, implementation, and self-assessment of using DI in classrooms in three elementary schools in one Appalachian state. Combining interview data and lesson plan analysis, the qualitative data showed teachers expressed they were using minimal DI strategies in ELA and little to no DI in mathematics. Teachers believed the constant classroom disruptions created by pullout services hindered their ability to be successful towards implementation as well as a lack of training.

The three-day professional development training was created to help third and fourth grade teachers overcome these challenges by providing training on the implementation of DI in both areas of ELA and mathematics as well as introduce teachers to coteaching strategies and alternative instructional support models. Through this PD opportunity, teachers will have the opportunity to grow professionally by collaborating with their colleagues and creating a working environment that is conducive to their 
instructional needs. In Section 4, I provide in-depth information about the project study, along with my reflection, conclusions, and recommendations. 
Section 4: Reflections and Conclusions

In this qualitative case study, I investigated perceptions of third- and fourth-grade instructors on their knowledge, implementation, and self-assessment of using DI in classrooms in three elementary schools in one Appalachian state. DI is defined as a targeted process that involves forward planning, programming, and instruction. It uses teaching, learning, and assessment strategies that are flexible and reoccurring to provide an appropriate level of challenge and engagement for students in meaningful ways (Cooney, 2019). This teaching strategy can be implemented in any content area by modifying the content, process, and product of the lesson (Tomlinson, 2014). In Section 4, I examine my role as a scholar-practitioner and include the study's implications on social change and possible future study.

\section{Project Strengths and Limitations}

The PD program that I created was based on the data from this study that was theoretically and conceptually aligned. The findings addressed teachers' current use of DI and specific barriers to their work environment. This PD program will provide 3 days of specific training on areas teachers indicated as being weak in their instructional practice with specifically indicating they needed more PD. The program followed DarlingHammond et al.'s (2017) suggestions of the seven elements for successful PD: is content focused, incorporates active learning, supports collaboration, uses models of effective practice, provides coaching and expert support, offers feedback and reflection, and is of sustained duration. This program is also based on current research of best practices 
associated with DI, coteaching, and alternative approaches to instructional support. It allows for the opportunity for modeling, role playing scenarios, creating lesson plans, and teacher reflection and collaboration. Also incorporated is an extended reflection analysis that will allow the teacher to revisit the PD presented ideas several weeks after the implementation to see if the strategies have been useful in the real-world setting.

Because the research is founded within research-based practices and is specific to the learning environment of the research sites, the PD is specific to teacher needs. This allows for the opportunity for PD to be connected to the teachers' interests and identified needs (Dennis \& Hemmings, 2019). When teachers become more aware of how they can improve their practice, they become more knowledgeable and willing to try new things. They also become more confident and knowledgeable in their teaching expertise, ultimately advancing student learning. By using DI, a research-based best practice, instruction will be targeted to the individual students' needs allowing the student to develop and learn within their capability. Not only would this raise the student's sense of accomplishment but also an overall achievement. Because PD opportunities tend to improve instruction and raise student achievement specific PD such as this program could cultivate students' learning and have a positive impact on standardized testing and classroom achievement.

Despite these advantages of the project, one of the limitations that I identified for this project is funding. If the program were to be implemented during the school year, substitute teachers would be needed to fill teacher positions during training days. The 
most cost-effective way to incorporate this training into teacher prescribed PD would be to implement this program during the first 2 weeks of school during what is known as the “teacher academy" or during the specified days throughout the year set forward for PD.

Teachers also need to have an interest, and administrators should see the purpose of the PD to increase effectiveness through teacher buy-in. The findings from the study showed specific areas of weakness in the application of DI in instructional practices and lesson planning. Teachers also indicated a lack of PD as being a barrier as well as the amount of pull-out services students received and a lack of instructional feedback. Over the past 5 years, teachers have only received one training on DI arising the question if differentiation is a concern with administrators and central office personnel. However, because the PD is founded within the research findings specific to the site, teachers need to be interested in learning new strategies that could be implemented toward improved instructional practices, student engagement, and overall student achievement.

Another limitation of the study and the program developed is a result of the small sample size. The county in which this project was based incorporates three elementary schools with 14 third- and fourth-grade teachers. Nine of the 14 teachers chose to participate in the study creating generalizability of the teacher perceptions within the sites. To address this limitation and increase generalizability, the study could be conducted within other grade bands within the school district (see Creswell, 2015) to further the development of teacher's use of DI and address similar barriers. 
The final limitation of this study is my lack of experience and competency as a researcher as I lack experience in collecting, analyzing data, and developing a project of this length. But research before this included several action research projects in the education setting, which aided in my understanding of data collection, presentation, and analysis. Also, the coursework up to the doctoral dissertation through Walden University provided insight on all facets of doctoral research and has been beneficial. Though these ideas have been presented over the preceding years, I emphasized the use of research strategies that would strengthen the credibility of the research. Member checking, transcript review, and triangulation were used to address this limitation.

\section{Recommendations for Alternative Approach}

Using a PD framework, the project addresses ways teachers can use DI within their teaching and ideas to remedy the hindrances stated by teachers during data collection. The major problems addressed within the PD focus on co-teaching and instructional support strategies along with a lack of training on differentiation. An alternative project based on the findings regarding differentiation and the struggle for consistent implementation could be a position paper on current legislation involving inclusive practices within the Appalachian state.

An alternative to using PD to address the findings of this study, a recommendation of policy change would relate to inclusive practices found within public education schools and the barriers these implementations have created. For example, teachers within the study reported having a wide variety of abilities in the classroom even 
with the mandated $30 \%$ limit of SWDs in the classroom. This ideally would mean in a class of 24 students, seven students could be placed on an IEP. The remaining 17 students could still have learning needs including medical issues resulting in learning accommodations; students identified to be placed for data tracking and on a student assistance team also receiving classroom accommodations, and students who have not been identified yet or have learning needs that do not result in a source of documentation. These classroom demands are strenuous for general education teachers resulting in a lack of differentiation.

The position paper would include the background of inclusive practices with a brief summary of this research's findings. It would present major evidence from the literature and current research backing the findings from this project study and suggestions. The paper would outline recommendations toward policy changes that would include an inclusive percentage of all students with learning needs that receive accommodations. As mentioned, a state suggestion would be $30 \%$ all-inclusive including any student who receives a classroom accommodation. Furthermore, if a classroom would need to go over this limit a special educator as a co-teacher would be provided to assist in the general education classroom.

The overall goal of this position paper would be to increase awareness of the impacts of inclusion in the general education classroom while assisting policymakers in creating a law that produces a more conducive classroom to learning. The policy recommendation would allow for teachers to more readily use best practices like 
differentiation that would enable student growth. Not only would students find the learning culture more inviting and motivating, but it is predicted that teacher burnout would decrease, and teacher retention would greatly increase creating a competitive education community.

\section{Scholarship, Project Development, and Evaluations, and Leadership and Change}

The data collected from this study will provide stakeholders in education information about third and fourth-grade teachers' knowledge of differentiation and how they are currently using DI in the inclusive classroom. The findings also indicate the struggles that teachers are facing to implementing DI in the inclusive classroom. By improving these teachers' knowledge of differentiation, providing teachers with alternative teaching strategies like coteaching and alternative instructional support strategies, teachers will become more confident in their teaching pedagogy and set skills. Overall, by addressing the specific needs found within this research study teachers will become more knowledgeable of how to differentiate to meet the needs of all students helping all students achieve academically. Teachers will also become a support for one another through co-teaching and instructional support activities creating a stronger school climate, which also has increased achievement.

\section{Self-Analysis of Scholarship}

This study helped me grow as an educator and researcher while instilling in me a strength and determination to persevere through tough decisions. During the initial process, the examination of the research problem allowed me to think critically about the 
area of concentration and how I could remedy the problem. I learned valuable information about the research site and even more about ways to improve its academic success. The literature review signified a large turning point within the study for me as I started making connections within the literature that could be applied to the instructional setting both in research and in my own practice as an educator.

During the process, I learned how to be a researcher. I identified a problem, I created a purpose, I designed research questions to guide the study and found a conceptual framework to enable the study to be embedded in current literature. I learned patience and how to be explicit in my research analysis. I learned how to conduct a thorough research study and analyze data to determine the findings. As a math person, I found the qualitative analysis to be challenging but also imperative to a successful study as I truly wanted to know how teachers thought about using DI and what was impeding the consistent use within the research site.

The experiences I have gained through the design, implementation, analysis and overall design of the project study to reflection have contributed in some way to help me grow as a professional. I have a stronger desire and passion to share my knowledge about differentiation and to help teachers come up with creative ways that will further enable them to implement the strategy while growing professionally in their own fields of study.

\section{Self-Analysis of Project Development}

Having been in the profession of education for 6 years, I have realized the value of in-school PD that enlightens teachers to current and relevant struggles they are facing. 
While most school systems make sure PD is pertinent to the needs of the teacher, some PD addresses the current trend rather than the current need. During the interviews and through data analysis I saw a trend of teachers reiterating my own ideas that PD is needed and wanted within the research site. Teachers wanted time to work with their colleagues and create activities that could be shared with one another. They also wanted to learn more DI techniques and ways it could be implemented easily within their already existing routines and curriculum. When I asked teachers what hindered their ability, their responses, however, were not what I expected. Teachers explained they had enough planning time to put towards planning for differentiation. They wanted fewer classroom interruptions and less traffic going in and out of the rooms. They also wanted some sort of instructional support that would allow them to grow continuously as a professional. Therefore, for the PD program, I wanted to spend a day reviewing what differentiation was and the basic concepts. I wanted teachers to have time to meet with their grade level colleagues and collaborate with one another to create these much-needed changes while incorporating different components of differentiation. I also wanted to start giving teachers ideas of alternative teaching strategies like coteaching. With so many professional supports available and teachers seeing the value in them, I wanted to introduce a strategy that has been proven to have the same positive outcomes but would also decrease classroom disruptions. I also wanted to provide strategies that allowed the teacher to continue to grow after the PD ended. By introducing teachers to alternative instructional support, the teachers can take it upon themselves to mentor, monitor, and 
experiment with their own instructional practices. All of the strategies presented within the PD can be used throughout the year and can foster growth within the profession. It was important to me to create a project that would be meaningful to the participant while also inspiring educators to continue their learning as lifelong learners themselves.

\section{Self-Analysis of Leadership and Change}

As with any journey, I was not sure where this one would lead. I attended Walden University and gained a great deal of knowledge as a young educator pursuing her master's degree. The knowledge was critical to my development as an educator and created a passion for educational change. I began this doctoral journey without knowing where it would take me. I am the first generation of my family to attend college, to earn a master's degree, and now to fully be a Doctor of Education. At first, I chose this past to be the first. To have something to be proud of. To show my community and peers I have the intuition and courage to take the strides towards educational change. While I was trying to show everyone else, I ended up seeing a huge change within myself. I have developed perseverance and the belief in myself to make a change within the educational environment. I have become more knowledgeable of the problems found within my county and state and now feel more capable to speak towards betterment on many different aspects. Through my doctoral journey, I have discovered my own leadership potential. I am focused on educational change and being a positive change agent with hopeful new career opportunities in the near future. 


\section{Reflection on Importance of the Work}

As I reflect on my journey at Walden University, I see so many changes within myself. I have grown into a scholar-practitioner. I have learned patience and attention to detail. I have learned the importance of truly listening and following my passion for true social change. Although I often felt overwhelmed by the whole process, my passion for change and stubbornness to create change in every classroom kept me focused. As an early educator, I struggled in the inclusive classroom. I turned to education to further my understanding and found a school system that fostered my passion for change. Having faced many of the same issues, I wanted to find a solution to current instructional problems such as differentiation to help other teachers. I became more confident in my own understanding of the importance of differentiation and in my ability to help teachers truly understand the impact this strategy can make. While I understood using DI was only part of the issue at the research site, I wanted to also introduce teachers to alternative school structures such as co-teaching and instructional supports to continue growth.

Now that my journey is coming to a close, it is exciting to know my work could positively affect the instructional practices of other third and fourth grade teachers with possible implications throughout other elementary school grades. While this chapter is coming to a close, so many more doors have opened due to the results and research presented throughout this study. I have even more questions that need answered with due time which is the start towards positive social change. 


\section{Implications, Applications, and Directions for Future Research}

I designed a professional development program that addressed the components of DI and its implications in the inclusive classroom. Upon discussion with teachers, it was found that teachers felt pull out services were a constant distraction to student learning and teachers wanted more instructional support. It was my goal to increase teacher knowledge of differentiation, but also provide strategies that could be implemented to decrease the number of classroom disruptions and support teacher growth. Using this information from the study and the professional development program created, the study site can address third and fourth grade teachers' challenges to fully and consistently implement DI which could lead to positive social change.

By improving teachers' knowledge of DI and how it can be applied to the existing curriculum, teachers will become more confident in their instructional practices.

Administrators would see a direct result of the PD as teachers would start planning for DI as an artifact of their understanding. Furthermore, all students would start to achieve at a much greater rate of learning. When instruction is tailored to meet the needs of students, student motivation increases, interest increases, and overall student engagement goes up creating achievement gains (Tomlinson, 2014).

Providing a way for teachers to have a voice in their school and make changes within their own teaching practices was also a goal of the project. Teachers were introduced to coteaching strategies through modeling and observing videos. Teachers had time to collaborate with their colleagues and determine which strategies would be most 
beneficial in their specific educational setting. This gives teachers a voice in how their classroom functions as they take control of the learning environment. Coteaching allows for growth between both educators in the room as well as more students have access to more adult help. As a result, student achievement should also increase.

Lastly, teachers needed a way to continue their growth after the PD. I wanted teachers to be aware of alternative instructional support strategies to encourage continued growth. Teachers again would learn through modeling and watching videos and then plan with their colleagues' ways these strategies could be implemented. I wanted teachers to feel empowered with their careers while making choices to benefit each other. When teachers are knowledgeable and working together, a team culture is created which in return creates a positive school culture.

Implications for my project study are a change in instructional practices throughout the research site and ongoing PD that addressed DI and implementation barriers. This research study could be implemented at other elementary schools throughout the state where Title 1 services or additional supports are overwhelming teachers. The information gathered throughout this study could be shared with districtlevel supervisors, continuing education programs, or local universities working with preservice teachers or administrators. Teachers want to be knowledgeable of research based best practices with supports found within their educational setting to be more effective in the classroom. For additional research, I recommend extending the research to include lower elementary teachers as they also are charged with inclusive practices 
throughout the identified Appalachian state. I also recommend examining why some schools choose pull-out versus push-in services or why some elementary schools choose to be compartmentalized rather than being a close classroom.

\section{Conclusions}

In this study, I focused on teachers' perceptions of differentiation and how they currently were using DI in an inclusive setting. I then focused on determining the challenges third and fourth grade teachers faced consistently implementing the strategy. From the findings, I created a three-day PD program to address teacher knowledge on DI and how it could apply to their current curriculum. Teachers were given time to collaborate with their colleagues and plan for differentiation in their classroom setting. Teachers were provided with a solution to limit instructional interruptions, coteaching. Coteaching strategies and techniques were introduced and modeled followed by collaboration. Lastly, teachers were provided with ideas to provide alternative instructional support for one another to continue growth within the profession. By providing teachers with these strategies and ideas, they become a critical component in the functionality of the school. Teachers are given a voice in the instructional practice of their students but also become leaders of change within their own schools. By observing and reflecting upon their own practices, they become practitioners and change agents within themselves. It is my hope that the three-day PD increases student achievement scores through the increased use of differentiation in the inclusive setting, increases instructional time for students and adds more support within the inclusive classroom, and 
encourages teachers to continue their own growth through actionable feedback. If effective, this professional development program may be valuable to other schools facing similar barriers to consistent implementation of differentiation. 


\section{References}

Anastasiou, D., Kauffman, J. M., \& Di Nuovo, S. (2015). Inclusive education in Italy: description and reflections on full inclusion. European Journal of Special Needs Education, 30(4), 429-443. doi:10.1080/08856257.2015.1060075

Archibald, L. (2017). SLP- educator classroom collaboration: A review to inform reasonbased practice. Autism \& Developmental Language Impairments, (2) 1-17. doi: $10.1177 / 2396941516680369$

Arnaiz Sánchez, P., de Haro Rodríguez, R., \& Maldonado Martínez, R. M. (2019). Barriers to student learning and participation in an inclusive school as perceived by future education professionals. Journal of New Approaches in Educational Research, 8(1), 18-24. doi:10.7821/naer.2019.1.321

Aschbacher, P., \& Ing, M. (2017). Who wants to learn more science? The role of elementary school science experiences and science self- perceptions. Teachers College Record, 119(9), 735-743. Retrieved from http://www.tcrecord.org/

Avery, R. A. (2017). Teacher willingness on implementing differentiated instruction (DI) in the elementary classroom: A multiple case study (Doctoral dissertation). ProQuest Dissertations \& Theses Global. Accession number (1964252438)

Bagot, E., \& Latham, R. (2019). Teaching from an overflow: Develop, deliver, differentiate: Tried and tested techniques, combined with a love of history, make differentiated instruction rewarding for teachers as well as students. Agora, 54(2), 27-32. Retrieved from https://agorajournal.squarespace.com/ 
Bates, C. C. (2013). Flexible grouping during literacy centers: A model for differentiating instruction. YC Young Children, 68(2), 30-33. Retrieved from https://www.jstor .org/journal/ycyoungchildren

Beasley, J., \& Beck, D. (2017). Defining differentiation in cyber schools: What online teachers say. TechTrends: Linking Research \& Practice to Improve Learning, 61(6), 550-559. doi:10.1007/s11528-017-0189-х

Bemiller, M. (2019). Inclusion for all? An exploration of teacher's reflections on inclusion in two elementary schools. Journal of Applied Social Science, 13(1), 74-88. doi:10.1177/1936724419826254

Benders, D. S., \& Craft, T. (2016). The effect of flexible small groups on math achievement in first grade. Networks: An Online Journal for Teacher Research, 18(1), 1-9. doi:10.4148/2470-6353.1022

Bicehouse, V., \& Faieta, J. (2016). IDEA at age forty: Weathering common core standards and data driven decision making. Contemporary Issues in Education Research (CIER), 10(1), 33. Retrieved from https://www.clutejournals.com

Birnie, B. F. (2015). Making the Case for Differentiation. Clearing House, 88(2), 62-65. doi:10.1080/00098655.2014.998601

Black, A., Lawson, H., \& Norwich, B. (2019). Lesson planning for diversity. Journal of Research in Special Educational Needs, 19(2), 115-125. doi:10.1111/14713802.12433 
Bodovski, K., Byun, S., Chykina, V., \& Chung, H. J. (2017). Searching for the golden model of education: Cross-national analysis of math achievement. Compare: A Journal of Comparative and International Education, 47(5), 722-741. doi: $10.1080 / 03057925.2016 .1274881$

Bondie, R. S., Dahnke, C., \& Zusho, A. (2019). How does changing “one-size-fits-all” to differentiated instruction affect teaching? Review of Research in Education, 43(1), 336-362. doi:10.3102/0091732X18821130

Boroson, B. (2017). Inclusive education: Lessons from history. Educational Leadership, 74(7), 18-23. Retrieved from http://www.ascd.org/publications/educationalleadership.aspx

Brevik, L. M., Gunnulfsen, A. E., \& Renzulli, J. S. (2018). Student teachers' practice and experience with differentiated instruction for students with higher learning potential. Teaching and Teacher Education, 71, 34-45. doi:10.1016/j tate. 2017.12.003

Brigandi, C. B., Gilson, C. M., \& Miller, M. (2019). Professional development and differentiated instruction in an elementary school pullout program: A gifted education case study. Journal for the Education of the Gifted, 42(4), 362-395. doi:10.1177/0162353219874418

Brigandi, C. B., Weiner, J. M., Siegle, D., Gubbins, E. J., \& Little, C. A. (2018). Environmental perceptions of gifted secondary school students engaged in 
an evidence-based enrichment practice. Gifted Child Quarterly, 62, 1-17. doi:10.1177/0016986218758

Brikci, N. (2007). A guide to using qualitative research methodology. Medecins Sans Frontieres. Retrieved from https://cloudfront.ualberta.ca/-/media/science/resear ch-and-teaching/teaching/qualitative-research-methodology.pdf

Burkholder, G., Cox, K., Crawford, L., \& Hitchcock, J. (2019). Research Design and Methods. Thousand Oaks, CA: Sage Publications

Bushie, C. (2015). Literature review: Differentiation in education. BU Journal of Graduate Studies in Education, 7(2), 35-42. Retrieved from http://www.bu.edu /journalofeducation/

Callahan, C. M., Moon, T. R., Oh, S., Azano, A. P., \& Hailey, E. P. (2015). What works in gifted education: Documenting the effects of an integrated curricular/instructional model for gifted students. American Educational Research Journal, 52, 137-167. doi:10.3102/0002831214549448

Calvert, L. (2016). Moving from compliance to agency: What teachers need to make professional learning work. Oxford, OH: Learning Forward and NCTAF.

Campbell, C., Lieberman, A., \& Yashkina, A. (2016). Developing professional capital in policy and practice: Ontario’s teacher learning and leadership program. Journal of Professional Capital and Community. 1(3), 219-236. doi:10.1108/JPCC-032016-0004 
Canaran, Ö., \& Mirici, İ. H. (2019). An overview of the recent views and practices in teacher professional development. Journal of Theory \& Practice in Education (JTPE), 15(4), 350-362. doi:10.17244/eku.559281

Casa, T. M., Firmender, J. M., Gavin, M. K., \& Carroll, S. R. (2017). Kindergarteners' achievement on geometry and measurement units that incorporate a gifted education approach. Gifted Child Quarterly, 61, 52-72. doi:10.1177/0016986216671806

Cash, R. (2017). Advancing Differentiation: Thinking and Learning for the $21^{\text {st }}$ Century. Minneapolis, MN

Chubb, J. E. (2012). The best teachers in the world: Why we don't have them and how we could. Stanford, CA: Hoover Institution Press

Civitillo, S., Denessen, E., \& Molenaar, I. (2016). How to see the classroom through the eyes of a teacher: Consistency between perceptions on diversity and differentiation practices. Journal of Research in Special Educational Needs, 16, 1. doi:10.1111/1471-3802.12190

Coldwell, M. (2017). Exploring the influence of professional development on teacher careers: A path model approach. Teaching and Teacher Education, 61, 189-198. doi:10.1016/j.tate.2016.10.015

Conderman, G., \& Hedin, L. (2015). Differentiating instruction in co-taught classrooms for students with emotional/behaviour difficulties. Emotional \& Behavioral Difficulties, 20(4), 349-361. doi:10.1080/13632752.2014.976918 
Cooney, P. (2019). Dealing with Difference: Differentiation in the Christian School. Christian Teachers Journal, 27(2), 12-15. Retrieved from https://www.cen.ed u.au/index.ph p/services/christian-teachers-journal

Coubergs, C., Stryven, K., Vanthournout, G., \& Engels, N. (2017). Measuring teachers' perceptions about differentiated instruction: the DI-Quest instrument and model. Stud. Educ. Eval. 53, 41-54. doi:10.1016/j.stueduc.2017.02.004

Creswell, J., \& Poth, C. (2017). Qualitative inquiry and research design. Retrieved from https://rafflesbangkokacademia.files.wordpress.com/2014/07/case-study-outlinecreswell.pdf

Creswell, J. W. (2015). Educational research: Planning, conducting, and evaluating quantitative and qualitative research (4th ed.). Upper Saddle River, NJ: Pearson Education.

Dack, H. (2019). The role of teacher preparation program coherence in supporting candidate appropriation of the pedagogical tools of differentiated instruction. Teaching \& Teacher Education. 78, 125-140. doi:10.1016/j.tate.2018.11.011

Darling-Hammond, L., Hyler, M. E., \& Gardner, M. (2017). Effective teacher professional development. Palo Alto, CA: Learning Policy Institute.

Deane, P., Sabatini, J., Feng, G., Sparks, J., Song, Y., Fowles, M....Foley, C. (2015). Key practices in the English Language Arts (ELA): Linking learning theory, assessment, and instruction. ETS Research Report Series. doi:10.1002/ets2.12063 
Deason, J. (2017). General education teachers' differentiated instruction in elementary inclusion (Order No. 3613947). Available from ProQuest Dissertations \& Theses Global. (1524723141). Retrieved from https://ezp.waldenulibrary .org

Dennis, D., \& Hemmings, C. (2019). Making the simple more complex: The influence of job-embedded professional development in supporting teacher expertise in reading. Literacy, 53(3), 143-149. doi:10.1111/lit.12172

Deunk, M. I., Smale-Jacobsel, A. E., de Boer, H., Doolaard, S., \& Bosker, R. J. (2018). Effective differentiation practices: A systematic review and meta- analysis of studies on the cognitive effects of differentiation practices in primary education. Educational Research Review, 24, 31-54. doi:10.1016/j.edurev.2018.02.002

Drew, V., Priestley, M., \& Michael, M. K. (2016). Curriculum development through critical collaborative professional enquiry. Journal of Professional Capital and Community, 1 (1) 92-106. doi:10.1108/JPCC-09-2015-0006

Faber, J., Glas, C., \& Visscher, A. (2018). Differentiated instruction in a data-based decision-making context. School Effectiveness \& School Improvement, 29(1), 4363. doi:10.1080/09243453.2017.1366342

Feldman, K. (2016). Actionable feedback for teachers: The missing element in school improvement. Retrieved from https://2019kansasmtsssymposium.sched.com

Fer Coenders \& Nellie Verhoef. (2019). Lesson study: Professional development (PD) for beginning and experienced teachers. Professional Development in Education. 45(2), 217-230. doi:10.1080/19415257.2018.1430050 
Flick, U. (2018). The SAGE handbook of qualitative data analysis. London: SAGE Publications Ltd. doi:10.4135/9781526416070

Florian, L., \& Beaton, M. (2017). Inclusive pedagogy in action: getting it right for every child. International Journal of Inclusive Education, 22(8), 870-884. doi:10.1080/13603116.2017.1412513

Florian, L., \& Pratt, L. (2015). Embedding equality and diversity in the curriculum: An education practitioner's guide. York: Higher Education Academy.

Freer, J. R. (2018). Pre-service Educational Assistants' Attitudes Toward Inclusion. Exceptionality Education International, 28(1), 68-85. doi:10.5206/eei.v28i1.7759

Friend, M., Cook, L., Hurley-Chamberlain, D., \& Shamberger, C. (2010). Co-teaching: An illustration of the complexity of collaboration in special education. Journal of Educational and Psychological Consultation, 20(1): 9-27. doi: $10.1080 / 10474410903535380$

Friend, M. P., \& Bursuck, W. D. (2014). Including students with special needs: A practical guide for classroom teachers. New York, NY: Pearson.

Frunză, V., \& Petre, C. (2015). Obstacles in learning's differentiation and individualization on primary school. Procedia - Social and Behavioral Sciences, 180, 573-579. doi:10.1016/j.sbspro.2015.02.162

Gaines, R. E., Osman, D. J., Maddocks, D. L. S., Warner, J. R., Freeman, J. L., \& Schallert, D. L. (2019). Teachers' emotional experiences in professional development: Where they come from and what they can mean. Teaching and 
Teacher Education, 77, 53-65. doi:10.1016/j.tate.2018.09.008

Gaitas, S., \& Alves Martins, M. (2017). Teacher perceived difficulty in implementing differentiated instructional strategies in primary school. International Journal of Inclusive Education, 21(5), 544-556. doi:10.1080/13603116.2016.1223180

Gavin, M. K., Casa, T. M., Firmender, J. M., \& Carroll, S. R. (2013). The impact of advanced geometry and measurement curriculum units on the mathematics achievement of first-grade students. Gifted Child Quarterly, 57, 71-84. doi:10.1177/0016986213479564

Gilmour, F. (2018). Has inclusion gone too far? Weighing its effects on students with disabilities, their peers, and teachers. Education Next, 18(4), 8. Retrieved from https://www.educationnext.org/

Glazer, J. (2018). Learning from those who no longer teach: Viewing teacher attrition through a resistance lens. Teaching and Teacher Education, 74. 62-71. doi: /10.1016/j.tate.2018.04.011

Gokcearslan, S. (2017). Perspectives of students on acceptance of tablets and selfdirected learning with technology. Contemporary Educational Technology, 8(1), 40-55. doi:10.30935/cedtech/6186

Gonzalez, A., Orange, A., \& Grisby, B. (2016). The influence of high-stakes testing on teacher self-efficacy and job-related stress. Cambridge Journal of Education. 47 (4). doi:10.1080/0305764X.2016.1214237 
Gore, J., Lloyd, A., Smith, M., Bowe, J., Ellis, H., \& Lubans, D. (2017). Effects of professional development on the quality of teaching: Results from a randomized controlled trial of quality teaching rounds. Teaching and Teacher Education, 68, 99-113. doi:10.1016/j.tate.2017.08.007

Gregory, J. (2018). Not my responsibility: The impact of separate special education systems on educators' attitudes towards inclusion. Educational Policy Analysis and Strategic Research, 13(1), 127-148. doi:10.29329/epasr.2018.137.8

Gumpert, M., \& McConnell, W. (2019). Different strokes for different folks: Crosscurricular differentiation strategies for inclusion classrooms. Science \& Children, 57(2), 62-70. doi:2505/4/sc19_057_02_62

Gupta, A., \& Guang-Lea, L. (2020). The effects of a site-based teacher professional development program on student learning. International Electronic Journal of Elementary Education, 12(5), 417-428. doi:10.26822/iejee.2020562132

Haelermans, C., Ghysels, J., \& Prince, F. (2015). Increasing performance by differentiated teaching? Experimental evidence of the student benefits of digital differentiation. British Journal of Educational Technology, 46(6), 1161-1174. doi:10.1111/bjet.12209

Hagaman, J. L., \& Casey, K. J. (2018). Teacher attrition in special education: Perspectives from the field. Teacher Education and Special Education, 41(4), 277-291. doi:10.1177/0888406417725797 
Haug, P. (2016). Understanding inclusive education: Ideals and reality. Scandinavian Journal of Disability Research 19:206-17. doi:10.1080/15017419.2016.1224778

Hennink, M. M., Kaiser, B. N., \& Marconi, V. C. (2017). Code saturation versus meaning saturation: How many interviews are enough? Qualitative Health Research, 27, 591-608. doi:10.1177/1049732316665344

Hunt, P., Kozleski, E., Lee, J., Mortier, K., Fleming, D., \& Hicks, T.... Youngtha, O. (2020). Implementing comprehensive literacy instruction for students with severe disabilities in general education classrooms. Exceptional Children, 86(3), 330-347. doi:10.1177/0014402919880156

Jenset, I. S., Klette, K., \& Hammerness, K. (2018). Grounding teacher education in practice around the world: An examination of teacher education coursework in teacher education programs in Finland, Norway, and the United States. Journal of Teacher Education, 2, 184. doi:10.1177/0022487117728248

Jordan, C. (2016). The community-engaged scholars' program: Designing a professional development program to enhance individual capacity, community benefit, and institutional support. Journal of Community Engagement and Higher Education, 8(3), 6-15. Retrieved from http://www.indstate.edu/jcehe/index.htm

Juvova, A., Chudy, S., Neumeister, P., Plischke, J., \& Kvintova, J. (2015). Reflection of constructivist theories in current educational practice. Universal Journal of Educational Research, 3(5), 345-349. Retrieved from doi: 10.13189/ujer.2015.030506 
Kaur, A., Noman, M., \& Awang-Hashim, R. (2016). Exploring strategies of teaching and classroom practices in response to challenges of inclusion in a Thai school: A case study. International Journal of Inclusive Education, 20(5), 474-485. doi: $10.1080 / 13603116.2015 .1090489$

Kennedy, M. M. (2016). How does professional development improve teaching? Review of Educational Research, 86(4) 945-980. doi:10.3102/0034654315626800

Khan, I. K., Hashmi, S. H., \& Khanum, N. (2017). Inclusive education in government primary schools: Teacher perceptions. Journal of Education \& Educational Development, 4(1), 32-47. doi:10.22555/joeed.v4i1.1331

King-Sears, A., Brawand, M., Jenkins, M., \& Preston-Smith, S. (2014). Co-teaching perspectives from secondary science co-teachers and their students with 125 disabilities. Journal of Science Teacher Education, 25, 651-680. doi:10.1007/s10972-014-9391-2

Klette, K., \& Hammerness, K. (2016). Conceptual framework for analyzing qualities in teacher education: Looking at features of teacher education from an international perspective. Acta Didactica Norge, 10(2). doi:10.5617/adno.2646

Knisely, A. (2020). Poverty still plagues West Virginia, but signs of hope can be found. USA Today [online]. Retrieved from https://www.usatoday.com/story/opin ion/202 0/02/27/ west-virginia-still-struggles-deep-poverty-but-hope-takes-rootcolumn/4879484002/ 
Lang, M. L. (2019). Planning for differentiated instruction: Instructional leadership practices perceived by administrators and teachers in middle schools. Educational Planning, 26(2), 29-45. Retrieved from http://isep.info/educational-planning journal

Ledford, J. R., Barton, E. E., Severini, K. E., \& Zimmerman, K. N. (2019). A Primer on single-case research designs: Contemporary use and analysis. American Journal on Intellectual and Developmental Disabilities, 124(1), 35-56 Retrieved from https://aaiddjournals.org/

Lee, S., Wehmeyer, M. L., Soukup, J. H., \& Palmer, S. B. (2010). Impact of curriculum modifications on access to the general education curriculum for students with disabilities. Exceptional Children 76(2): 213-233.

doi:10.1177/001440291007600205

Leedy, P., \& Ormond, J. (2015). Practical research: Planning and design (11th ed). Boston, MA: Pearson.

Leshnick, S., Allen, J. S., \& Berman, D. (2019). Bridging the gap: Study reveals supports teachers need to move from understanding to implementation. Learning Professional, 40(4), 36-39. Retrieved from https://learningforward.org/thelearning-professional/

Lindner, K., Alnahdi, G., Wahl, S., \& Schwab, S. (2019). Perceived differentiation and personalization teaching approaches in inclusive classrooms: Perspectives of 
students and teachers. Frontiers in Education. (4) doi:10.3389/feduc.2019. 00058

Lochner, B., Conrad, R., \& Graham, E. (2015). Secondary teachers concern in adopting learning management systems: A U.S. perspective. TechTrends, 59(5), 62-70. doi:10.1007/s11528-015-0892-4

Lodico, M. G., Spaulding, D. T., \& Voegtle, K. H. (2010). Methods in educational research: From theory to practice. San Francisco, CA: Jossey-Bass.

Lunsford, K. (2017). Challenges to implementing differentiated instruction in middle school classrooms with mixed skill levels. Available from Dissertations \& Theses Walden University; ProQuest Dissertations \& Theses Global. (1973128867). Retrieved from https://ezp.waldenulibrary.org/

Mainini, M. J., \& Banes, L. C. (2017). Differentiating instruction to increase conceptual understanding and engagement in mathematics. Journal of Teacher Action Research, 4(1), 81-100.Retrieved from http://www.practicalteacherresearch.com/ Malacapay, M. C. (2019). Differentiated instruction in relation to pupils' learning style. International Journal of Instruction, 12(4), 625-638. doi:10.29333/iji.2 019.12440a

Manning, J. (2017). In vivo coding. In Matthes, J. (Ed.), The international encyclopedia of communication research methods. New York, NY: Wiley-Blackwell. Retrieved from doi:10.1002/9781118901731.iecrm0270 
Manrique, A. L., Dirani, E. T., Frere, A. F., Moreira, G. E., \& Arezes, P. M. (2019). Teachers perceptions on inclusion in basic school. International Journal of Educational Management, 2(409). doi:10.1108/IJEM-02-2018-0058

Martin, L. E., Kragler, S., Quatroche, D., \& Bauserman, K. (2019). Transforming schools: The power of teachers' input in professional development. Journal of Educational Research \& Practice, 9(1), 179-188. doi:10.5590/JERAP. 2019.09.1.13

McCray, K. H. (2016). Gallery educators as adult learners: The active application of adult learning theory. Journal of Museum Education, 41(1), 10-21. doi: $10.1080 / 10598650.2015 .1126058$

McGlynn, K., \& Kelly, J. (2017). Using formative assessments to differentiate instruction. Science Scope. 24(4), 22-25.doi:10.2505/4/ss17_041_04_22

Merriam, S. B. (2009). Qualitative research: a guide to design and implementation. San Francisco. CA:Jossey-Bass.

Mezirow, J. (1995). Transformation theory of adult learning. In M. R. Welton (Ed.), In defense of the lifeworld (pp. 39-70). New York, NY: SUNY Press.

Mezirow, J. (1997). Transformative learning in action. New Directions for Adult and Continuing Education, 74, 5-12.

Mezirow, J. (2003). Transformative learning and discourse. Journal of Transformative Education, 1, 58-63. doi:10.1177/1541344603252172 
Miller, K. L. (2017). The use of evaluation in treatment programs for children with autism. Behavior Analysis in Practice, 10(1), 35-44. doi:10.1007/s40617- 0160130-3

Minor, E. C., Desimone, L., Lee, J. C., \& Hochberg, E. D. (2016). Insights on how to shape teacher learning policy: the role of teacher content knowledge in explaining differential effects of professional development. Education Policy Analysis Archives, 24(61), 1-34. doi:10.14507/epaa.24.2365

Mofield, E. L. (2020). Benefits and barriers to collaboration and co-teaching: Examining perspectives of gifted education teachers and general education teachers. Gifted Child Today, 43(1), 20-33. doi:10.1177/1076217519880588

Morningstar, M. E., Shogren, K. A., Lee, H., \& Born, K. (2015). Preliminary lessons about supporting participation and learning in inclusive classrooms. Research and Practice for Persons with Severe Disabilities, 40(3): 192-210. doi: $10.1177 / 1540796915594158$

National Center for Education Statistics. (2017). Home Page, part of the U.S. Department of Education. Retrieved from http://nces.ed.gov/

Ncube, S. (2011). Peer-Collaboration: An effective teaching strategy for inclusive classrooms. Journal of the International Association of Special Education, 12(1), 79-80. Retrieved from https://www.iase.org/publications.htm 
OfSTED. (2015). 'Ofsted inspections - clarification for schools. Retrieved from https://www.gov.uk/government/publications/school-inspection-handbook-fromseptember-2015

Ozaydin, L. (2015). Teaching play skills to visually impaired preschool children: Its effect on social interaction. Kuram ve Uygulamada Eğitim Bilimleri/Educational Sciences: Theory \& Practice, 15(4), 1021-1038. Retrieved from https://www. researchgate.net/journal/1303-0485_Educational_Sciences_Theory_and_Practice

Ozokcu, O. (2018). Investigating classroom teachers' attitudes towards inclusion. (English). Inonu University Journal of the Faculty of Education (INUJFE), 19(3), 418-433. doi:10.17679/inuefd.472639

Parks, M. (2019). Theory to practice: Differentiation for preservice teachers. Science \& Children, 57(2), 90. Retrieved from https://www.jstor.org/journal/sciechil

Pehmer, A. K., Gröschner, A., \& Seidel, T. (2015). How teacher professional development regarding classroom dialogue affects students' higher-order learning. Teaching and Teacher Education, 47, 108-119. doi:10.1016/j.tate.2014.12.007

Polly, D., McGee, J., Wang, C., Martin, C., Lambert, R., \& Pugalee, D. K. (2015). Linking professional development, teacher outcomes, and student achievement: The case of a learner-centered mathematics program for elementary school teachers. International Journal of Educational Research, 72, 26-37. doi: 10.1016/j.ijer.2015.04.002 
Prast, E. J., Van de Weijer-Bergsma, E., Kroesbergen, E. H., \& Van Luit, J. E. H. (2018). Differentiated instruction in primary mathematics: Effects of teacher professional development on student achievement. Learning and Instruction, 54, 22-34. doi: .1016/j.learninstruc.2018.01.009

Rachmawati, M. A., Nu’Man, T. M., Widiasmara, N., \& Wibisono, S. (2016). Differentiated instruction for special needs in inclusive schools: a preliminary study. Procedia - Social and Behavioral Sciences, 217, 585-593. doi: 10.1016/j.sbspro.2016.02.053

Rakap, S., Parlak-Rakap, A., \& Aydın, B. (2016). Investigation and comparison of Turkish and American preschool teacher candidates' attitudes towards inclusion of young children with disabilities. International Journal of Inclusive Education, 20(11), 1223-1237. doi:10.1080/13603116.2016.1159254

Ravitch, S. M., \& Carl, N. M. (2016). Qualitative research: Bridging the conceptual, theoretical, and methodological. Thousand Oaks, CA: Sage Publications.

Roberts, K. M. (2019). So all can learn: A practical guide to differentiation. Education Review 26, 1-5 doi:10.14507/er.v26.2431

Rubin, H. J., \& Rubin, I. S. (2012). Qualitative interviewing: The art of hearing data (3rd ed.). Thousand Oaks, CA: Sage Publications.

Sabb-Cordes, M. (2016). Teachers' perceptions of differentiated learning for at-risk second-grade students in reading. Available from Dissertations \& Theses at 
Walden University; ProQuest Central; ProQuest Dissertations \& Theses Global. (1798825050). Retrieved from https://ezp.waldenulibrary.org/

Schwab, S., Sharma, U., \& Loreman, T. (2018). Are we included? Secondary students' perception of inclusion climate in their schools. Teaching and Teacher Education, 75, 31-39. doi:10.1016/j.tate.2018.05.016

Shaffer, L., \& Thomas-Brown, K. (2015). Enhancing teacher competency through coteaching and embedded professional development. Journal of Education and Training Studies, 3(3), 117-125. doi:10.11114/jets.v3i3.685

Shaunessy-Dedrick, E., Evans, L., Ferron, J., \& Lindo, M. (2015). Effects of differentiated reading on elementary students' reading comprehension and attitudes toward reading. Gifted Child Quarterly, 59, 91-107. doi: $10.1177 / 0016986214568718$

Shepherd, D., \& Devers, C. J. (2017). Principal perceptions of new teacher effectiveness. Journal of Education, 197(2), 37-47. doi:10.1177/002205741719700205

Siam, K., \& Al-Natour, M. (2016). Teacher's differentiated instruction practices and implementation challenges for learning disabilities in Jordan. International Education Studies, 9(12), 167-181. doi:10.5539/ies.v9n12p167

Silveira-Zaldivar, T., \& Curtis, H. (2019). "I'm not trained for this!" and other barriers to evidence-based social skills interventions for elementary students with high functioning autism in inclusion. International Electronic Journal of Elementary Education, 12(1), 53-66. doi:10.26822/iejee.2019155337 
Smeets, E., Ledoux, G., Regtvoort, A., Felix, C., \& Moi Lous, A. (2015). Adaptive competencies for inclusive education: Research about competencies in primary school. Nijmegen, The Netherlands: ITS.

Smets, W. (2019). Challenges and checklists: Implementing differentiation: pedagogy provides a solid rationale for differentiated instruction in the History classroom, but this is not always an easy skill for teachers to acquire. Agora, 54(2), 22. Retrieved from https://www.uantwerpen.be/en/research/

Sofwan, Mujiyati, \& Tri Yuni Hendrowati. (2019). Perceptions of inclusion education by parents of elementary school-aged children in Lampung, Indonesia. International Journal of Instruction, 12(1), 199. Retrieved from http://e-iji.net/

Stites, M. L., Rakes, C. R., Noggle, A. K., \& Shah, S. (2018). Preservice teacher perceptions of preparedness to teach in inclusive settings as an indicator of preparation program effectiveness. Discourse and Communication for Sustainable Education, 9(2), 21-39. doi:10.2478/dcse-2018-0012

Strogilos, V., Avramidis, E., Voulagka, A., \& Tragoulia, E. (2020). Differentiated instruction for students with disabilities in early childhood co-taught classrooms: types and quality of modifications. International Journal of Inclusive Education, 24(4), 443-461. doi:10.1080/13603116.2018.1466928

Sumrall, W., \& Sumrall, K. (2018). Understanding by Design. Science \& Children, 56(1), 48-54. doi:10.2505/4/sc18_056_01_48 
Sunthonkanokpong, W., \& Murphy, E. (2019). Quality, equity, inclusion and lifelong learning in pre-service teacher education. Journal of Teacher Education for Sustainability, 21(2), 91-104. doi:10.2478/jtes-2019-0019

Svendsen, B. (2020). Inquiries into teacher professional development--What matters? Education, 140(3), 111-130

Tantawy, N. (2020). Investigating teachers' perceptions of the influence of professional development on teachers' performance and career progression. Arab World English Journal, 11(1), 181-194. doi:10.24093/awej/vol11no1.15

Taole, M. J. (2019). Differentiation in response to learner diversity in rural south African multi-grade classrooms. International Journal of Learner Diversity \& Identities, 26(2), 37-46. doi:10.18848/2327-0128/cgp/v26i02/37-48

Taylor, S. J., Bogdan, R., \& DeVault, M. L. (2016). Introduction to qualitative research methods : a guidebook and resource ( $4^{\text {th }}$ ed.). Wiley.

Thomas, G. (2017). How to Do Your Research Project: A Guide for Students. Thousand Oaks, CA: Sage Publications

Tobin, R., \& Tippett, C. D. (2014). Possibilities and potential barriers: Learning to plan for differentiated instruction in elementary science. International Journal of Science and Mathematics Education, 12, 423-443. doi:10.1007/s10763-0139414-Z

Tomlinson, C. A. (1999). Tomlinson, Carol A. (1999). The Differentiated Classroom: Responding to the Needs of All Learners. Alexandria, VA: Association for 
Supervision and Curriculum Development. Learners. Upper Saddle River, NJ: Pearson Education.

Tomlinson, C. A. (2001). How to differentiate instruction in mixed ability classrooms (2nd ed.). Alexandria, VA: Association for Supervision and Curriculum Development

Tomlinson, C. A. (2014). The Differentiated Classroom: Responding to the Needs of All. Alexandria, VA: Association for Supervision and Curriculum Development.

Tomlinson, C. A. (2015). Teaching for excellence in academically diverse classrooms. Society, 52(3), 203-209. doi:10.1007/s12115-015-9888-0

Tomlinson, C. A. (2017). How to differentiate instruction in academically diverse classrooms ( $\left.3^{\text {rd }} \mathrm{ed}\right)$. Alexandria, VA: Association for Supervision and Curriculum Development.

Tracy, S. (2013). Qualitative Research Methods: Collecting Evidence, Crafting Analysis, Communicating Impact. Wiley- Blackwell Publication

Tufford, L., \& Newman, P. (2010). Bracketing in Qualitative Research. Qualitative Social Work, 11(1). doi:10.1177/1473325010368316

United States Department of Education. (n.d.). Every student succeeds act (ESSA). Retrieved from https://www.ed.gov/essa?src=rn

U.S. Department of Education. (n.d.). Retrieved from https://www.ed.gov/ Valiandes, S., \& Neophytou, L. (2018). Teachers’ professional development for differentiated instruction in mixed-ability classrooms: investigating the impact of 
a development program on teachers' professional learning and on students' achievement. Teacher Development, 22(1), 123-138. doi:10.1080/136645 30.2017 .1338196

Vega, M. L. (2015). Inclusive education in schools in rural areas. Journal of New Approaches in Educational Research, 4(2), 107. doi:10.7821/naer.2015.4.120

Vella, J. (2002). Learning to listen, learning to teach. Montpelier, VT: Global Learning Partners, Inc.

Vlachou, A., \& Fyssa, A. (2016). Inclusion in practice: Programme practices in mainstream preschool classrooms and associations with context and teacher characteristics. International Journal of Disability, Development and Education, 63(5), 529. doi:10.1080/1034912X.2016.1145629

Wan, S. W.-Y. (2017). Differentiated instruction: are Hong Kong in-service teachers ready? Teachers \& Teaching, 23(3), 284-311. doi:10.1080/13540602.2 016.1204289

Willard, C. (2019). Four key ideas about coteaching in high school classrooms. International Journal of Whole Schooling, 15(2), 81-102.

Woodcock, S., \& Woolfson, L. M. (2018). Are leaders leading the way with inclusion? Teachers' perceptions of systemic support and barriers towards inclusion. International Journal of Educational Research. doi:10.1016/j.ijer.2018.11.004 Yin, R. (2014). Case Study Research and Applications. New York, NY: Guildford Publications. 
Yu, S. (2019). Head start teachers' attitudes and perceived competence toward inclusion.

Journal of Early Intervention, 41(1), 30-43. doi:10.1177/1053815118801372 
Appendix A: Professional Development on Differentiated Instruction, Co-teaching, and Alternative Instructional Support

The intended purpose of this project is to be interactive and hands-on. Teachers will be introduced to many facets of differentiation and concrete ways it can be implemented into both ELA and mathematics by adjusting the county wide curriculum. Teachers will also be given strategies that can be implemented to lessen the classroom disruptions through coteaching along with alternative instructional support strategies that will allow continual improvement of differentiation. This program is based on research in DI, coteaching, and instructional support along with findings of a study completed at three elementary schools in one county in the identified Appalachian state. The findings from the study suggested a need for professional development on the implementation of DI along with ways to deter the hindrances found within the study.

\section{Target Audience}

The target audience for this project will be third and fourth grade general education teachers who teach in the inclusive classroom. While it is specific to stated problems found within this grade range, it can be applied to any grade range looking to enhance their use of differentiated instruction, push in rather than pull out services, and looking for alternative instructional support. Day 2 could include support services to start the collaboration process with the general education teachers. 


\section{Professional Development Program}

This project includes three days of professional development with each day presenting a new topic: Day 1 differentiation strategies, Day 2 coteaching, and Day 3 alternative instructional support. Each day is grounded within best practice literature and the design and implementation of the professional development program were designed using the Adult Learning Theory (see Mezirow, 1995). Specific goals for the program include: (1) educate teachers on the components of DI and how it can be incorporated into their existing curriculum, (2) provide elementary teachers with coteaching strategies that can be easily implemented in the classroom as an alternative to pull out services, (3) provide teachers with alternative instructional support scenarios to allow for continued professional development, and (4) provide an opportunity for teachers to collaborate with their colleagues and reflect on their current practices in inclusive education.

\section{Day 1 Resources}

1. Smartboard

2. Projector

3. Speakers

4. Table supplies: Slide print-outs, pens, markers, teacher laptops, chart paper

\section{Day 1: What is differentiation?}

Objective: Teachers will have a deeper understanding of the components of DI based on how they can modify the content, process, and product in their inclusive classrooms. 


\begin{tabular}{|c|c|}
\hline 8:00- 8:30 AM & $\begin{array}{l}\text { Teacher arrival and sign in. Teachers will be asked to sit with their grade- } \\
\text { level teams. A welcome message and session norms will be posted on the } \\
\text { screen. } \\
\text { As teachers are getting settled, projected on the board will be a QR code } \\
\text { that directs students to complete a self-reflection of their current use of } \\
\text { differentiation in the classroom. }\end{array}$ \\
\hline 8:30- 8:45 AM & Share anonymous reflection results and the agenda for Day 1 \\
\hline 8:45- 9:00 AM & Overview of research study results \\
\hline 9:00- 10:00 AM & $\begin{array}{l}\text { Slide Show Presentation- What is DI- components (process, product, and } \\
\text { process). Key topics include different styles of grouping, how to gather } \\
\text { data, and how to plan for DI ( } 30 \text { minutes) } \\
\text { Video Clippings on DI- ( } 20 \text { minutes), What does differentiation look } \\
\text { like? Teachers will be given } 3 \text { short video clips on each component where } \\
\text { the teacher is asked to write down observations. How was it } \\
\text { differentiated? Describe the student-teacher interactions. } \\
\text { Teachers are to discuss their findings with their tablemates ( } 10 \text { minutes) }\end{array}$ \\
\hline 10:00-10:10 & Break \\
\hline 10:10- 11:00 & $\begin{array}{l}\text { What does it mean to be student centered? What activities should you } \\
\text { incorporate and how to make your classroom more student-friendly. How } \\
\text { to provide choice? } \\
\text { How do you provide all of these options within one workday?- scheduling } \\
\text { ideas and breakdown of content time ( } 50 \text { minutes) }\end{array}$ \\
\hline 12:00 & $\begin{array}{l}\text { Collaboration- Teachers are tasked with creating a student-centered } \\
\text { activity that incorporates choice in the area of mathematics. Teachers } \\
\text { should design seating options and an activity that is both student centered } \\
\text { and tailored to meet differentiation means ( } 30 \text { minutes) } \\
\text { Task 2- Teachers are tasked with creating a math choice board to be } \\
\text { completed as an option that can be incorporated into stations. ( } 20 \\
\text { minutes) } \\
\text { Task 3- Post a sample schedule that incorporates both small groups for } \\
\text { ELA and math. } \\
\text { Post examples throughout the professional development room to allow for } \\
\text { further teacher collaboration ( } 10 \text { minutes) }\end{array}$ \\
\hline 12:00- 1:00 PM & Lunch \\
\hline 1:00- 2:00 PM & $\begin{array}{l}\text { Teachers are asked to pick a content area and objective within their grade } \\
\text { level and among tablemates. Create three different activities on poster } \\
\text { paper that differentiates the process, product, and content. These should } \\
\text { be hung around the room as they are finished. }\end{array}$ \\
\hline 2:00- 2:20 PM & $\begin{array}{l}\text { Gallery Walk- Teachers can walk around the room looking at all of the } \\
\text { examples posted. ( } 10 \text { minutes) } \\
\text { Break ( } 10 \text { minutes })\end{array}$ \\
\hline $2: 20-3: 00$ & $\begin{array}{l}\text { Reflection- Share what has been learned, realizations. Further } \\
\text { collaboration time with colleagues on lessons that could be immediately } \\
\text { implemented in the classroom. ( } 30 \text { minutes) } \\
\text { Reflection survey ( } 10 \text { minutes) }\end{array}$ \\
\hline
\end{tabular}


Slide 1

\section{How to Navigate Differentiated Instruction and Its Created Obstacles}

Dr. Felicia Fordyce

M.Ed., Ed.D.

Slide 2

Day 1 Schedule

- 8:00- 9:00 Teacher Welcome and sign in. Review of professional development norms. Complete the reflection survey from the QR and review results. Discuss research that has developed the professional development.

- 9:00-10:00 What is Differentiation? How can it be implemented successfully into the county wide curriculum? Slide show and video presentations.

- 10:00 Break

- 10:10-11:00 What does it mean to be student centered? How do you provide choice? How can you fit all of these things into your schedule?

- 11:00- 12:00 Collaboration Time- Task 1- Mathematics student centered activity, Task 2- Math choice board Task 3- Revise a schedule to allow for both ELA and math stations.

- 12:00- 1:00 Lunch on your own

- 1:00- 2:00 Pick of Content Area- Pick one Learning objective from ELA or Math. With the one objective, create a lesson that differentiates content, a lesson that differentiates process, and a lesson that differentiates the product.

- 2:00-2:20 Gallary Walk and Break

- 2:20- 3:00 Reflection and Collaboration with colleagues. Wrap up.

The schedule will be passed out and placed on tables. 
Slide 3

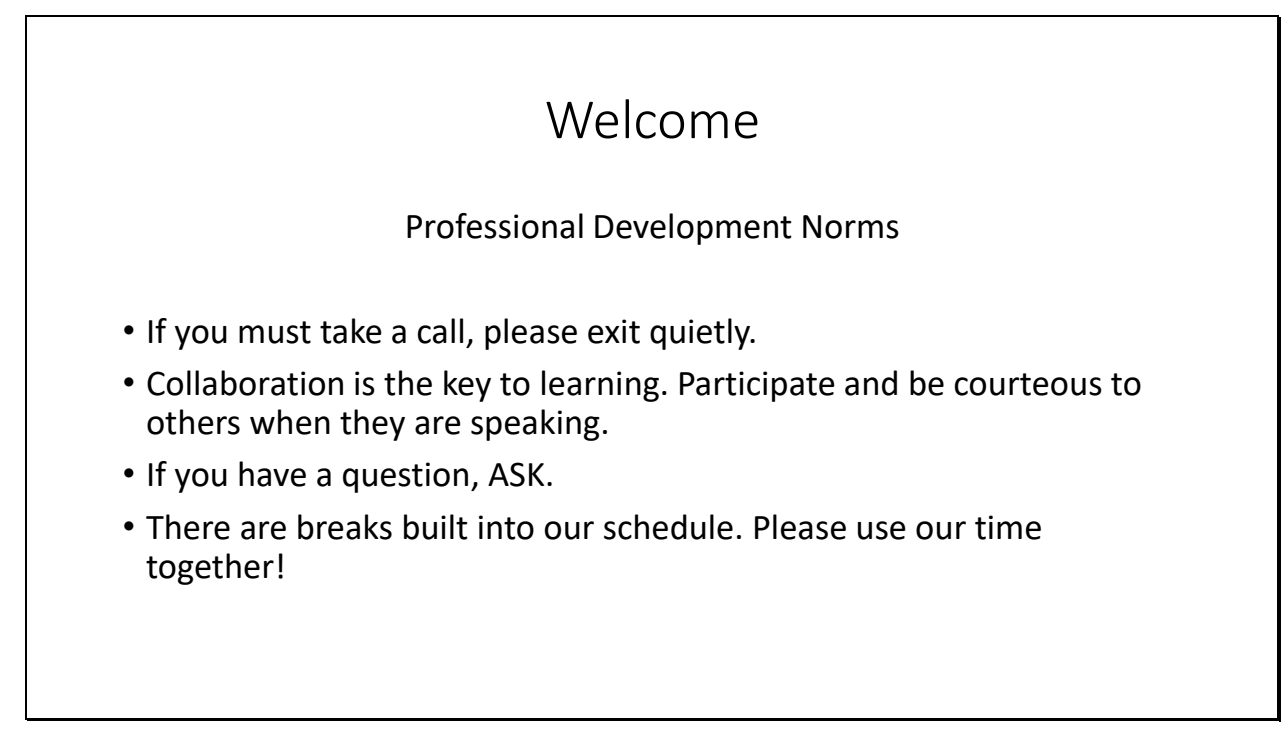

The facilitator will go over professional development norms.

Slide 4

\section{Reflective Survey}

• https://www.surveymonkey.com/r/S8WSLHD

Please complete the survey.

The facilitator will ask all participants to complete the survey monkey 4 questions survey to gauge the level of comfort with differentiation in both areas of ELA and mathematics. Anonymous results will be shared. 
Slide 5

\section{Overview of Research Study Results}

In a recent study, 9 of the county's 14 third and fourth grade teachers chose to participate in my doctoral research study.

- 9 out of 9 teachers stated they used guided reading groups as a form of differentiation.

- 2 our of 9 teachers states using math stations as a form of differentiation with others stating they lacked the time in their schedule.

- 9 out of 9 teachers recalled the differentiation training received last year on ELA with 9 out of 9 teachers stating they would like differentiation professional development in the area of mathematics.

- 7 out of the 9 participants needed clarification of what basic terminology meant during the interview regarding the use of differentiation.

- In analyzing 9 lesson plans, little to no differentiation was present.

- 0 out of 9 participants reported differentiating product

- All participants admitted to using support staff to meet the differentiation needs within the classroom.

The facilitator will go over the research study findings.

Slide 6

\section{What does it mean to differentiate?}

Differentiation is simply a teacher attending to the learning needs of a particular student or small groups of students, rather than teaching a class as though all individuals in it were basically alike.

- Carol Ann Tomlinson- 
What does it mean to differentiate? What did Carol Tomlinson mean when she said this? Discussion among tablemates and share out.

Slide 7

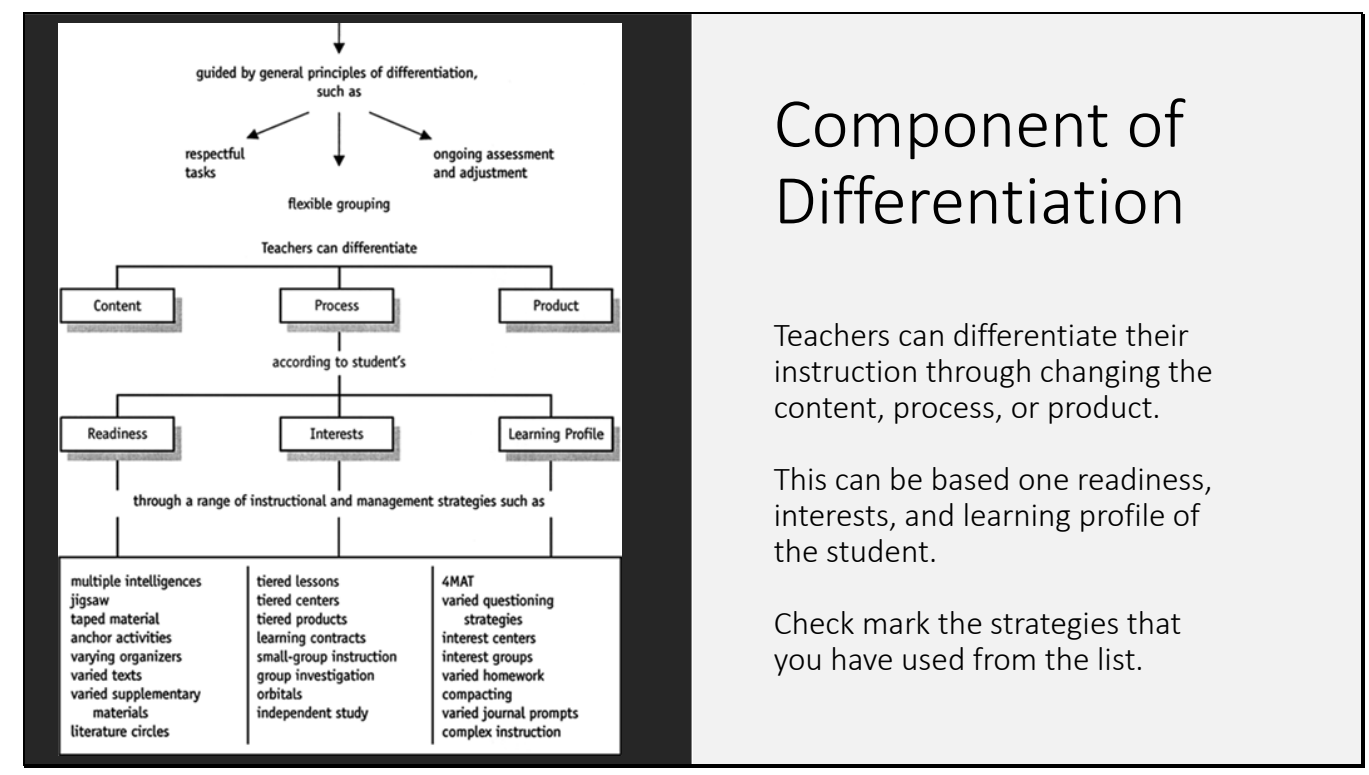

To begin with, differentiation is designed by the teacher and should contain respectful tasks and ongoing assessments to allow for readjustments. What does it mean by respectful tasks? (This does not mean giving students less work or more work because they are gifted). Ongoing assessments are also essential because as students address through improving their understanding, they should progress through different ability groups. Assessments data can be obtained through classroom observations, exit slips, quizzes, checklists, student reflections, unit assessments, benchmarks. The list is endless! Once the teacher was an idea of the child's ability, teachers can differentiate the content based on the content they are teaching. For example, in small groups, the content can be leveled to the level of the students. The process can be changed. For example, instead of showing multiplication in two different ways, the student can be asked to show the process through modeling. And the product can be differentiated through the way a student shows understanding. For example, students can apply their math skills in a real-world concept to make something authentic rather than an end of chapter test which also raises the level of difficulty. Teachers can differentiate the content, process, or product based on a child's readiness, interest, and learning profile. This is where the teacher needs to know the whole student. Teachers can use interest inventories and learning profile quizzes at the beginning of the year to understand the learner. Also, teachers can hold goal-setting meetings with each student to talk through some of these suggestions with the student to see their unique take on how they best learn. Take a few minutes and read through the list of strategies that teachers can use to differentiate. Which ones have you used? 
Slide 8

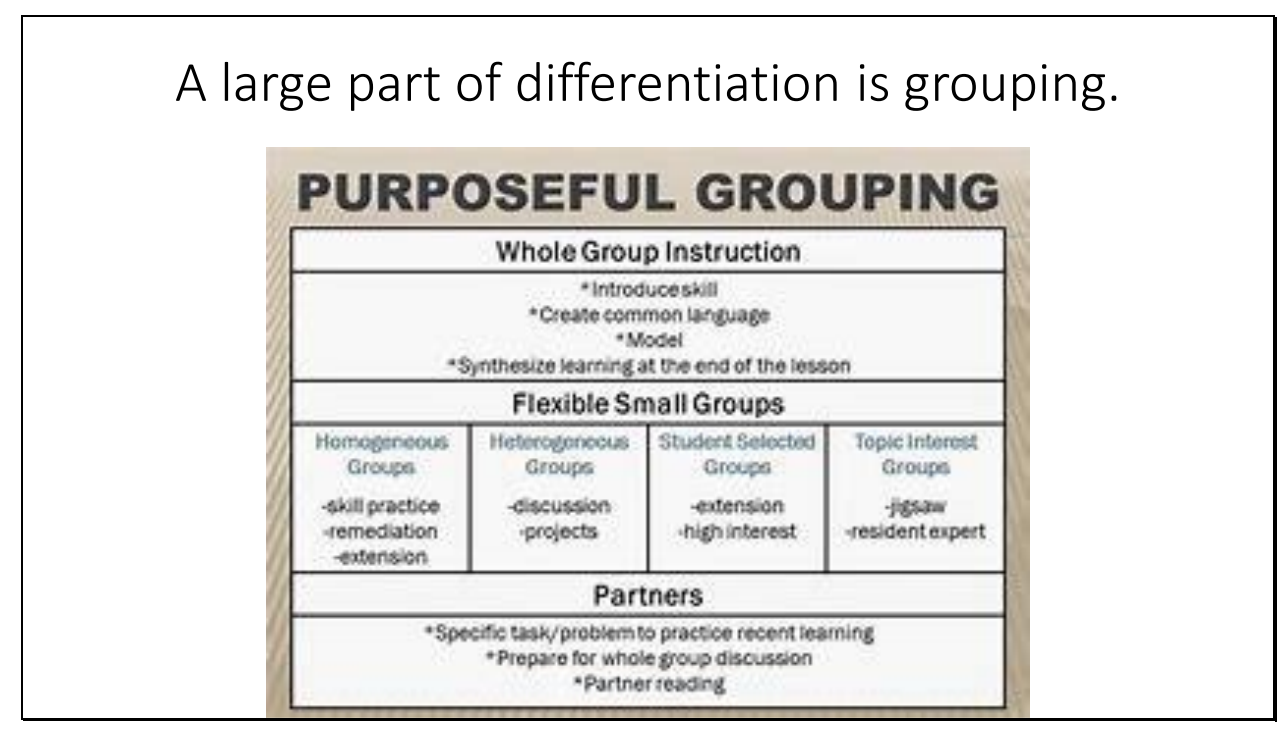

A large part of differentiation is grouping. In the research study, all teachers said they grouped based on ability and all teachers said they started their core instruction using whole group direct instruction. As you can see in the diagram, this is a great way to introduce a skill, create a common language, model and example, and wrap up a lesson. Small groups can be a bit more flexible and should be used for both ELA and mathematics. Homogeneous Groups or like ability groups and can be used to practice specific skills, remediation, or branching up a lesson with advanced learners. Heterogeneous groups can be used for discussions and projects as each student could play off of their strengths and help one another succeed. Student selected groups can be used for extension projects or high-interest projects. Topic interest groups can be used with jigsaw. Partners in the classroom should also be an option. Having a shoulder buddy throughout the day can be beneficial. For example, in math, if you are explaining a concept and want to do a quick check or verification of student understanding you can say, turn to your shoulder partner and explain what I just said. Or turn to your shoulder buddy and explain to them how to do the next problem and then switch roles. Partners can easily be incorporated into reading as well as partner reading, spelling practice, and a writing buddy. 
Slide 9

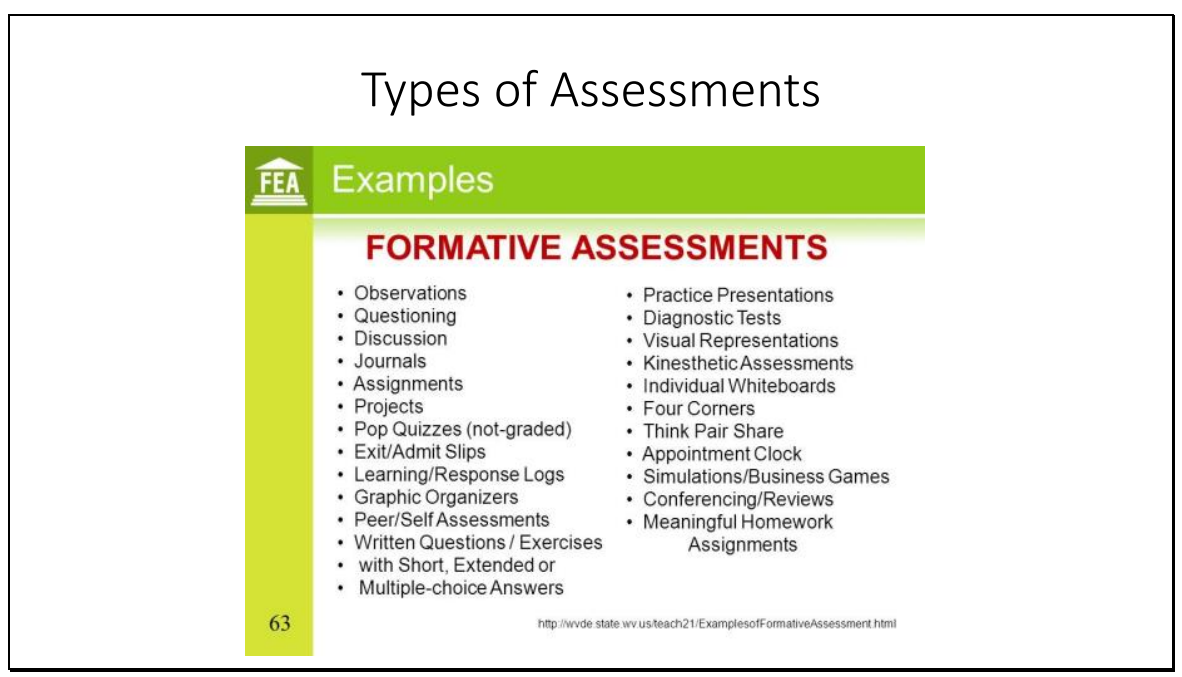

To gather data in the classroom to appropriately group students, teachers have many options. Take a look at the formative assessment list and talk with your table about the assessment you use and the assessments you want to start using.

Slide 10

Interest Inventories and Learning Profiles

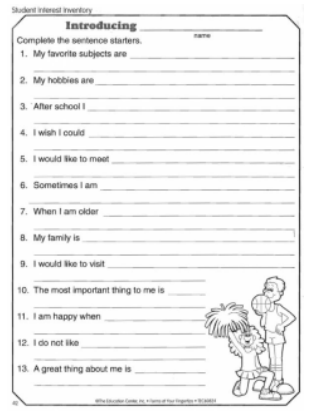

What kind of learner are you?

Gathering student performance data is only part of the equation. You need to know what the student enjoys, what they feel they are good at, and where they feel they struggle. You can also assign fun quizzes to learn more about the student and the student to reflect more about their 
selves. Click on what kind of learner are you and take the quiz! Discuss your findings with your table mates.

Slide 11

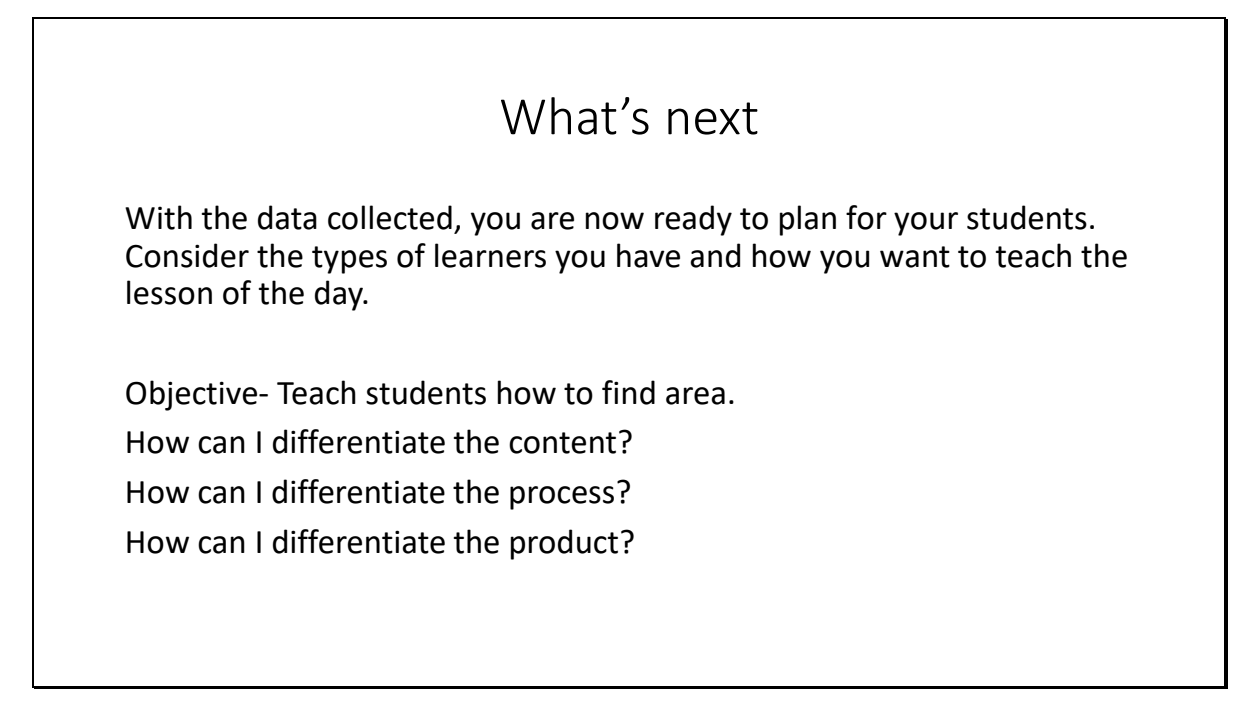

Talk with your tablemates and share your ideas.

Slide 12

What does differentiation look like in practice?

Video 1 https://www.youtube.com/watch?v=Kg38A1ggYiE

Video 2 https://www.youtube.com/watch?v=IBqwf2rqeTo

Video 3 https://www.youtube.com/watch?v=m4myn8JLilE4 
Watch the three short videos and allow time between videos to reflect on what differentiation looks like and how do students interact with this learning environment. How does the teacher interact?

Slide 13

\section{Let's take a break}

Slide 14

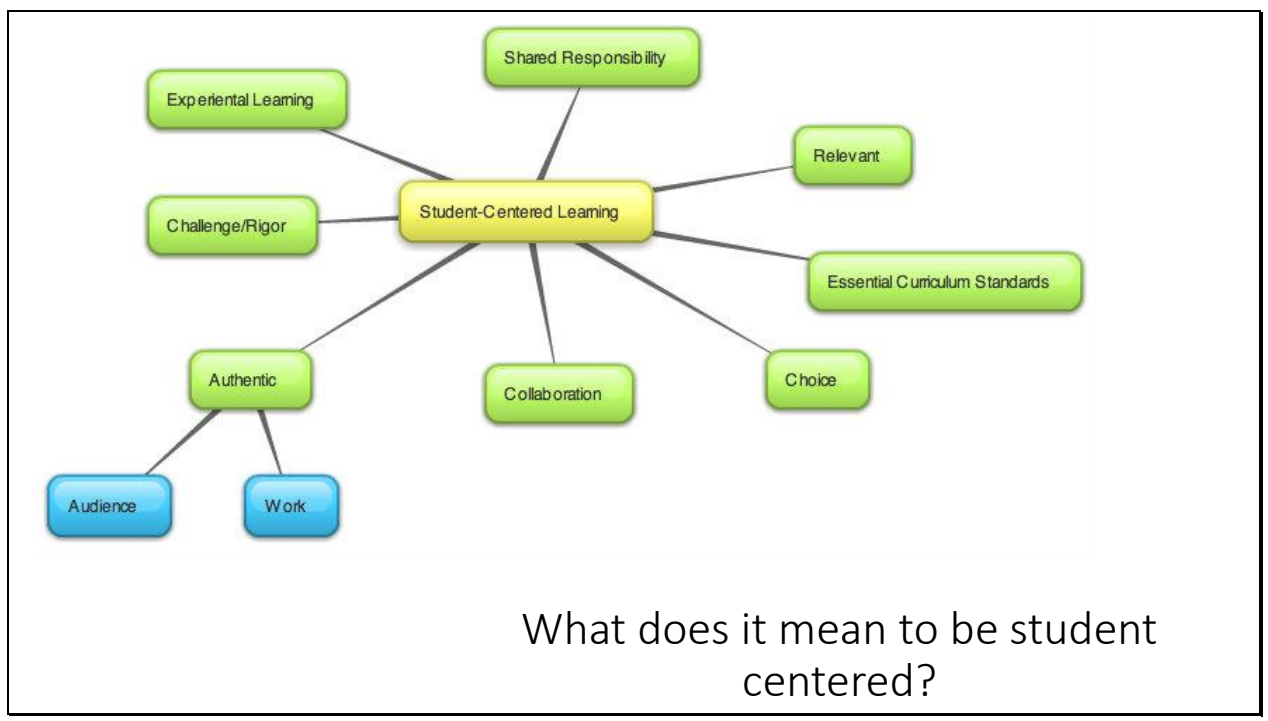

A big part of using differentiation is also being student centered. Students should share responsibility for their learning. The tasks should be relevant to the student's life by using essential curriculum standards. Students should have a choice in their learning, use collaboration 
with their peers, and be challenging. Students should experiment with their learning ideas and come up with the concept when necessary. How do you implement student-centered learning in your classroom?

Slide 15

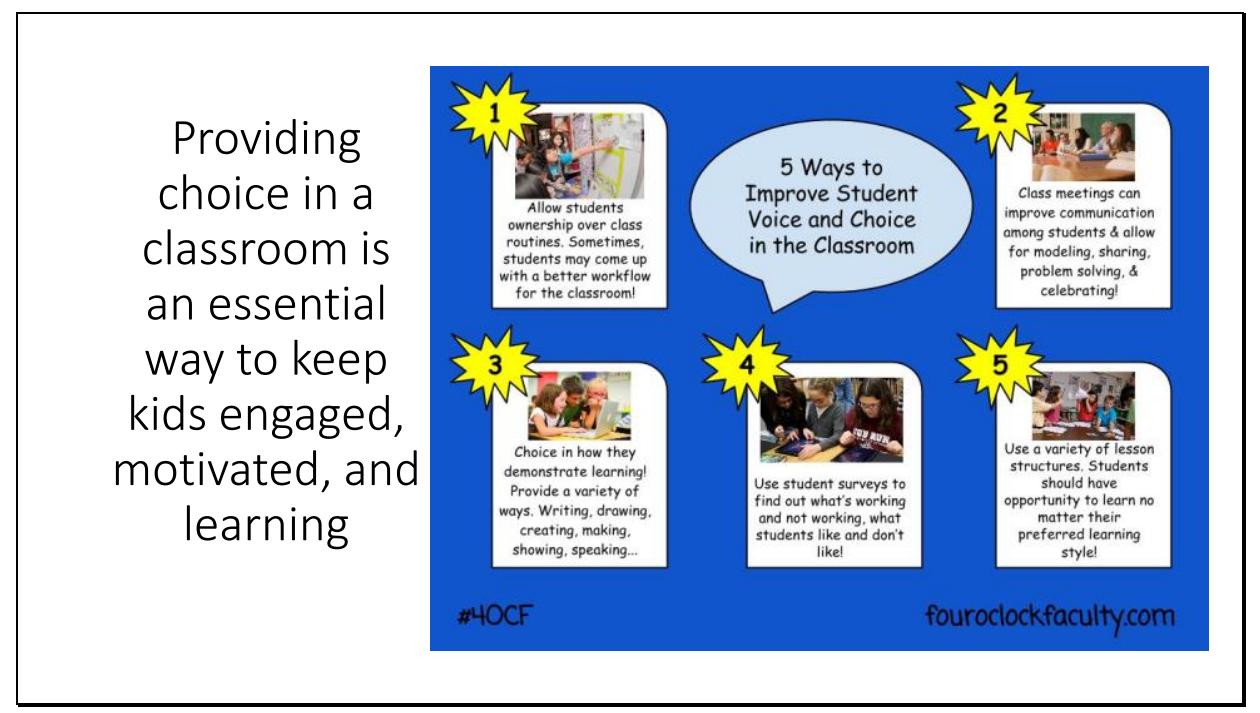

Teachers can provide choices in their classrooms in multiple ways. However, it is so important as it provides engagement, motivation, and a sense of ownership of student learning. Students can help make classroom routines and choose their weekly jobs. Class meetings can help students learn to communicate while using their own choice of how to explain answers and problemsolving. Lastly, teachers should provide a variety of ways students can demonstrate their learning. This can be through writing, drawing, creating, making, showing, or speaking! Teachers should also use a variety of lesson structures as not every student learns the same way. 
Slide 16

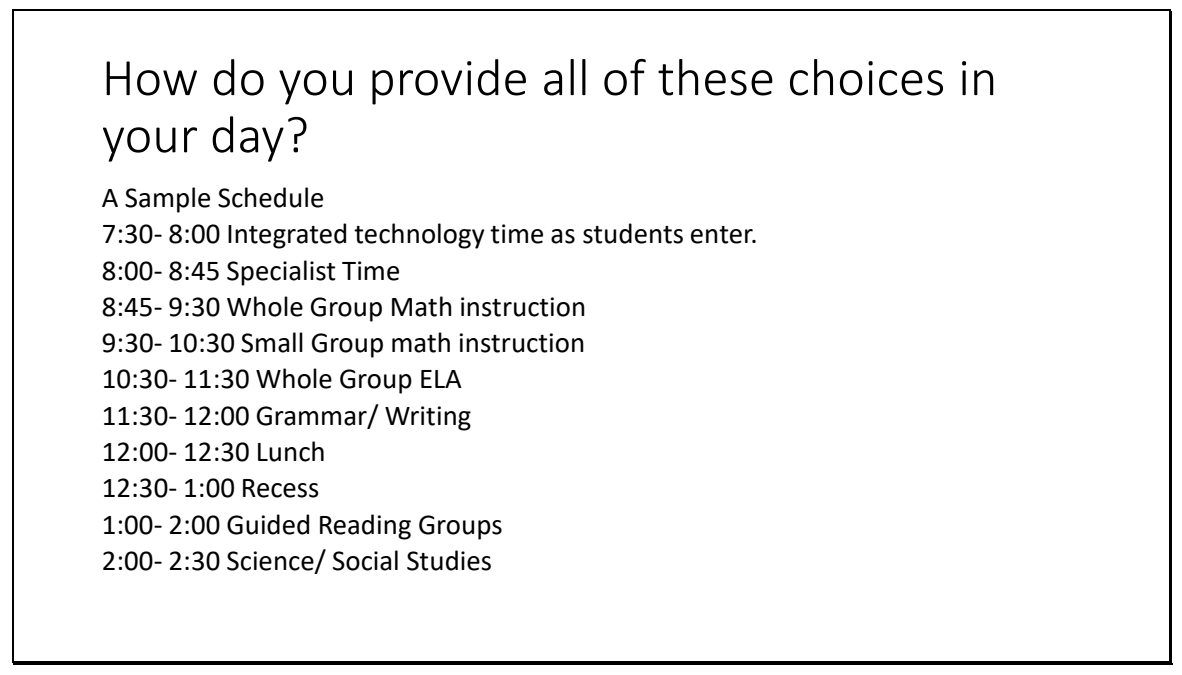

A sample breakdown of a typical third or fourth-grade teacher is shown. How can you incorporate both ELA and math groups into your schedule? What conflicts do you see within the model? Reflect with your tablemates as you will be revising and editing your schedule in the upcoming task.

Slide 17

\begin{tabular}{|c|c|c|}
\hline \multicolumn{3}{|c|}{$\begin{array}{l}\text { Your tasks. When you are finished post on large } \\
\text { poster paper around the room in the designated } \\
\text { areas. }\end{array}$} \\
\hline \begin{tabular}{|l|} 
Task 1: Create a student \\
centered activity that \\
incorporates choice in \\
the area of mathematics. \\
You should design seating \\
options and an activity \\
that is both student \\
centered and tailored to \\
meet differentiation \\
means
\end{tabular} & $\begin{array}{l}\text { Task 2: You are tasked } \\
\text { with creating a math } \\
\text { choice board to be } \\
\text { completed as an option } \\
\text { that can be incorporated } \\
\text { into stations. }\end{array}$ & $\begin{array}{l}\text { Task 3: Post a sample } \\
\text { schedule that } \\
\text { incorporates both small } \\
\text { groups for ELA and } \\
\text { mathematics. }\end{array}$ \\
\hline
\end{tabular}

For the next hour before lunch I want you to reflect on what you have learned. How can you apply these new ideas to your current position to make it more student centered while meeting more of the needs within your classroom? Work with your table partners to complete tasks 1,2, 
and 3. Post them on poster paper in the designated areas so that we can walk around and see some of your ideas. (Facilitator will walk around and talk with the different tables about their ideas and answer any lingering questions).

Slide 18

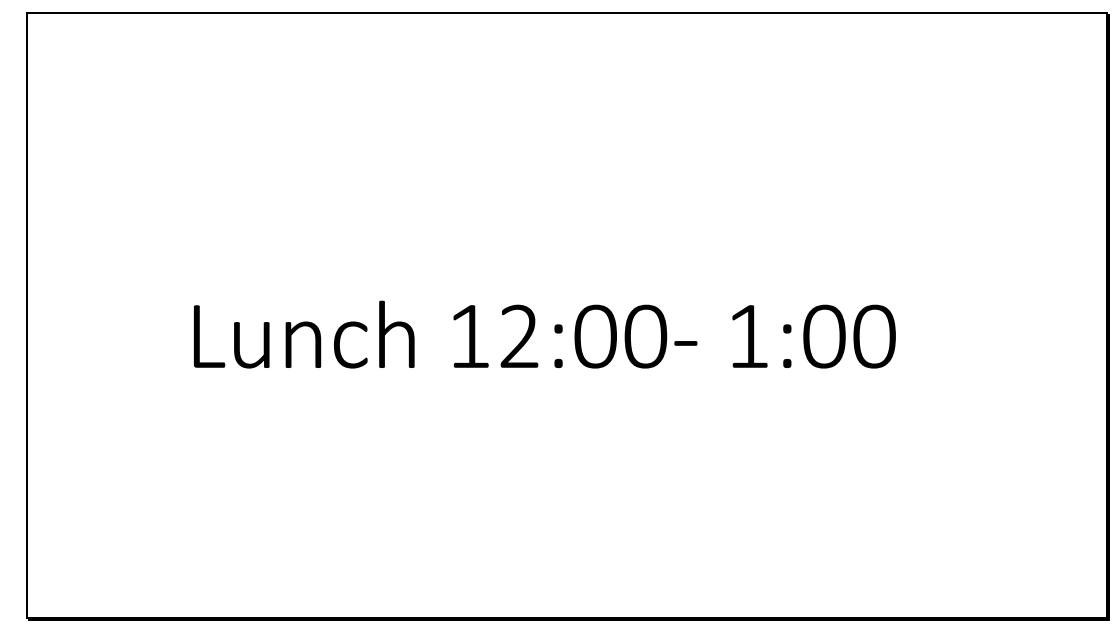

Slide 19

\section{Differentiated Tasks}

\begin{tabular}{|l|l|l|}
\hline $\begin{array}{l}\text { Task 1: Objective } \\
\text { of the lesson }\end{array}$ & $\begin{array}{l}\text { Task 2: Objective } \\
\text { of the lesson }\end{array}$ & $\begin{array}{l}\text { Task 3: Objective } \\
\text { of the lesson }\end{array}$ \\
$\begin{array}{l}\text { Design a task to } \\
\text { differentiate the } \\
\text { process. }\end{array}$ & $\begin{array}{l}\text { Design a task to } \\
\text { differentiate the } \\
\text { product. }\end{array}$ & $\begin{array}{l}\text { Design a task to } \\
\text { differentiate the } \\
\text { content. }\end{array}$ \\
\hline
\end{tabular}

On poster paper, I would like you to work on designing tasks that could be used in the inclusive classroom. You are again asked to complete three tasks. 1, design a lesson that differentiates the process. Task 2, differentiate the product and task 3, differentiate the content. Hang your ideas on the wall so we can all get a better idea of ways we can enhance our classrooms. Feel free to take pictures! 
Slide 20

\section{Reflection}

Talk with your table partners

What would you like to use more of in the classroom?

What kinds of supports are still needed to make you feel more comfortable?

How can you incorporate more of these ideas as a team?

What would be the benefits of being more student centered?

For the remaining of our time, review past lesson plans and look for examples of differentiation? Is it essential to plan for differentiation?

Make a plan for next steps.

Take a couple of minutes and share with your colleagues a few realizations you have had today during the training. What would you like to use more of in the classroom? What kinds of supports are still needed to make you more comfortable with using differentiation?

Slide 21

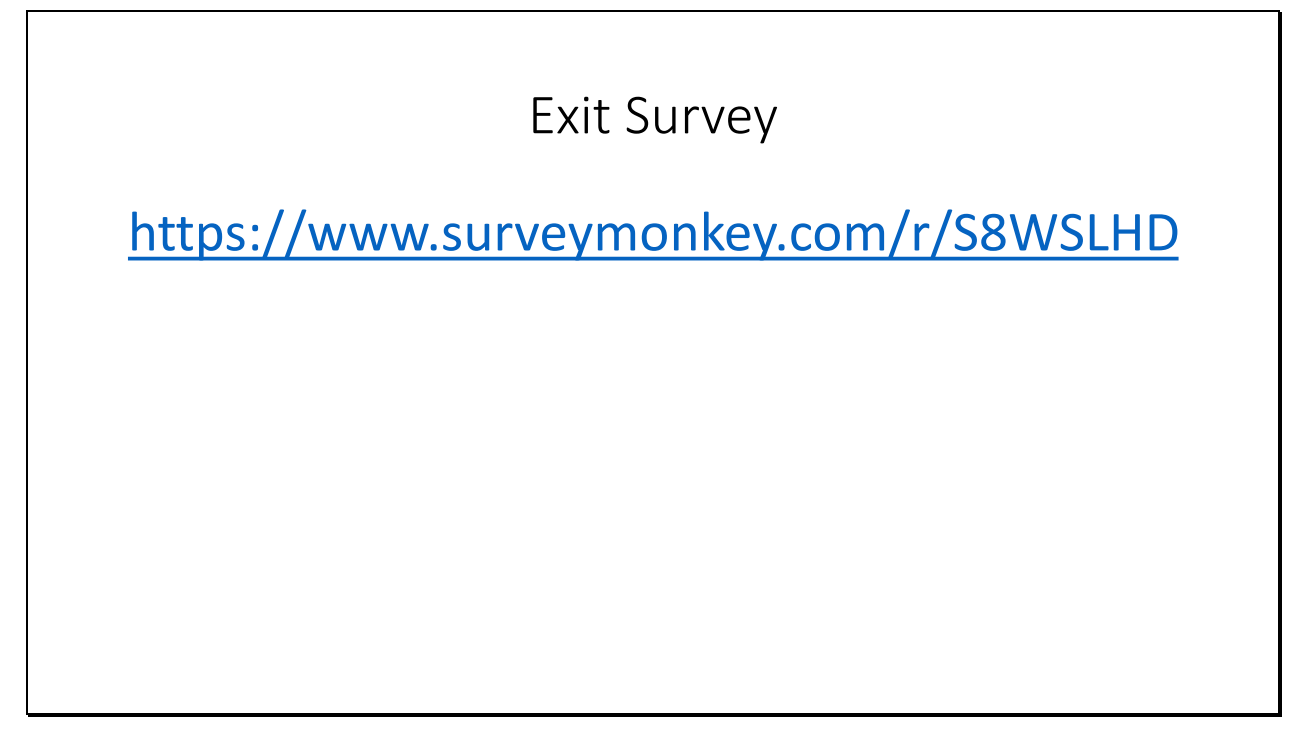

Thanks for your time and your hard work today! See everyone tomorrow at 8:00! 


\section{Day 2 Resources}

\section{Smartboard}

\section{Projector}

3. Table supplies: Slide printouts, teacher-laptops, chart paper, markers, highlighters

Day 2- Coteaching strategies and how teachers can move from complete pull out services to complete push in. Teachers will learn the different strategies associated with co-

teaching and will have time to collaborate with colleagues on ways to fully implement the strategy while meeting differentiation needs.

Objective- Introduce teachers to Co-teaching and provide a structure and support for future implementation. Help teachers find ways to implement differentiation within the coteaching format.

\begin{tabular}{|l|l|}
\hline $8: 00-8: 15$ AM & Teacher Arrival and Sign in, Welcome Back \\
\hline $8: 15-8: 30$ & $\begin{array}{l}\text { Turn and talk- Yesterday, we talked about differentiation and how } \\
\text { you could use components within the implemented curriculum. } \\
\text { What are some issues you see as barriers to implementing more of } \\
\text { differentiation in the classroom? } \\
\text { Share out responses and share out research findings from current } \\
\text { research within the research site. }\end{array}$ \\
\hline 8:30- 10:00 & Bhat is co-teaching? \\
\hline $10: 00-10: 10$ & Break \\
\hline $10: 10-10: 40$ & Video Clips of Co-teaching \\
\hline $10: 40-11: 40$ & $\begin{array}{l}\text { Take a closer look at co-teaching. Teachers will map out their } \\
\text { intended daily schedule by indicating pull out services for each } \\
\text { child. Make a new schedule to see what push-in services or } \\
\text { coteaching would look like. }\end{array}$ \\
\hline $11: 40-12: 00$ & Lunch \\
\hline $12: 00-1: 00$ & $\begin{array}{l}\text { Setting up the classroom, maintaining classroom management, } \\
\text { Rules, Methods of Discipline, Parity, Planning, and being self- } \\
\text { reflective. }\end{array}$ \\
\hline $1: 00-2: 00$ & Break \\
\hline $2: 00-2: 10$ & \\
\hline
\end{tabular}


Slide 22

\section{Day 2 \\ WELCOME BACK \\ How to Navigate Differentiated Instruction and Its Created Obstacles}

What challenges are presented with differentiation?

What is Co-teaching, and how can it be implemented?

Slide 23

\section{Schedule of the Day}

8:00- 8:15 Teacher arrive and sign in

8:15- 8:30 Turn and Talk- What are the barriers you see as you further implement differentiation in the classroom?

8:30- 10:00 What is Co-teaching?

10:00- 10:10 Break

10:10-10:40 Video clips of coteaching

10:40-11:40 Role Playing the different co-teaching strategies

11:40-12:00 Taking a closer look- Mapping out daily schedules and creating a new schedule including coteaching opportunities.

12:00- 1:00 Lunch

1:00- 2:00 Setting up the classroom, maintaining classroom management, Rules, Methods of Discipline, Parity, Planning, and being self reflective.

2:00- 2:10 Break

2:10- 3:00 Finish afternoon session as a continual of reflection and planning between coteachers 
Slide 24

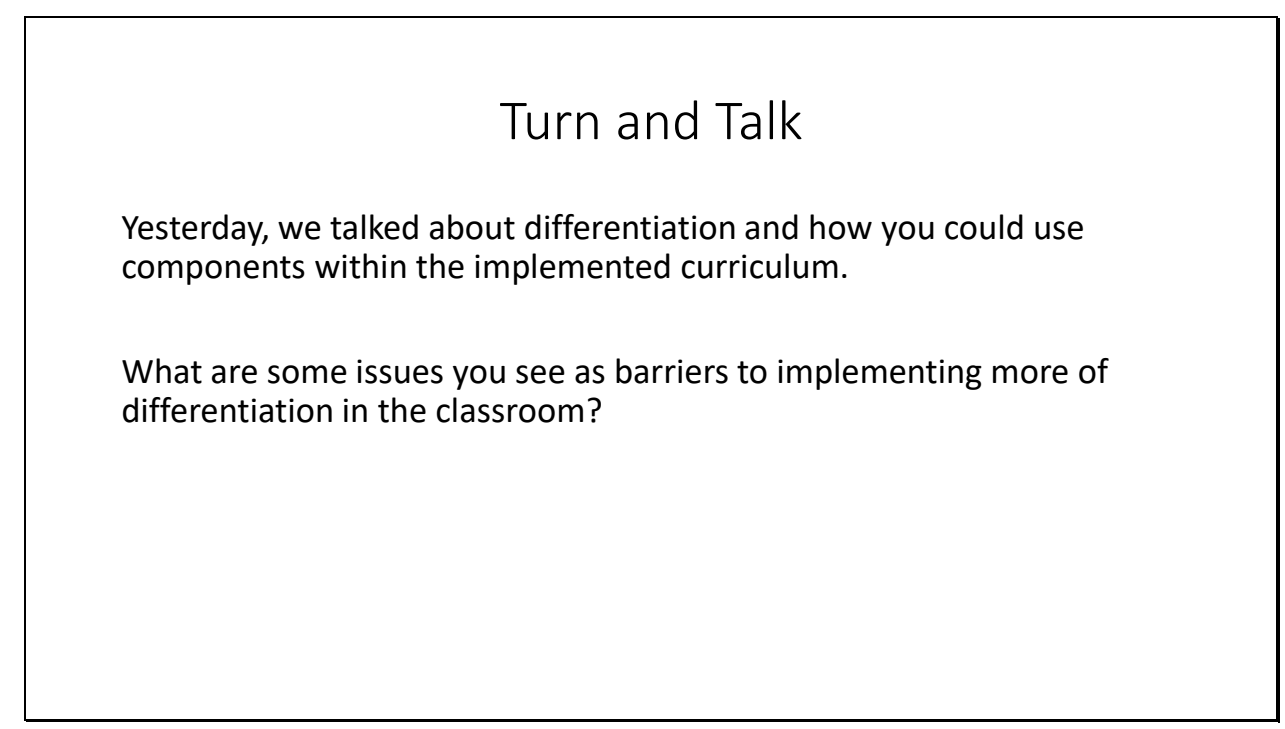

The facilitator to start the session off with this question. Turn and talk. (10 minutes) share ideas (5)

Slide 25

\section{Research Findings}

In a recent study within the research site, 5 out of 9 participants recommended coteaching as a coping strategy to help limit the amount of class disruptions occurring due to pull out services.

6 out of 9 participants said they relied on supplemental supports for differentiation needs

5 out of 9 participants indicated the supplemental support services that use pull out services are a hinderance to full differentiation implementation.

The facilitator will discuss research findings. 
Slide 26

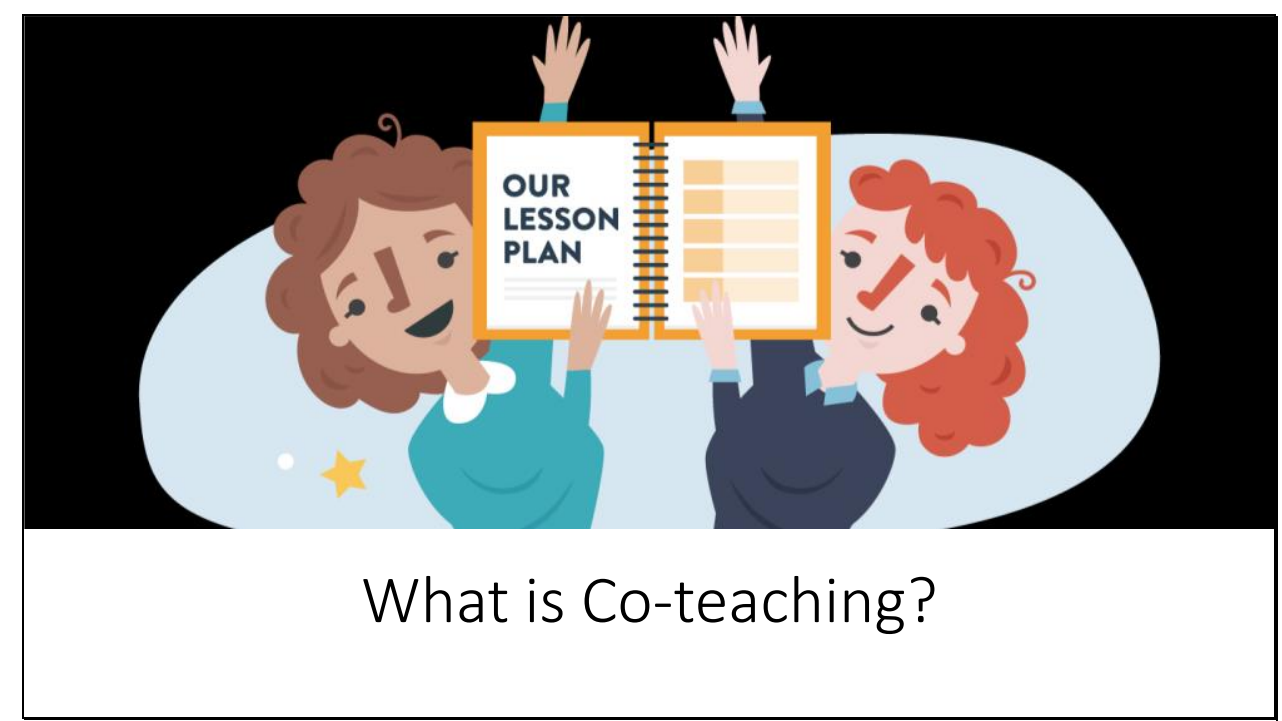

The facilitator will Instruct participants to turn and talk for 5 minutes then share out ideas.

Slide 27

Co-Teaching

Co-teaching is defined as two or more teachers working together with groups of students. They share responsibility for planning, delivery, and assessment of instruction, as well as the organization of the physical space.

Facilitator- Read the Slide 
Slide 28

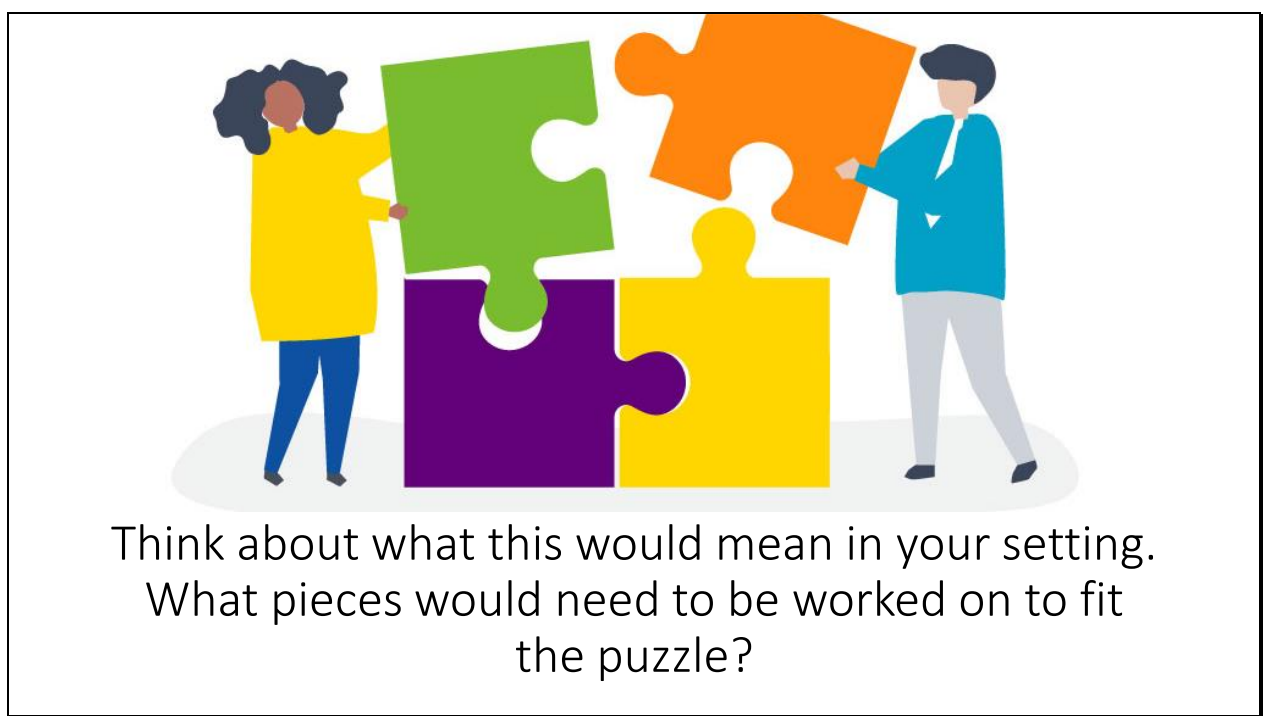

Facilitator- Ask the question, So what would this look like in your personal setting? What pieces would need to be worked on so that the pieces fit together? What are the pieces of coteaching? Personal reflection time- Ask participants to jot down some notes.

Slide 29

\section{Setting}

In most schools, schools have a plethora of support.

Title 1 Teachers

Tutors

Speech Teachers

Occupational Teachers

Special Education Teachers 
Facilitator- There are instances in schools that have many different instructional supports. Classrooms and schools also have a range of abilities. Take a second and jot down your individual supports your students receive in your classroom. Tally how many times students are pulled from your room and entering. Share with your table mates.

Slide 30

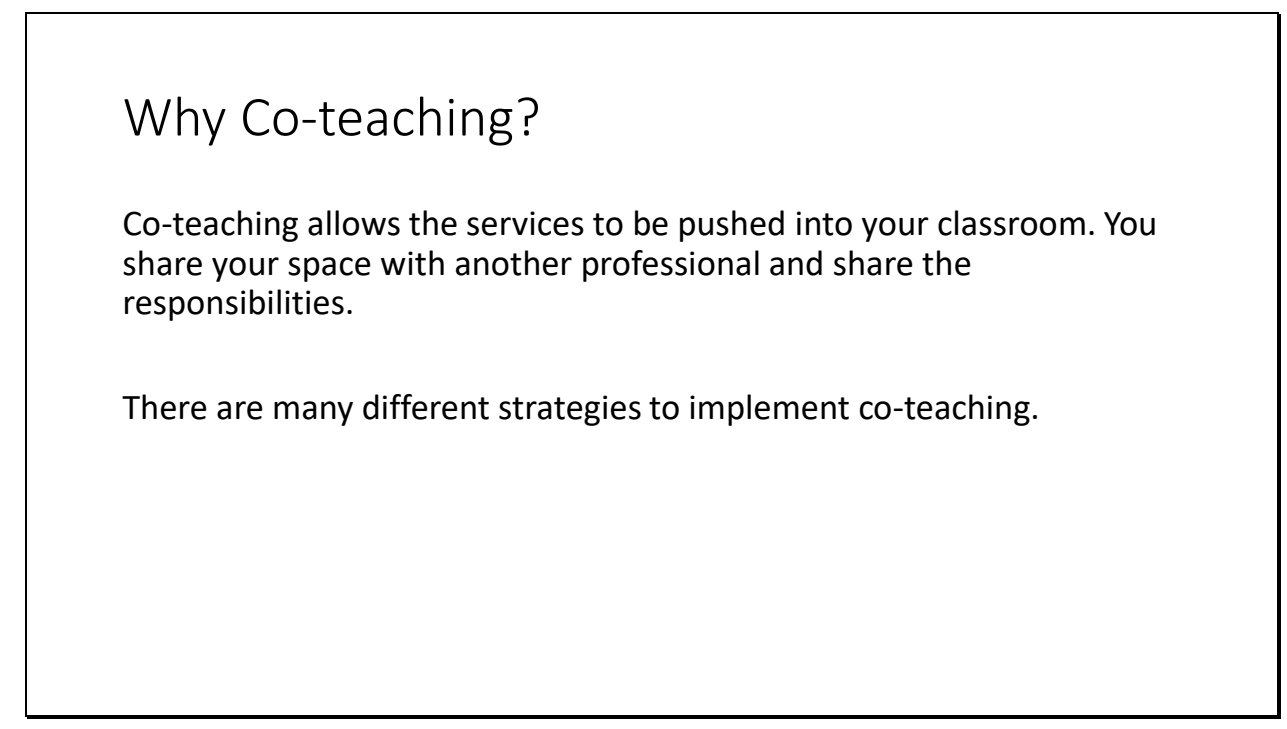

Facilitator- Why coteaching? Coteaching limits the number of pullout services a student receives allowing them to spend the maximum amount of time in the general education classroom. Not only does this limit distractions but it also benefits other students who would never receive the extra help. 
Slide 31

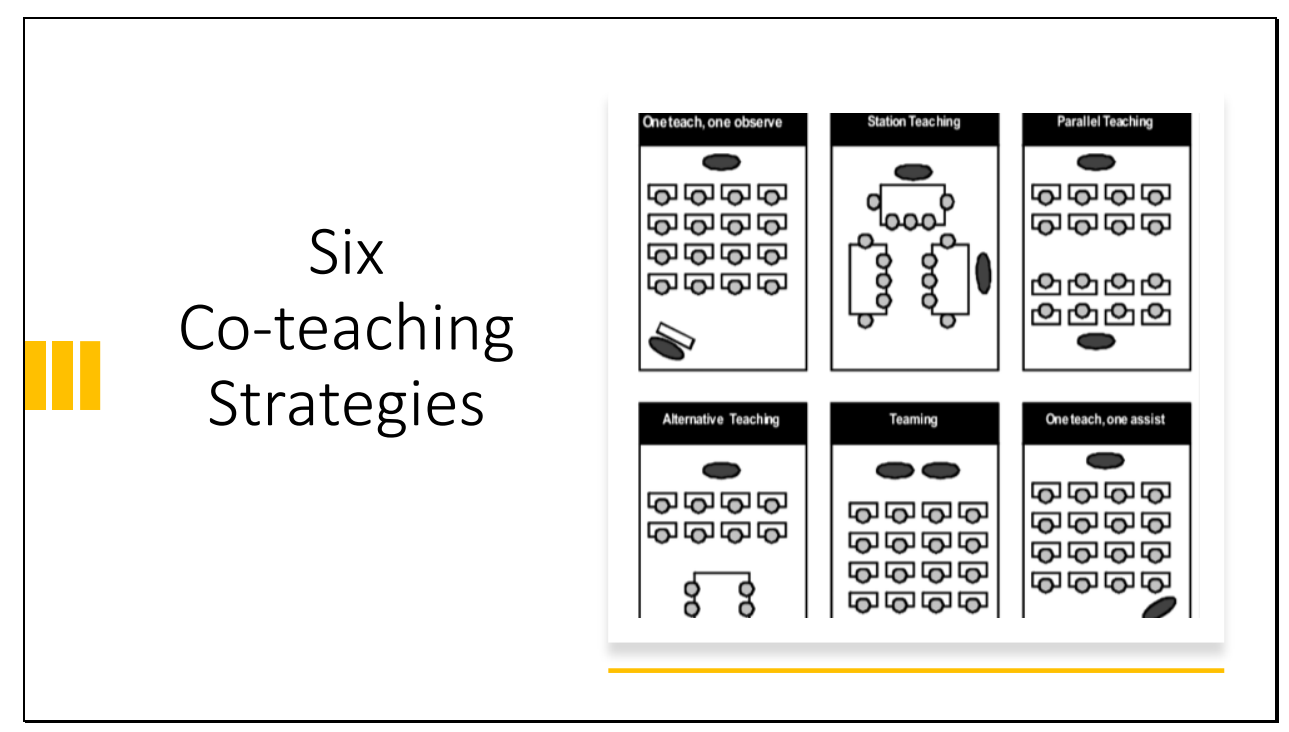

Facilitator- Let's look closely at what each diagram means.

Slide 32

One Teach, One Support is a co-teaching model where one teacher has the primary responsibility for delivery whole-class instruction while another teacher assists students with their work and maintaining expected behaviors.

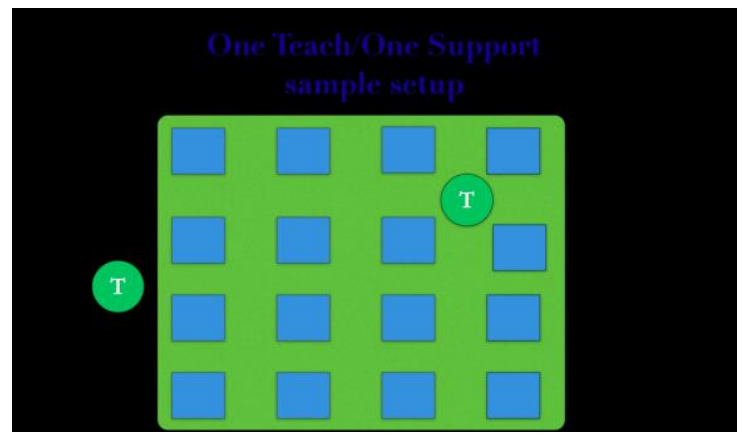

The facilitator writes one teach, one supports on a large poster paper and draws the seating diagrams. She then holds a discussion when this would be most appropriate. Examples: When behavior is an issue when one teacher is stronger than an area than another when students might need the extra one on one support with staying on task. 
Slide 33

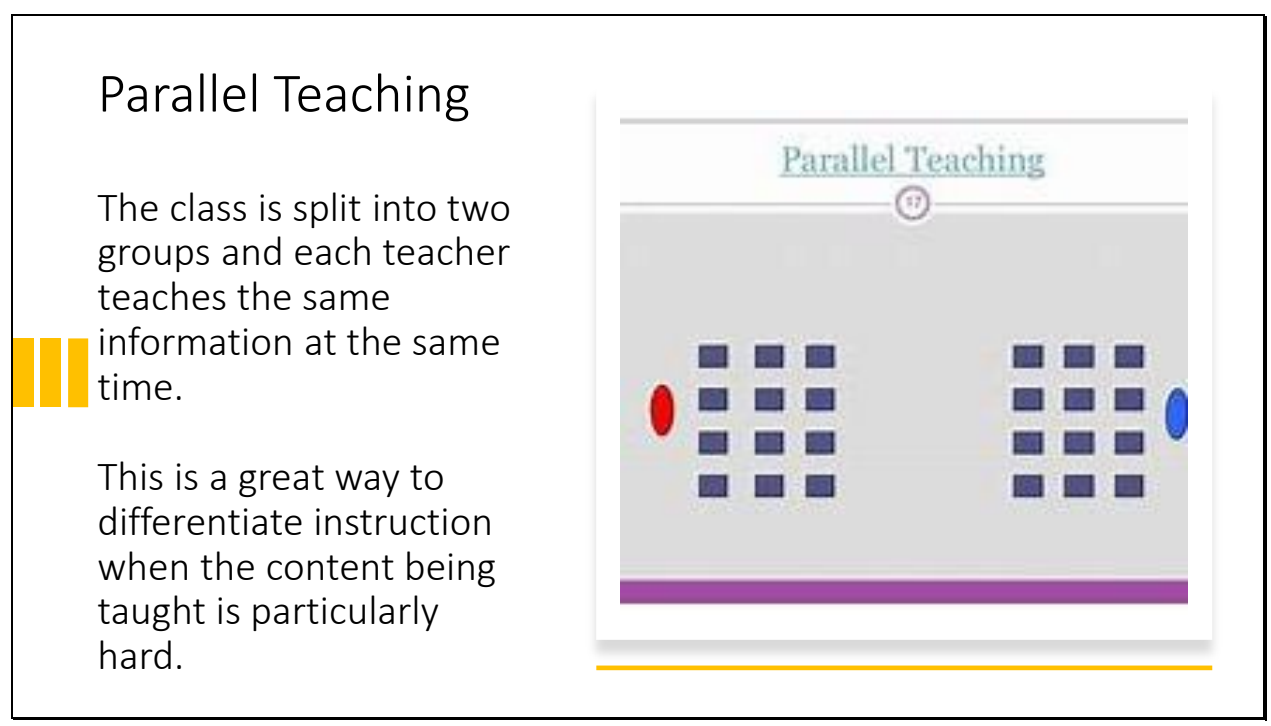

Parallel Teaching- Students can benefit from learning difficult material in a smaller group. This can be a great way to start co-teaching. You and your coworker plan together to make sure you're covering the same material. Because you are teaching your own half of the class, you feel less observed by your colleague.

Slide 34

Team Teaching

Both teachers are in the room at the same time but takes turn teaching the whole class.

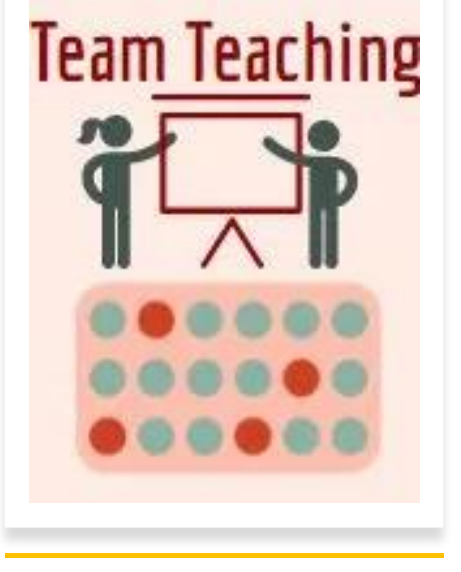


In team teaching, both teachers are in the same room at the same time but take turns teaching the whole class. Team teaching is sometimes called "tag-team teaching". You and your co-teacher are alike co-presenters. You don't plan who takes which part of the lesson. The others can jump in and elaborate if needed. This style can make you feel vulnerable. This opens you up to allow judgment from another person but also allows you to learn about and improve your own teaching.

Slide 35

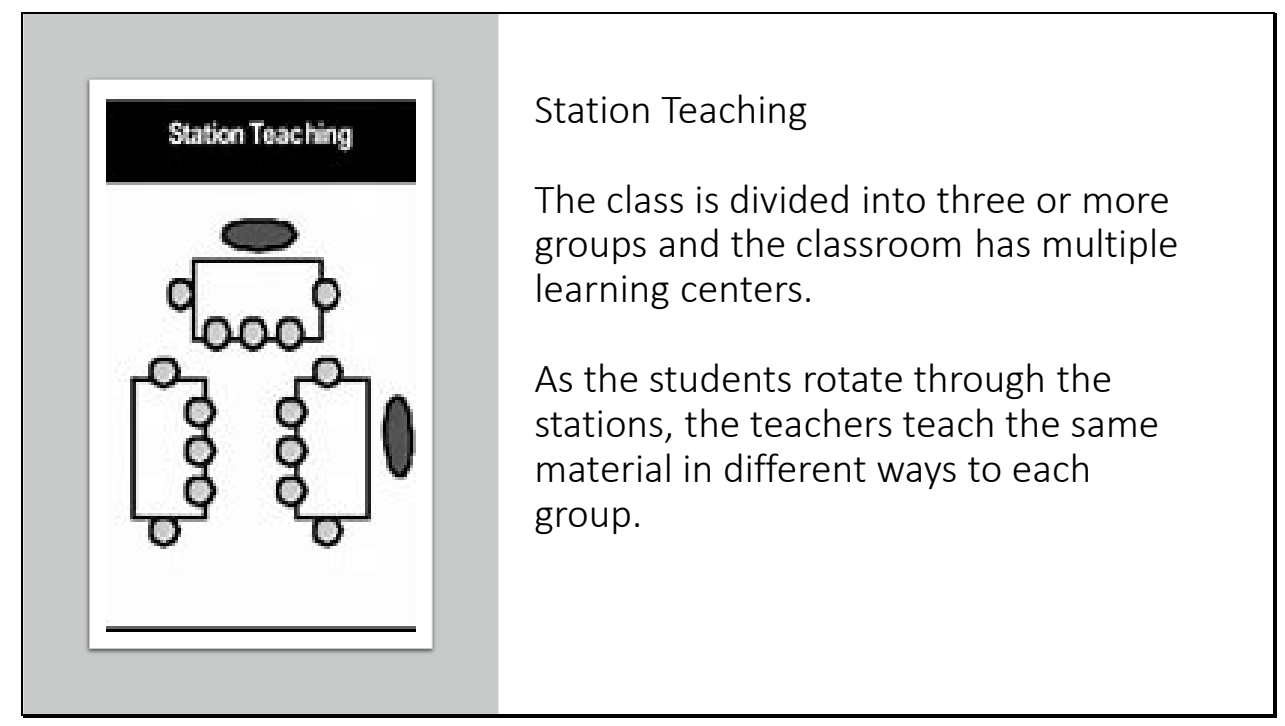

Facilitator- The class is divided into three or more groups and the classroom has multiple learning centers. As the students rotate through the stations, the teachers reach the same material in different ways to each group. Both you and your co-teacher are responsible for planning and teaching an in-depth concept that helps meet the overall lesson goal. 
Slide 36

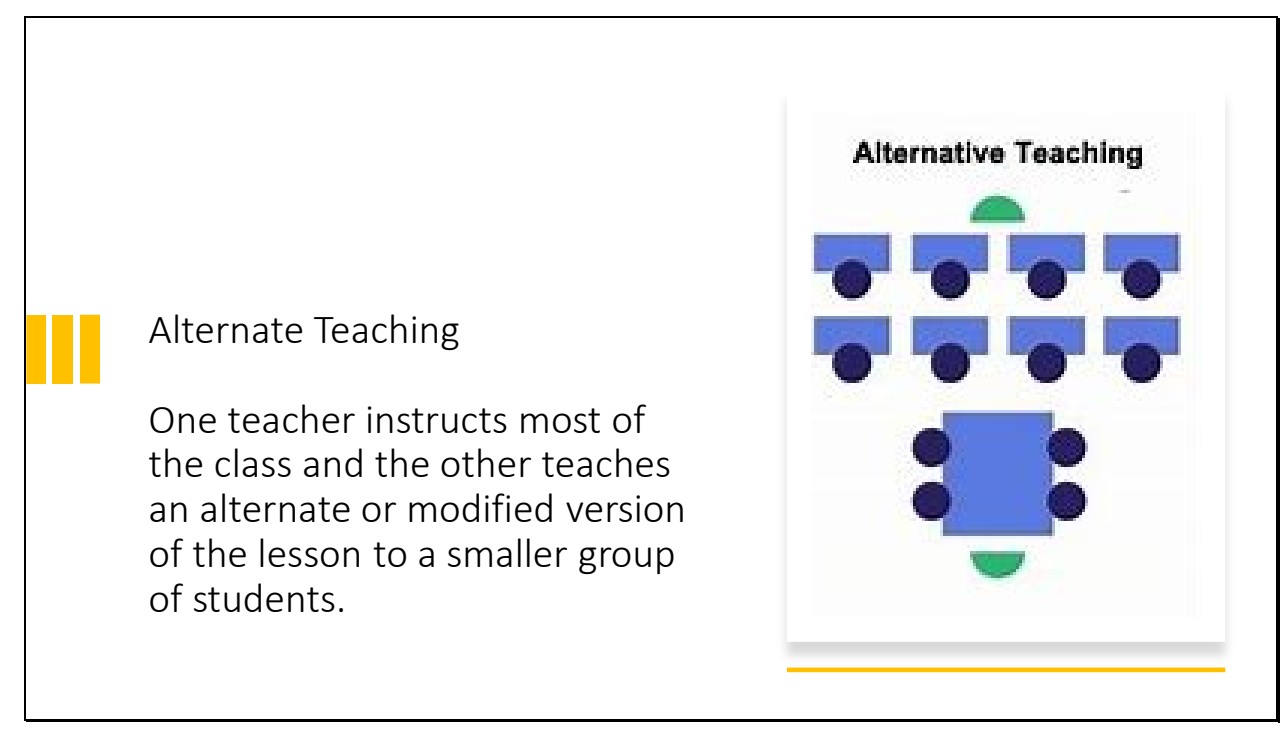

In alternative teaching, one teacher instructs most of the class and the other teacher teaches an alternate or modified version of the lesson to a smaller group of students. Small groups are often put together based on students learning needs.

Slide 37

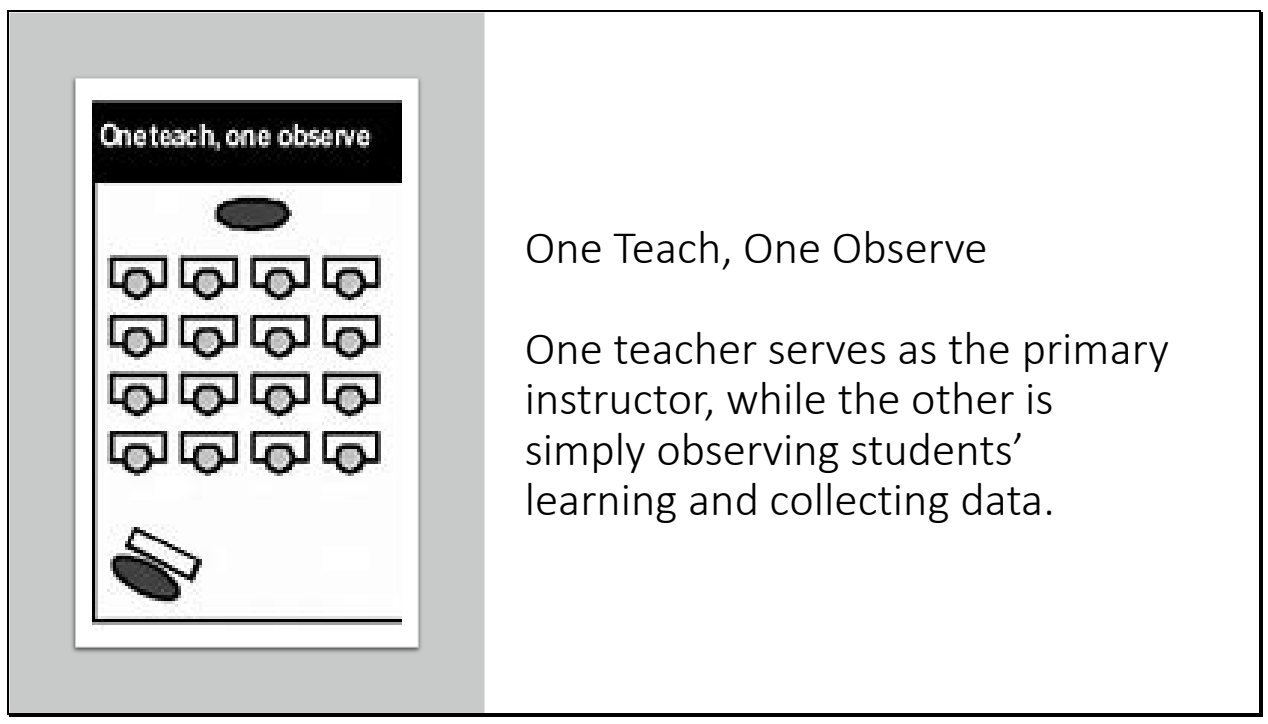


Facilitator- Read Slide. This can be used for determining what instruction takes place next.

Seeing which students need additional help. Deciding what co-teaching model may be used next to address any identified needs. Identifying and tracking helpful school services such as IEP, 504 plans, functional behavioral assessments, behavior intervention plans, or response to intervention.

Slide 38

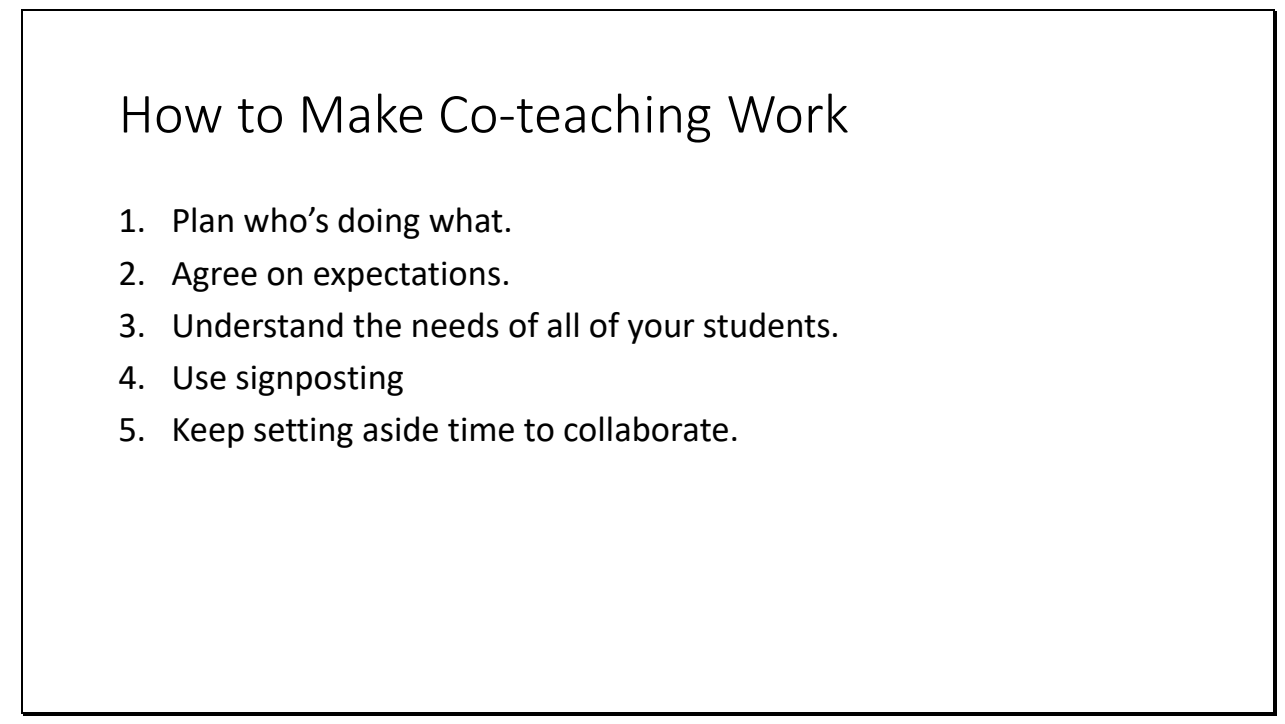

Co-teaching has benefits but it can also be challenging to implement. Here are some suggestions. 1. Plan who's doing what. No matter which strategy you use, you need to have a plan of responsibilities. 2. Have a conversation before the year begins about your expectations for students, behavior, homework, bathroom use..etc. Avoid the good cop bad cop situation that might arise. 3. Understand the needs of all of your students. Both you and your co-teacher should understand the needs of all of your students, including those who learn and think differently. This creates a shared responsibility for meeting accommodation goals. 4. Use signposting. Make sure both of your names appear on the door or assignments which helps students see you as a team. 5 . Keep setting aside time to collaborate. Planning and reflecting on the lessons you teach together is especially important. Keep lines of communication open, raising concerns respectfully, and having a supportive and involved administrator can help bridge any gaps. 
Slide 39

\section{Let's Take a Break!}

Slide 40

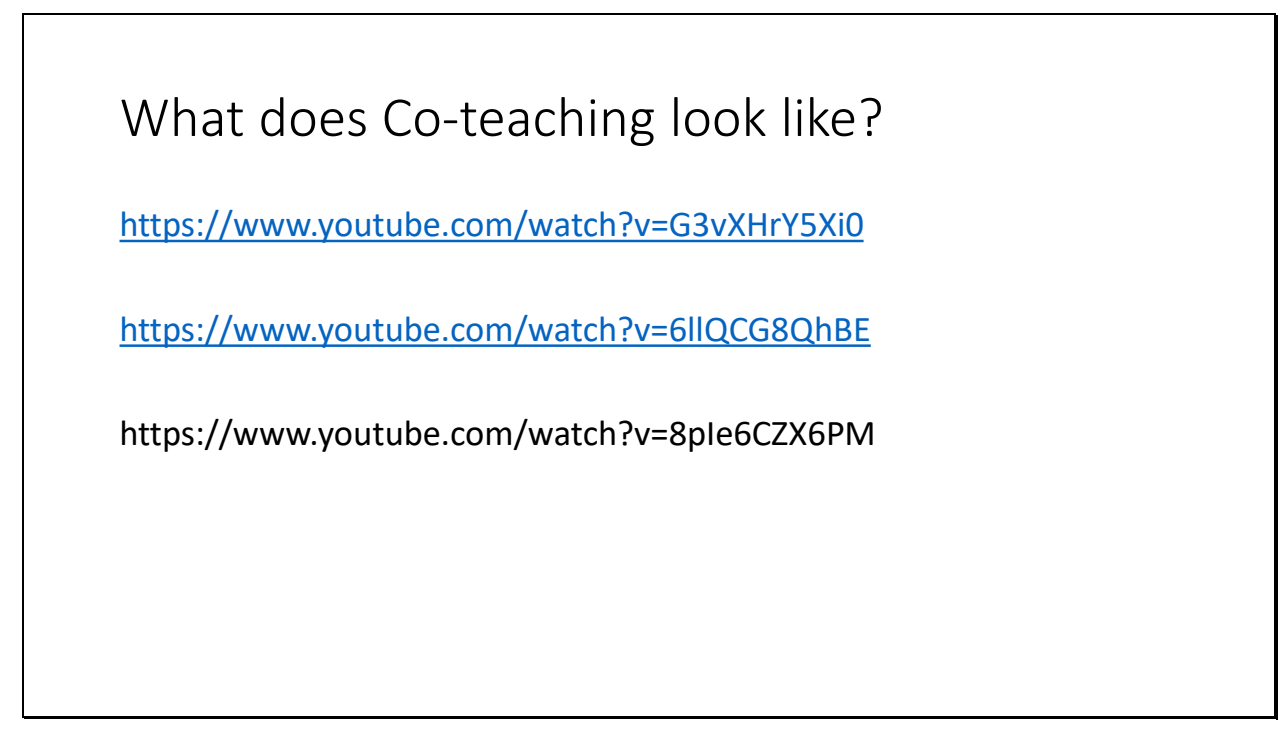

Facilitator- We are going to watch a few short clips of co-teaching in action. Take note of which model you think is being used. Also, note any benefits you see or further questions you may have. Share observations and questions 
Slide 41

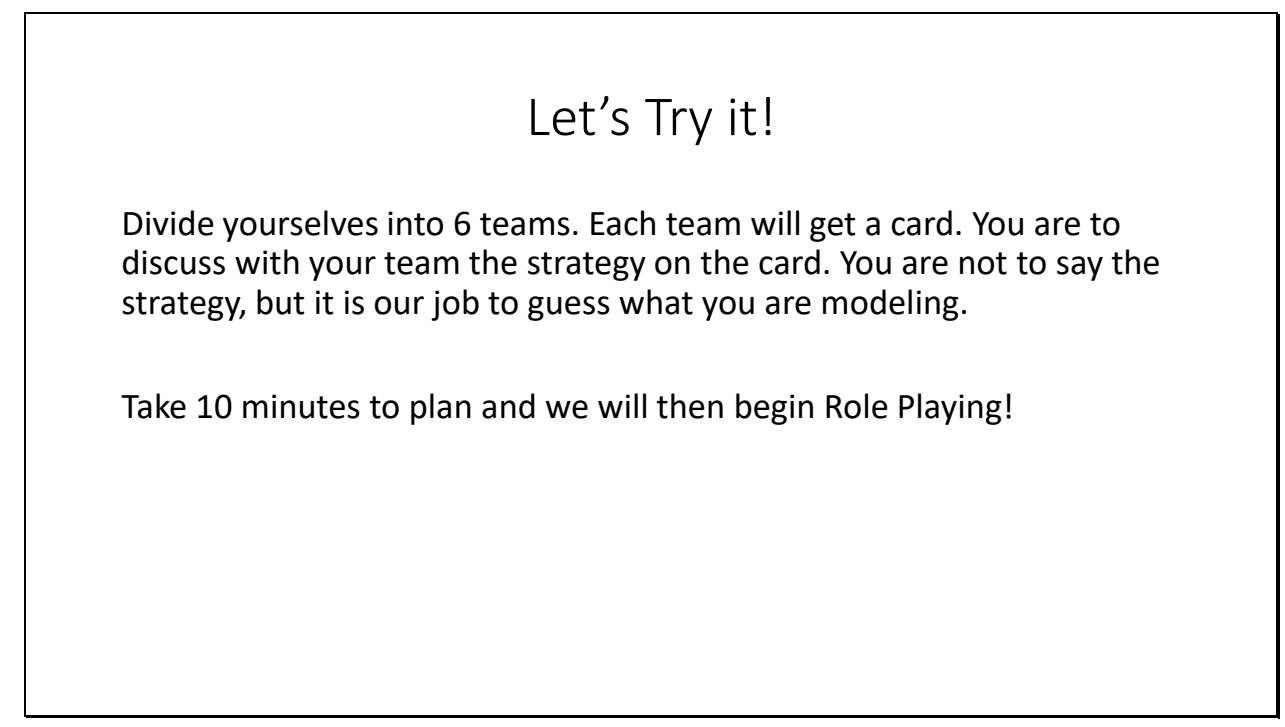

Facilitator- Divide yourself into six teams. Next, each team is going to get a card. Discuss with your group how to model the strategy. Do not say the strategy as it is for the rest of the audience to guess the strategy being implemented. Groups are divided and given cards. Groups are given 10 minutes to plan and they are to act out their strategy with the remaining participants deciding which strategy is being displayed.

Slide 42

\section{Co-teaching Strategy 1}

One Teach, One Observe. There is a general education teacher and a special educator in the room. The general education teacher is at the front of the room demonstrating how to multiply two digit by two digit problems while the special educator is sitting off to the side. 
Slide 43

\section{Co-teaching Strategy 2}

One Teach, One Assist

The general education teacher is at the front of the classroom teaching how to classify shapes based on the number of sides while the other teacher is walking around the room keeping students on task.

Slide 44

\section{Co-teaching Strategy 3}

Parallel Teaching

The class is split in half. The topic of discussion is multiplying by 10 . 
Slide 45

\section{Co-teaching Strategy 4}

Station Teaching

Students are divided into three groups. The objective of the stations is to teach students how to subtract three digit by three digit numbers.

Slide 46

\section{Co-teaching Strategy 5}

Alternative Teaching

There are a group of students who are really struggling starting their opinion writing on climate change. The general education teacher stays with the larger group while the smaller group of students are pulled aside into a small group setting. 
Slide 47

\section{Co-teaching Strategy 6}

Team Teaching

Two teachers are at the front of the room reading over the story of the week. Both must share responsibilities and share instructional time.

Slide 48

\section{Lunch Time}

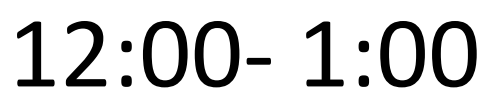


Slide 49

\section{Afternoon Session}

1:00- 2:00 Setting up the classroom, maintaining classroom management, Rules, Methods of Discipline, Parity, Planning, and being self reflective.

2:00- 2:10 Break

2:10- 3:00 . With Support Services, discuss "Best Practices in Coteaching" handout including areas in Co-planning, Co-classroom management, $\mathrm{Co}$-instruction, Co-behavior management, and Coassessment.

Slide 50

\section{It's time to mix it up!}

General education teachers, please seat yourself with the support services that serve your room.

Get to know your co-teachers personally and professionally.

Conversation starters:

What are your hobbies? What are your pet peeves? What is your teaching style? How would you like to be approached when a problem arises?

Facilitator- For teachers to work harmoniously together, we first should see each other as equals. Take 5 minutes and get to know your co-teachers both personally and professionally. 
Slide 51

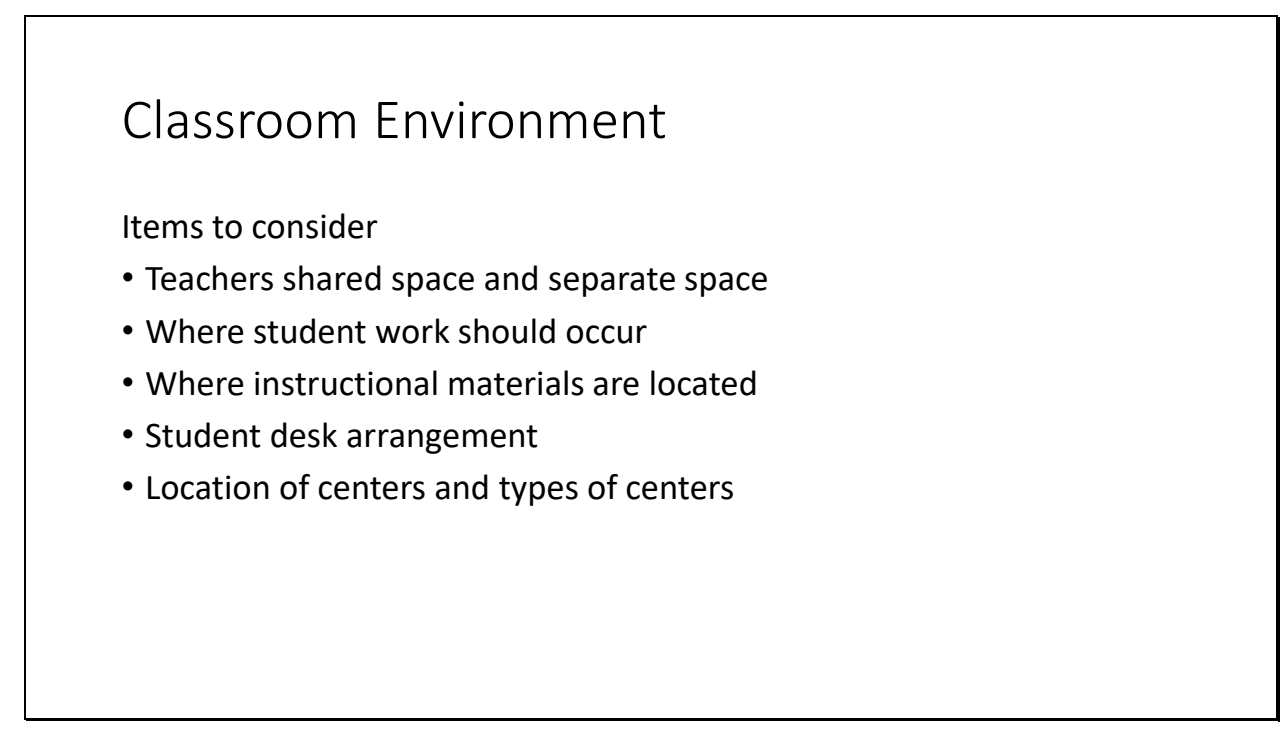

Facilitator- Both teachers in the room should have a say on classroom decisions. With your coteachers consider the following and come up with a plan. Where will each teacher's separate area be in the classroom and where will be shared space be. Where will students work to be displayed and collected? Where will instructional materials be located? How will students desks be arranged? What kinds of centers will be used and where will they be located? Keep in mind the types of co-teaching strategies that can be used and the ones that you wish to implement. This determines the setup and types of fluidity you want in your room.

Slide 52

\section{Establishing, Implementing, and Maintaining Classroom Management}

You should consider the following:

- Organization of student information

- Planning and implementing daily routines

- Rules that facilitate classroom management and routines

- Classroom management discipline 
As you can see, many decisions need to take place before co-teaching is implemented. There should be a shared decision on many components if you are sharing your classroom $100 \%$ of the time with another teacher. While this isn't always the case, the general education teacher should make the decisions and discuss their ideas with their co-teachers. If there is something that isn't understood or something you don't agree with, you should discuss this with your partner teacher. To establish, implement, and maintain classroom management teachers should have a shared system for keeping records of student information and monitoring student progress. Planning and implementing daily routines should be discussed. These can include morning routines, walking in the hallway, bathroom breaks, student jobs, and transitioning between subjects. Both teachers should collaborate regarding their expectations for their classroom rules. These expectations should address being student-centered, written in simple terms, 3-5 established rules, visibly posted, both responsible for implementing rules, and all stakeholders should be aware of the expectations.

Take 10 minutes and work through these topics with your co-teachers.

Slide 53

\section{Methods of Classroom Discipline}

Both teachers need to discuss their philosophy on discipline and develop a standard discipline plan. This needs to be implemented consistently.

An example: Positive Behavior Interventions Supports (PBIS)

Rainbow Ladder-Students move their clips up or down

Table Points- Each table can earn points

Tickets or Dollars

Class Points

Classroom management is key in any grade, but it's essential in elementary school. Both teachers should be invested in the program and knowledgeable of classroom rules and consequences.

Take 5 minutes and talk this over with your co-teachers. 
Slide 54

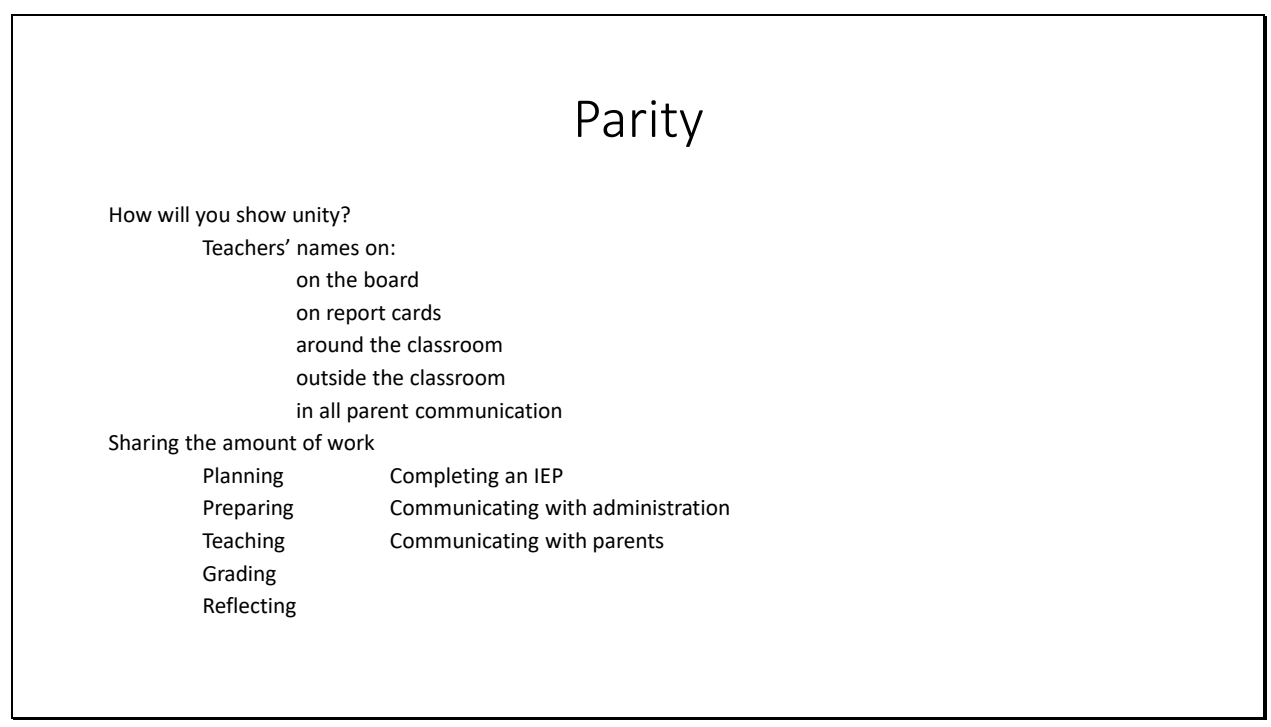

Both teachers should be viewed as equals among the school community. Parity will be accomplished once both teachers share roles and responsibilities within the classroom. Both should be recognized as the classroom teachers. It is important for parity to be established so all students' needs will be met comfortably.

How will these topics be addressed? Take 10 minutes and discuss these topics.

\section{Slide 55}

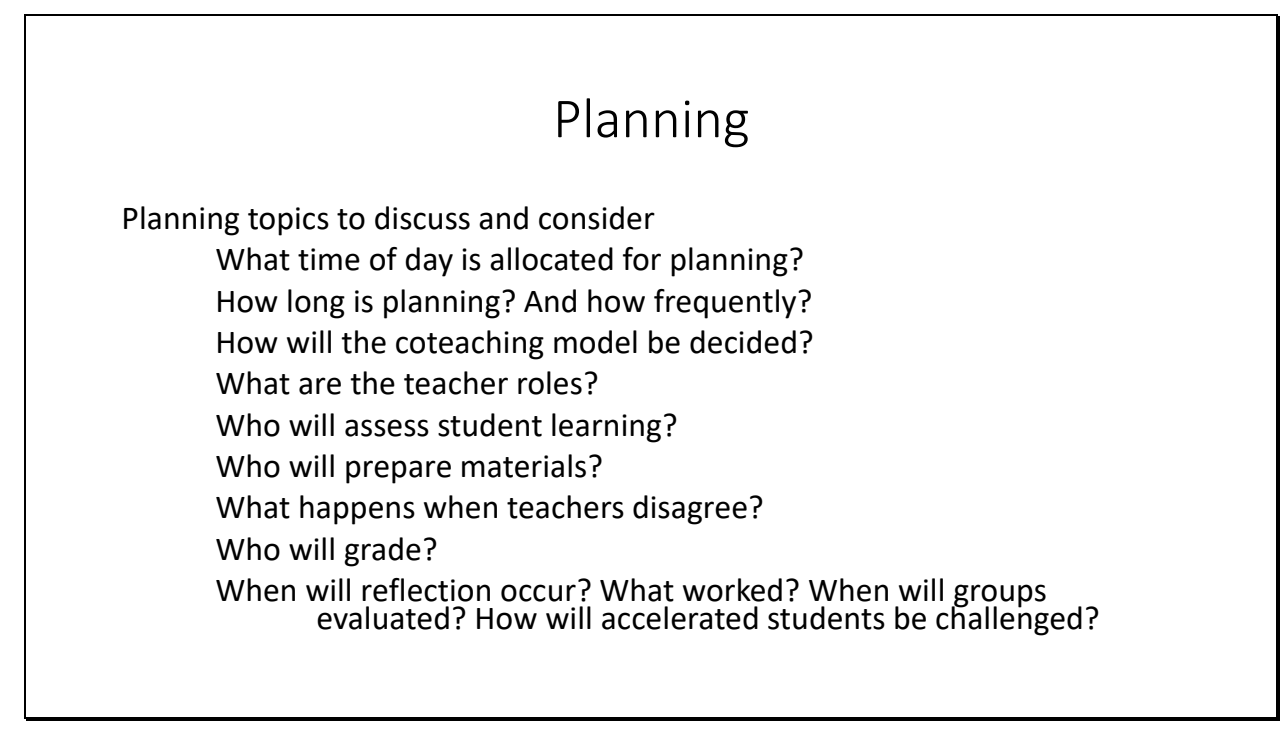


Planning is an ongoing process throughout the school year. Before the school year is a great time to find a common planning time that will work for both teachers. Once the planning time is established, this time should be shared with the staff so that they recognize and acknowledge that this time should not be interrupted. After each teaching session, both teachers need to reflect on the lesson and assess student learning.

Slide 56

\section{Reflection}

After spending the day considering Coteaching, how would it help or hinder your ability to implement differentiation in ELA and mathematics?

The facilitator poses the question and takes responses. 
Slide 57

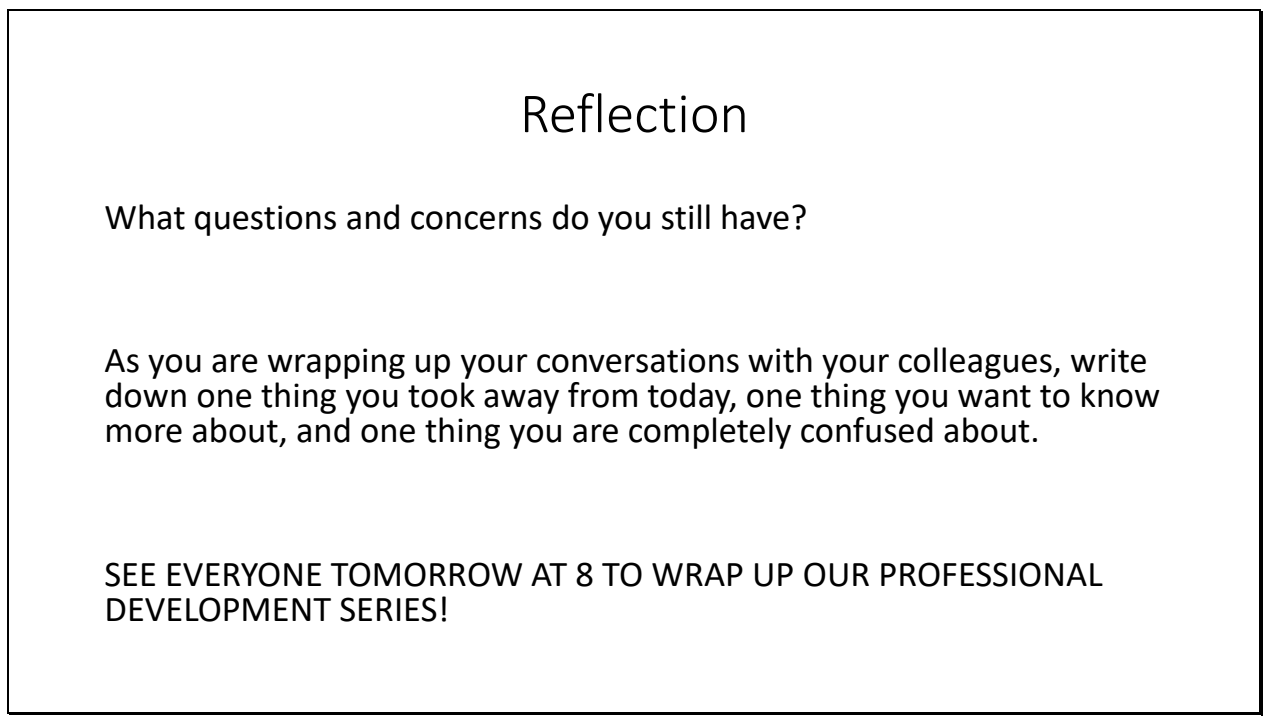

The facilitator takes notes of questions and concerns to be addressed at the next professional development meeting and to adjust professional development for future presentations. 


\section{Day 3 Resources}

1. Smartboard

2. Projector

3. Speakers

4. Table supplies: Slide print-outs, pens, markers, teacher laptops, chart paper

Day 3: Alternative Instructional Support

Objective: Teachers will know alternative instructional support practices as they continue their professional development on differentiation and coteaching strategies.

\begin{tabular}{|l|l|}
\hline 8:00- 8:15 & Teacher sign in and seating \\
\hline 8:15- 9:00 & $\begin{array}{l}\text { Reflection and recap on the past two days of the program. A brief } \\
\text { overview of research about differentiation, co-teaching, and } \\
\text { instructional feedback. }\end{array}$ \\
\hline 9:00- 10:00 & $\begin{array}{l}\text { Instructional supports- How does it tie into differentiation and } \\
\text { coteaching, what supports are currently provided, and what are } \\
\text { some alternative ways you can continue developing as an educator. }\end{array}$ \\
\hline 10:00- 10:10 & Break \\
\hline 10:10- 11:00 & $\begin{array}{l}\text { Continue instructional supports presentation.- 6 Strategies Learning } \\
\text { walks, peer to peer, video feedback, expert coaching, principal } \\
\text { walk, co-planning, interview/ survey students }\end{array}$ \\
\hline 11:00- 12:00 & $\begin{array}{l}\text { Video examples of alternative instructional supports to follow the } \\
\text { explanation of each strategy. }\end{array}$ \\
\hline 12:00- 1:00 & Lunch \\
\hline 1:00- 2:00 & Role-Playing alternative instructional supports scenarios \\
\hline 2:00- 3:00 & $\begin{array}{l}\text { Collaboration and Preplanning for instructional supports and } \\
\text { continued professional development }\end{array}$ \\
\hline
\end{tabular}


Slide 58
Day 3
How to Navigate Differentiated Instruction and Its Created Obstacles

Alternative Instructional Supports

Slide 59

\section{Reflection on Professional Development}

Day 1: Differentiated instruction

Day 2: Co-Teaching

Day 3- Alternative Instructional

Supports

Day 1 of the professional development training consisted of the components of differentiated instruction and how teachers can easily implement these components into their county wide mandated curriculum. 
Day 2 looked at obstacles heterogeneous classrooms create and teachers perceived barriers to the implementation of differentiation. Co-teacher was identified as a strategy that could be implemented to ease burdens set forth by DI.

Today, Day 3 will discuss the topic of alternative instructional supports.

Slide 60

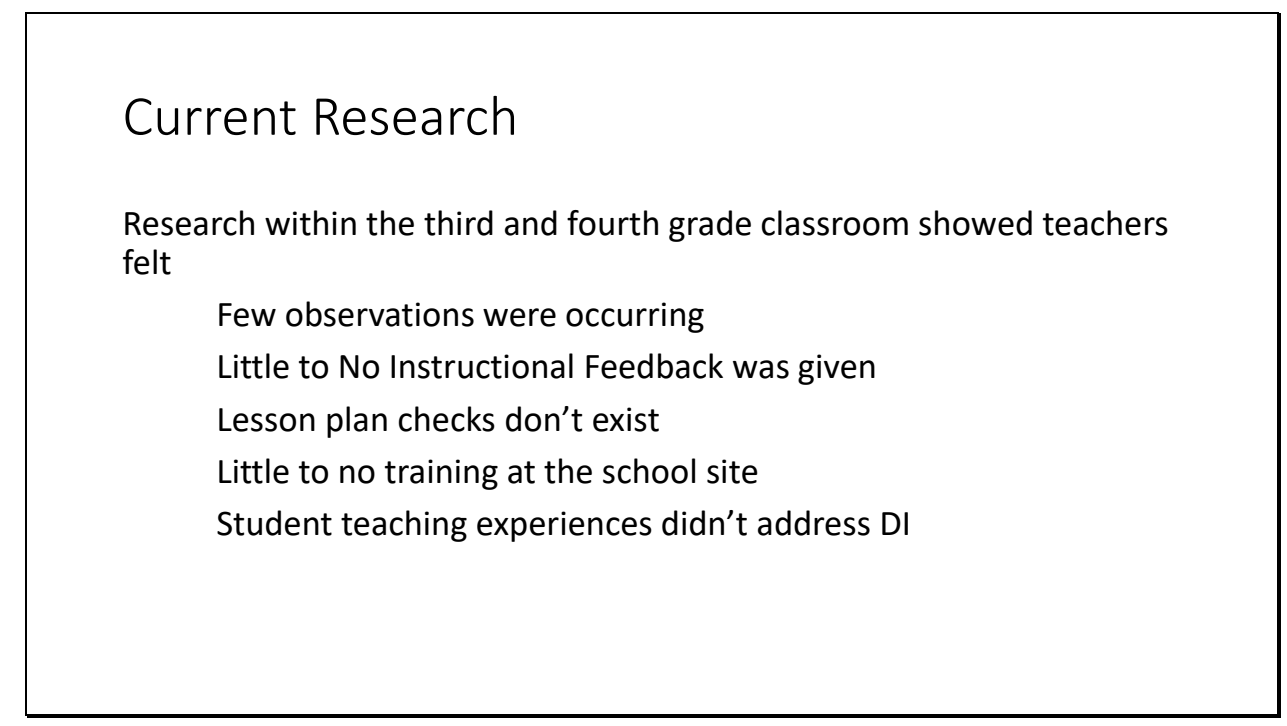

Slide 61

\section{What is instructional support?}

Research (Visible Learning, Hattie, 2009) indicates a key factor in changing/improving complex human skills such as teaching is "actionable performance feedback" (effect size of .79) From sports, to the arts, to business we devote untold time and creative energy to figuring out how to provide useful productive feedback thus improving performance. 
Facilitator- Research (Visible Learning, Hattie, 2009) indicates a key factor in changing/improving complex human skills such as teaching is "actionable performance feedback" (effect size of .79) From sports, to the arts, to business we devote untold time and creative energy to figuring out how to provide useful productive feedback thus improving performance. What's going on in our schools? While everyone is overworked with not enough time in their schedules, today's professional development will provide alternative ways to continue growing as professionals as we explore differentiation further and experiment with co-teaching.

Slide 62

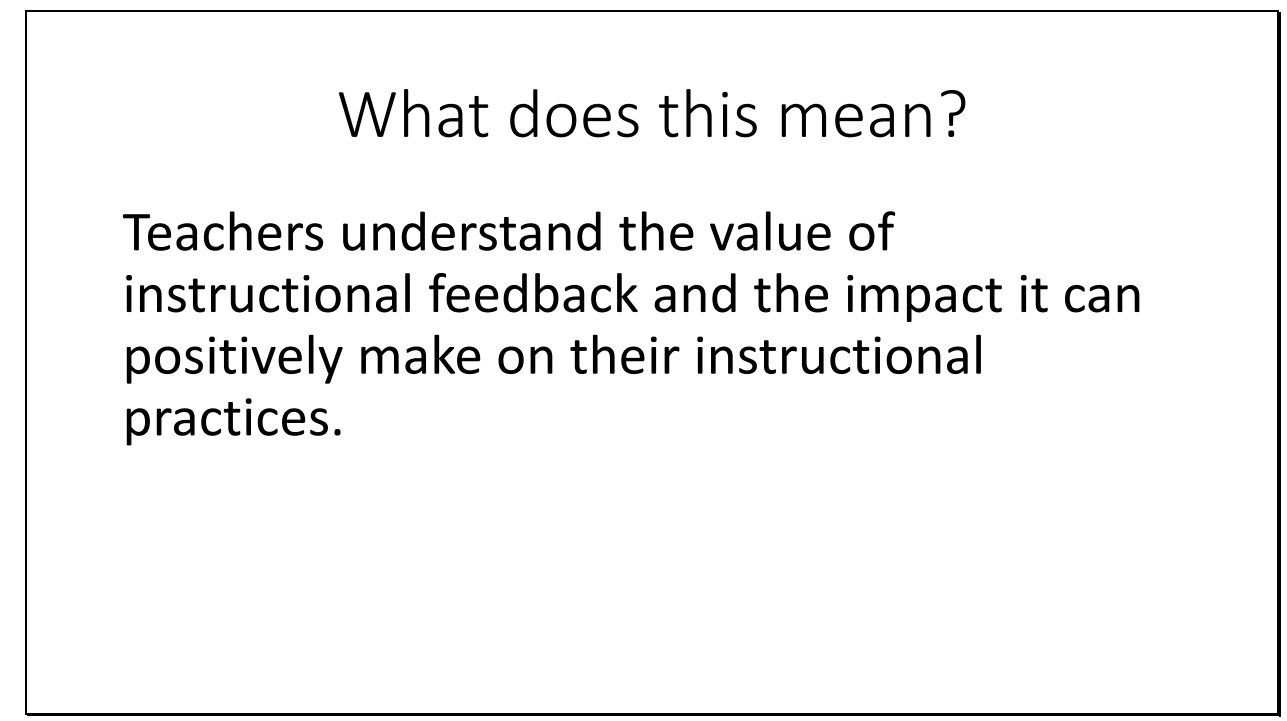

Pose the question- In what ways are you currently receiving instructional feedback?

Turn and Talk 
Slide 63

\section{How does this tie into differentiation and co-teaching?}

Differentiation is a best practice used by teachers to meet the needs of all of their students.

Co-teaching is a strategy that teachers can use to share classroom responsibilities. More than one teacher would be help accountable for student learning and less students would be pulled from the general education classroom to receive remediation services.

Instructional Support is needed as teachers continue to develop their skills. What they are doing correctly, what they can improve on, and ideas for new strategies can be shared to enable continued professional development.

Slide 64

\section{Let's Take A Break}


Slide 65

\section{What can teachers do to improve their instruction through instructional feedback?}

7 Alternative Instructional support strategies for teachers:

1. Learning Walks

2. Peer to Peer

3. Video Feedback

4. Expert Coaching

5. Principal Walk

6. Co-planning

7. Interview/survey students

Slide 66

Before walks occur, teachers must all be aware of school-wide implemented observation norms.

1. Teachers who are observing should be objective in their evaluations and never critical to hurt someone's feelings.

2. Feedback should be actionable- Provide suggestions that teachers can take immediately to improve their instructional practice.

3. Always point out the good you see too! 
Slide 67

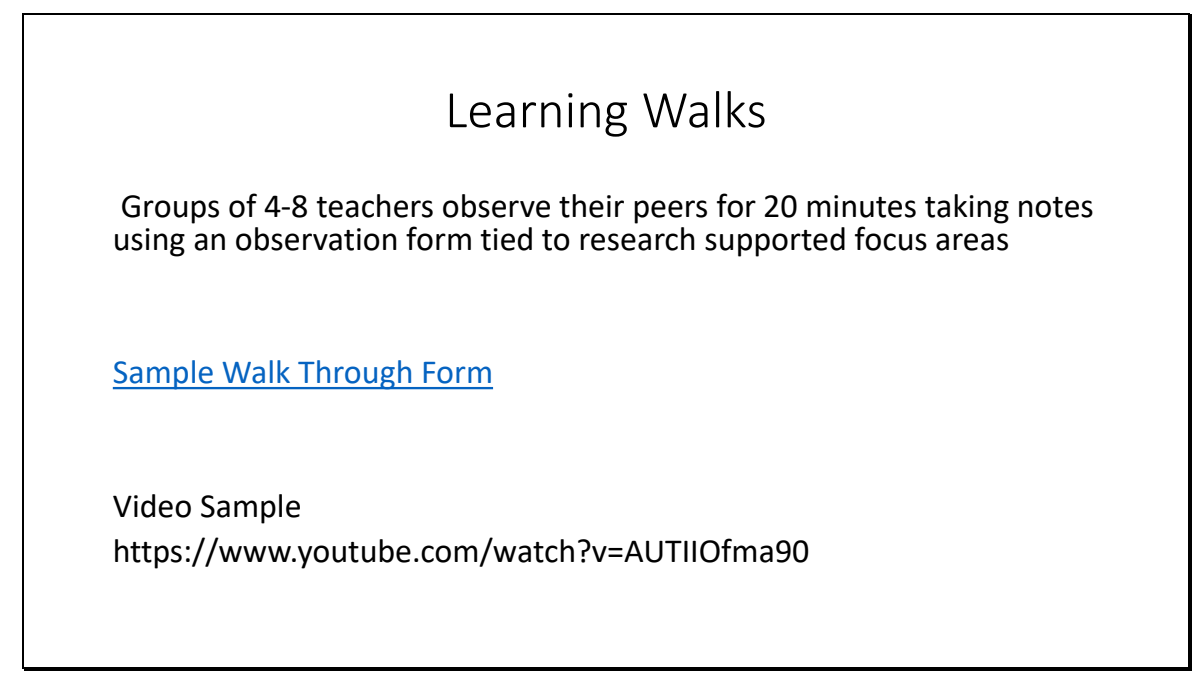

The purpose of a School-wide learning walk is to obtain a quick snapshot of each classroom in order to collect evidence based on a specific focus to improve instruction and learning as well as opening up opportunities for collaboration.

Learning walks should occur during each team's designated planning time. Members of the walk can interact with the teacher and or students if it does not interrupt instruction. Each observation should last 8-10 minutes and include a brief 4-5 minute debriefing after each observation. A copy of the form either print out or digital should be shared with the observed teacher.

A sample form has been attached. The observation form should reflect what is being worked ondifferentiation and coteach.

Let's watch the video to see an example of learning walks. 
Slide 68

\section{Peer to Peer}

Teachers choose a learning partner within or across their grade/content area and observe 20-30 minutes using the same observation form from Learning Walks.

These forms of instructional feedback can be used as informal talking points during PLC's while providing informal feedback to teachers.

The format of the Learning Walks and Peer to Peer are very similar.

Let's practice giving back supportive but actionable feedback.

Slide 69

\section{Peer observation: a role play}

A: Imagine you were the teacher in the video. Listen to your colleagues feedback. Be aware of your own intellectual and emotional reactions

B:Give feedback to your colleagues based on your notes. Be aware of the facts, inferences, suggestions, and opinions you are communicating. Be cautious with your wording. 
Pair up with a partner. Role-play the scenario and switch. How did it make you feel to give feedback and how did it feel receiving it?

Slide 70

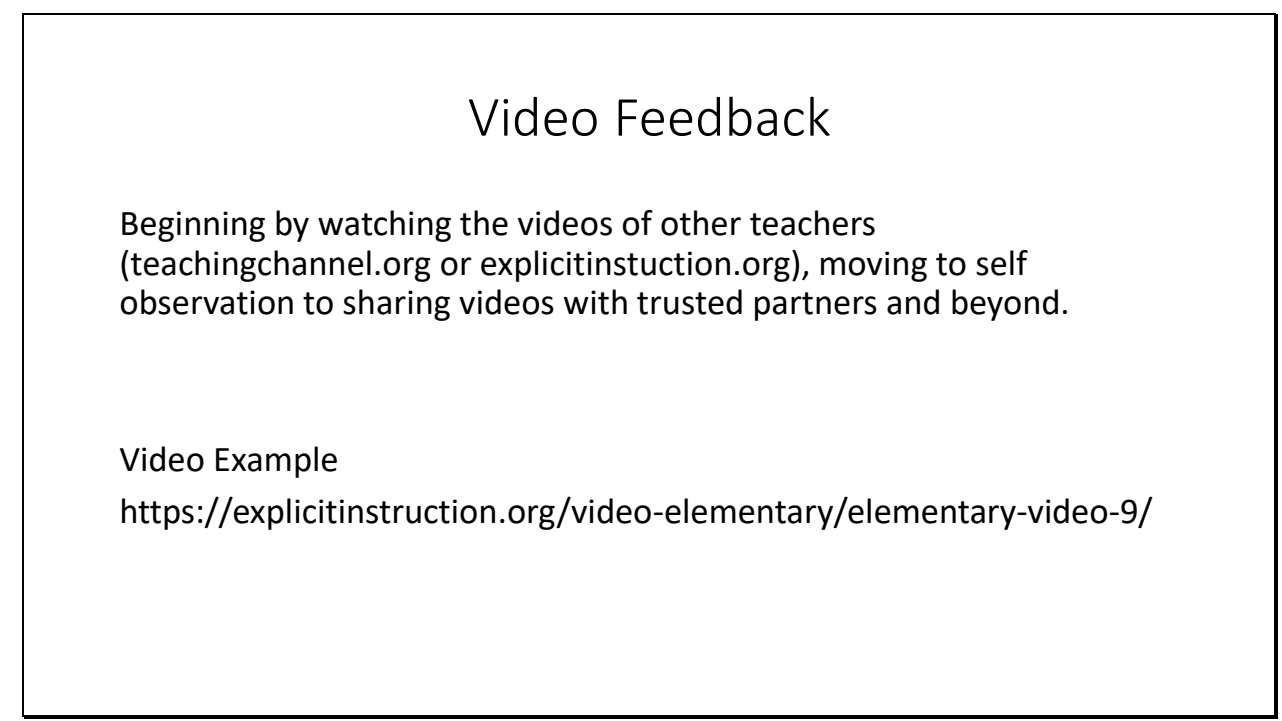

Teachers who are uncomfortable with observing others or being observed should first start with watching prerecorded videos. Notes should be taken very similarly to the observation checklist. Once the teacher feels more comfortable with observing, ask a trusted colleague to allow you in their room to observe. Then, move to self-observations.

Let's practice. We will be watching the video and completing the observation form in the previous slide. Please find it and pull it up. The boxes are editable. 
Slide 71

\section{Expert Coaching}

District and school based coaches provide observations and feedback as well as covering the classroom so a teacher can observe a particularly skilled colleague focused on an area of professional need.

Some counties do not provide expert coaching but your staff is full of these experts! If you have a weaker area and you want to improve it, ask around. Teachers will tell you who the best of the best is.

Slide 72

$$
\text { Principal Walk }
$$

These observations are brief usually lasting 5-10 minutes are can be helpful to have small $3 \times 5$ cards 
Principals are willing and able to complete these brief walkthroughs. If you are wanting an observation completed by your administrator, you should ask for support within an area and invite the administrator to your room. As that they provide you with 2-3 specific pieces of actionable feedback.

Slide 73

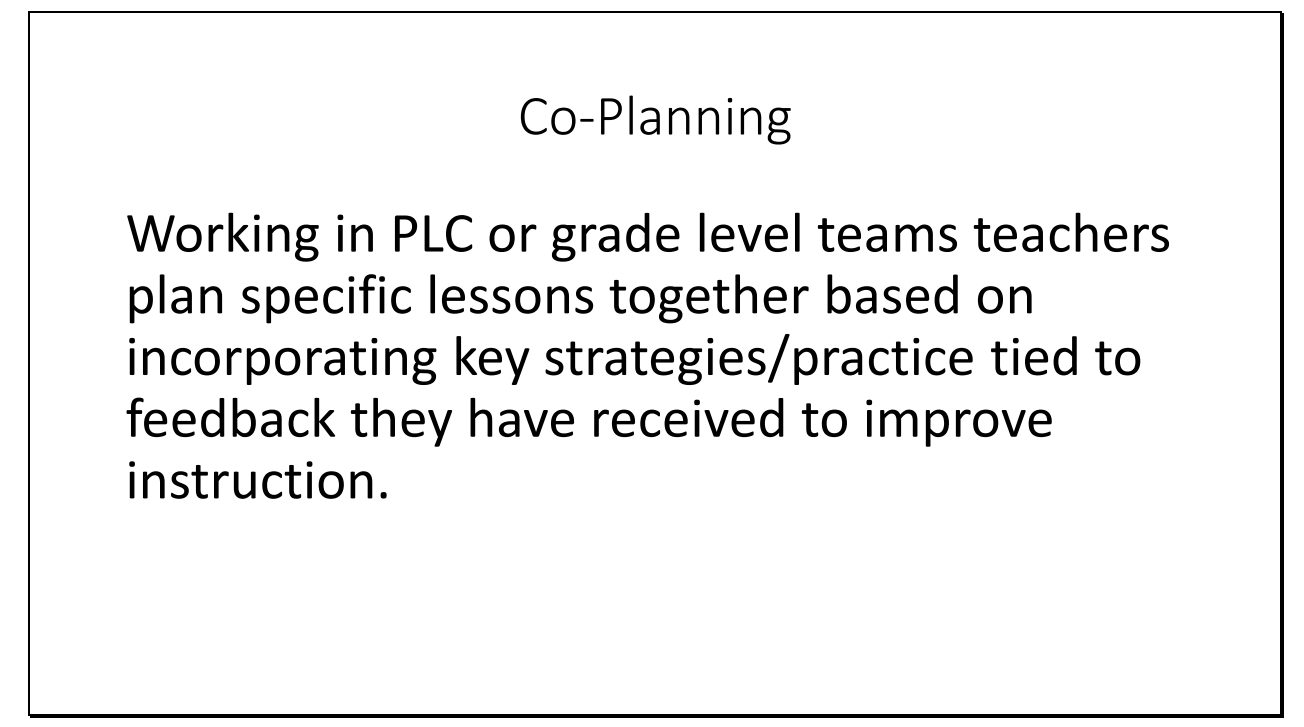

Slide 74

\section{Interview or Survey Students}

This can take many forms, a number of research validated tools have been developed that give students a voice in the school improvement project. 
The most different from the other 6, can be one the most beneficial. Students play one of the biggest roles in changing the climate of a school. What questions would you want to ask your students?

The facilitator will make a list of questions with the participants that could be used towards a student questionnaire or interview guide.

Slide 75

\section{If teachers aren't comfortable with observing or being observed...}

1. Focus on journal writing

Teachers pick one topic they wish to work on and journal on what they do to implement the new strategy. Questions to answer are:

What happened when I intentionally engaged in more ...? How did the children react?

2. Record a video for self-reflection

With a camera or smartphone, record a short-segment of teaching. Review the video and make note of which specific behaviors are exemplified.

Teachers are to self-record and self-reflect without expecting them to share their video recordings. 
Slide 76

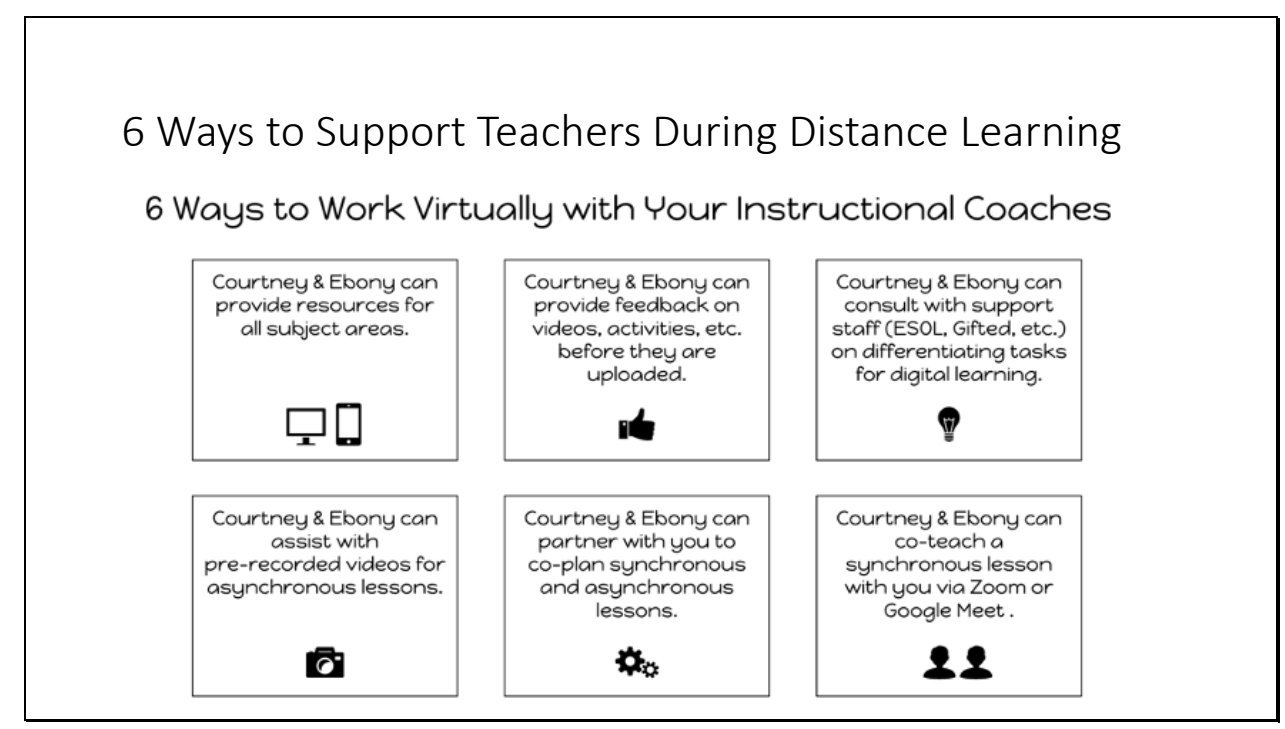

In unconventional times and not knowing what's coming ahead, how can teachers support one another as they continue to grow professionally?

Teachers can provide resources for all subject areas for one another. Teachers can still provide feedback on videos and activities before they are uploaded to students. Teachers can consult with support staff for support for differentiation. Teachers can assist one another in pre-recording lessons as students work independently on assignments. Teachers can co-plan together and collaborate for future lessons. Lastly, Teachers can co-teach lessons together to support one another. Working together and creating a culture of collaboration and respect between coworkers is a beginning step towards trust working towards a productive school culture. 
Slide 77

\section{Lunch 12:00- 1:00 on your own}

Slide 78

\section{Afternoon Session- 3 Day Professional Development Wrap Up.}

Teachers are tasked with forming two groups per grade level for a total of 4 groups.

In groups teachers are to create a lesson of their choice using differentiation as a focal point of the lesson with the use of a coteaching strategy. They are to document their ideas and plan on large poster paper to be displayed after their demonstration.

Each group will perform their lesson with the rest of the participants forming a "learning walk observation"

Facilitator- Groups will be given 30 minutes to plan for the activity. Each demonstration should last between 5-10 minutes for a total of an hour.

Observations should use the walkthrough observation form. 
Slide 79

\section{Wrap Up}

Teachers will work with their grade level teams to work on differentiation tasks, coteaching plans, and further plans towards alternative instructional supports.

Slide 80

\section{Questionnaire}

One a scale of $1-5,1$ not sure 2 . maybe 3 . in the middle 4 . yes 5 absolutely

1. I can use differentiation in the mathematics classroom.

2. I can use differentiation in the ELA classroom.

3. I am knowledgeable of Co-teaching.

4. I am excited to use Co-teaching.

5. I think instructional support strategies are important.

6. I will use these instructional support strategies at least twice a nine weeks.

7. I felt this professional development was beneficial.

8. I would recommend this professional development.

Further Suggestions 
Slide 81

\section{Reflections}

Thank you for your time and dedication to our three day professional development!

Before you leave, please complete the short questionnaire that has been placed on your table! 


\section{Appendix B: Research Question 1 Round 3 of Coding}

\begin{tabular}{|c|c|c|c|c|c|c|}
\hline Choice & Technology & $\begin{array}{l}\text { Data-driven } \\
\text { instruction }\end{array}$ & $\begin{array}{l}\text { Teacher } \\
\text { collaboration }\end{array}$ & Training & $\begin{array}{l}\text { Learner } \\
\text { inventory }\end{array}$ & Accommodations \\
\hline $\begin{array}{l}\text { seating based on } \\
\text { behavior }\end{array}$ & technology & Instruction & $\begin{array}{l}\text { collaboration } \\
\text { with } \\
\text { teachers }\end{array}$ & $\begin{array}{l}\text { professional } \\
\text { development }\end{array}$ & $\begin{array}{l}\text { visual and } \\
\text { auditory }\end{array}$ & manipulatives \\
\hline grouped into pods & $\begin{array}{l}\text { school } \\
\text { provided } \\
\text { technology }\end{array}$ & $\begin{array}{l}\text { whole group } \\
\text { instruction }\end{array}$ & teams & $\begin{array}{l}\text { state } \\
\text { professional } \\
\text { development }\end{array}$ & $\begin{array}{l}\text { different } \\
\text { learning } \\
\text { styles }\end{array}$ & visual aids \\
\hline $\begin{array}{l}\text { students choose } \\
\text { seats }\end{array}$ & $\begin{array}{l}\text { ability based } \\
\text { programs }\end{array}$ & $\begin{array}{l}\text { whole group } \\
\text { to small } \\
\text { groups }\end{array}$ & $\begin{array}{l}\text { Sat, IEP, } \\
504 \text { Teams }\end{array}$ & $\begin{array}{l}\text { last year DI } \\
\text { training }\end{array}$ & $\begin{array}{l}\text { observable } \\
\text { missing } \\
\text { skills }\end{array}$ & $\begin{array}{l}\text { number of } \\
\text { problems }\end{array}$ \\
\hline job choices & $\begin{array}{l}\text { supplement } \\
\text { with } \\
\text { technology }\end{array}$ & $\begin{array}{l}\text { mandated } \\
\text { guided } \\
\text { reading } \\
\text { groups }\end{array}$ & $\begin{array}{l}\text { common } \\
\text { planning }\end{array}$ & $\begin{array}{l}\text { college prep } \\
\text { with DI }\end{array}$ & $\begin{array}{l}\text { learning } \\
\text { style } \\
\text { inventory }\end{array}$ & $\begin{array}{l}\text { remediate and } \\
\text { enrichment }\end{array}$ \\
\hline $\begin{array}{l}\text { free time to pick } \\
\text { activity }\end{array}$ & $\begin{array}{l}\text { technology } \\
\text { assistance }\end{array}$ & $\begin{array}{l}\text { "Start with } \\
\text { whole group } \\
\text { instruction" }\end{array}$ & PLC & $\begin{array}{l}\text { guided } \\
\text { reading } \\
\text { training }\end{array}$ & $\begin{array}{l}\text { interest } \\
\text { survey }\end{array}$ & thinking maps \\
\hline silent reading book & $\begin{array}{l}\text { technology } \\
\text { ability based }\end{array}$ & $\begin{array}{l}\text { "guided } \\
\text { reading } \\
\text { based on } \\
\text { ability" }\end{array}$ & $\begin{array}{l}\text { learning on } \\
\text { own and } \\
\text { from others }\end{array}$ & $\begin{array}{l}\text { some college } \\
\text { training }\end{array}$ & & $\begin{array}{l}\text { smaller spelling } \\
\text { test }\end{array}$ \\
\hline $\begin{array}{l}\text { student seating } \\
\text { choice }\end{array}$ & $\begin{array}{l}\text { school } \\
\text { provided } \\
\text { laptops and } \\
\text { iPad }\end{array}$ & $\begin{array}{l}\text { real world } \\
\text { application }\end{array}$ & $\begin{array}{l}\text { watching } \\
\text { colleagues }\end{array}$ & $\begin{array}{l}\text { educational } \\
\text { training }\end{array}$ & & $\begin{array}{l}\text { read aloud for } \\
\text { modification }\end{array}$ \\
\hline $\begin{array}{l}\text { choose between } \\
\text { online or paper } \\
\text { tests }\end{array}$ & $\begin{array}{l}\text { availably of } \\
\text { tech support }\end{array}$ & $\begin{array}{l}\text { interest } \\
\text { based } \\
\text { instruction }\end{array}$ & $\begin{array}{l}\text { DI book } \\
\text { study }\end{array}$ & $\begin{array}{l}\text { math4life } \\
\text { training }\end{array}$ & & $\begin{array}{l}\text { graphic } \\
\text { organizers }\end{array}$ \\
\hline choose partners & $\begin{array}{l}\text { one to one } \\
\text { devices }\end{array}$ & $\begin{array}{l}\text { mandated } \\
\text { technology } \\
\text { time }\end{array}$ & & & & tests read aloud \\
\hline $\begin{array}{l}\text { own silent reading } \\
\text { material }\end{array}$ & $\begin{array}{l}\text { technology } \\
\text { training }\end{array}$ & $\begin{array}{l}\text { small group } \\
\text { instruction }\end{array}$ & & & & \\
\hline choice boards & $\begin{array}{l}\text { computer } \\
\text { games }\end{array}$ & & & & & \\
\hline \multicolumn{7}{|l|}{ ELA choice } \\
\hline \multicolumn{7}{|l|}{$\begin{array}{l}\text { How to solve math } \\
\text { choice } \\
\text { recess activities } \\
\text { choice } \\
\text { choice boards for } \\
\text { spelling } \\
\text { book list for choice } \\
\text { writing on interest }\end{array}$} \\
\hline
\end{tabular}




\begin{tabular}{|c|c|c|c|c|c|c|}
\hline $\begin{array}{l}\text { Student } \\
\text { Collaboration }\end{array}$ & $\begin{array}{l}\text { Data Driven } \\
\text { Instruction }\end{array}$ & Assessment & Expectations & Identifying & Curriculum & $\begin{array}{l}\text { Diverse } \\
\text { Activities }\end{array}$ \\
\hline buddy system & $\begin{array}{l}\text { Data driven } \\
\text { instruction }\end{array}$ & informal feedback & $\begin{array}{l}\text { similar } \\
\text { expectations }\end{array}$ & bubble kids & $\begin{array}{l}\text { county wide } \\
\text { curriculum }\end{array}$ & $\begin{array}{l}\text { Stem } \\
\text { Activities }\end{array}$ \\
\hline partner work & $\begin{array}{l}\text { Content } \\
\text { based on } \\
\text { ability }\end{array}$ & $\begin{array}{l}\text { informal } \\
\text { assessment }\end{array}$ & $\begin{array}{l}\text { common } \\
\text { goals and } \\
\text { expectations }\end{array}$ & $\begin{array}{l}\text { self-directed } \\
\text { learners }\end{array}$ & $\begin{array}{l}\text { mandated } \\
\text { curriculum }\end{array}$ & $\begin{array}{l}\text { extra work to } \\
\text { advanced } \\
\text { learners }\end{array}$ \\
\hline $\begin{array}{l}\text { collaboration } \\
\text { and group } \\
\text { work }\end{array}$ & $\begin{array}{l}\text { Remediation } \\
\text { groups }\end{array}$ & $\begin{array}{l}\text { benchmark } \\
\text { assessments }\end{array}$ & $\begin{array}{l}\text { set own } \\
\text { goals }\end{array}$ & & $\begin{array}{l}\text { common } \\
\text { curriculum }\end{array}$ & $\begin{array}{l}\text { branch up to } \\
\text { harder skills }\end{array}$ \\
\hline stem groups & Reading level & $\begin{array}{l}\text { End of year GSA } \\
\text { data }\end{array}$ & & & $\begin{array}{l}\text { reading } \\
\text { series }\end{array}$ & stations \\
\hline \multirow[t]{2}{*}{$\begin{array}{l}\text { collaborative } \\
\text { learning } \\
\text { projects }\end{array}$} & $\begin{array}{l}\text { Student } \\
\text { strengths and } \\
\text { weaknesses }\end{array}$ & exit tickets & & & math series & \\
\hline & $\begin{array}{l}\text { Analysis of } \\
\text { data }\end{array}$ & & & & & \\
\hline $\begin{array}{l}\text { Differentiated } \\
\text { materials }\end{array}$ & $\begin{array}{l}\text { Differentiated } \\
\text { work }\end{array}$ & Grouping & $\begin{array}{l}\text { Importance } \\
\text { of DI }\end{array}$ & Supplies & Goal Setting & Programs \\
\hline leveled books & $\begin{array}{l}\text { independent } \\
\text { writing } \\
\text { samples }\end{array}$ & ability groups & $\begin{array}{l}\text { teaching on } \\
\text { their level }\end{array}$ & supplies given & $\begin{array}{l}\text { Goal setting } \\
\text { with } \\
\text { students }\end{array}$ & Planbook \\
\hline Harder books & $\begin{array}{l}\text { project based } \\
\text { for advanced }\end{array}$ & & $\begin{array}{l}\text { helping them } \\
\text { succeed and } \\
\text { make } \\
\text { progress } \\
\text { getting skills } \\
\text { they are } \\
\text { missing }\end{array}$ & $\begin{array}{l}\text { lots of } \\
\text { resources }\end{array}$ & $\begin{array}{l}\text { Goal setting } \\
\text { with } \\
\text { teachers }\end{array}$ & \\
\hline
\end{tabular}

\begin{tabular}{llll}
\hline $\begin{array}{l}\text { Title and } \\
\text { tutors }\end{array}$ & $\begin{array}{l}\text { Classroom } \\
\text { DI }\end{array}$ & $\begin{array}{l}\text { Classroom } \\
\text { Accommodations }\end{array}$ & $\begin{array}{l}\text { Student } \\
\text { Tracking }\end{array}$ \\
\hline Title 1 & group charts & flexible seating & $\begin{array}{l}\text { technology } \\
\text { program } \\
\text { progress } \\
\text { monitoring }\end{array}$ \\
Tutors & $\begin{array}{l}\text { leveled books } \\
\text { in classroom } \\
\text { library }\end{array}$ & $\begin{array}{l}\text { table for small } \\
\text { group instruction }\end{array}$ & \\
$\begin{array}{l}\text { Title 1 and } \\
\text { tutor } \\
\text { remediate }\end{array}$ & centers & reading table & \\
Support staff & & & \\
\hline
\end{tabular}




\section{Appendix C: Research Question 2 Round 3 of Coding}

\begin{tabular}{|c|c|c|c|c|c|c|}
\hline Pull out & Lack of Time & $\begin{array}{l}\text { Lack of } \\
\text { training }\end{array}$ & $\begin{array}{l}\text { No DI in } \\
\text { Product }\end{array}$ & $\begin{array}{l}\text { Instructional } \\
\text { Support }\end{array}$ & Curriculum & $\begin{array}{l}\text { Student } \\
\text { Needs }\end{array}$ \\
\hline $\begin{array}{l}\text { Pull out } \\
\text { services }\end{array}$ & No time & $\begin{array}{l}\text { What is } \\
\text { product? }\end{array}$ & $\begin{array}{l}\text { Chapter } \\
\text { Tests }\end{array}$ & $\begin{array}{l}\text { Mandated } \\
\text { technology } \\
\text { time }\end{array}$ & $\begin{array}{l}\text { Mandated } \\
\text { curriculum }\end{array}$ & $\begin{array}{l}\text { Learning } \\
\text { disabilities } \\
\text { need more } \\
\text { one on one } \\
\text { time }\end{array}$ \\
\hline \multirow[t]{2}{*}{$\begin{array}{l}\text { Retired } \\
\text { teachers as } \\
\text { coach }\end{array}$} & time shortage & $\begin{array}{l}\text { More or less } \\
\text { questions }\end{array}$ & $\begin{array}{l}\text { End of unit } \\
\text { tests }\end{array}$ & $\begin{array}{l}\text { Classroom } \\
\text { management }\end{array}$ & $\begin{array}{l}\text { Certain } \\
\text { curriculum to } \\
\text { follow }\end{array}$ & $\begin{array}{l}\text { More } \\
\text { clarification } \\
\text { and } \\
\text { prompting }\end{array}$ \\
\hline & $\begin{array}{l}\text { A struggle to } \\
\text { DI all the time }\end{array}$ & $\begin{array}{l}\text { What is } \\
\text { process? }\end{array}$ & $\begin{array}{l}\text { Don't } \\
\text { differentiate } \\
\text { in math }\end{array}$ & $\begin{array}{l}\text { Observable } \\
\text { feedback }\end{array}$ & & $\begin{array}{l}\text { Required } \\
\text { extra time }\end{array}$ \\
\hline
\end{tabular}

\begin{tabular}{|c|c|c|c|c|c|c|}
\hline Interruptions & Misconceptions & Scheduling & $\begin{array}{l}\text { More } \\
\text { planning }\end{array}$ & $\begin{array}{l}\text { Different } \\
\text { instruction }\end{array}$ & $\begin{array}{l}\text { Administrative } \\
\text { help }\end{array}$ & $\begin{array}{l}\text { Losing } \\
\text { Instruction }\end{array}$ \\
\hline $\begin{array}{l}\text { Lower } \\
\text { students are } \\
\text { pulled out } \\
\text { more }\end{array}$ & $\begin{array}{l}\text { Lower level } \\
\text { students up } \\
\text { front }\end{array}$ & $\begin{array}{l}\text { Need to } \\
\text { rearrange } \\
\text { schedule }\end{array}$ & $\begin{array}{l}\text { More } \\
\text { planning } \\
\text { time }\end{array}$ & $\begin{array}{l}\text { Different } \\
\text { instruction } \\
\text { with pullout }\end{array}$ & $\begin{array}{l}\text { Not enough } \\
\text { administrative } \\
\text { help }\end{array}$ & $\begin{array}{l}\text { Students } \\
\text { miss } \\
\text { instruction }\end{array}$ \\
\hline \multirow{3}{*}{$\begin{array}{l}\text { Special } \\
\text { education } \\
\text { distractions } \\
\text { Entering and } \\
\text { exiting } \\
\text { distraction }\end{array}$} & $\begin{array}{l}\text { Don't use } \\
\text { choice boards }\end{array}$ & $\begin{array}{l}\text { Conflicting } \\
\text { schedules }\end{array}$ & $\begin{array}{l}\text { Only plan } \\
\text { for whole } \\
\text { group }\end{array}$ & & $\begin{array}{l}\text { Very little } \\
\text { administrative } \\
\text { support }\end{array}$ & $\begin{array}{l}\text { Missing } \\
\text { instruction }\end{array}$ \\
\hline & $\begin{array}{l}\text { Give less } \\
\text { questions }\end{array}$ & & & & $\begin{array}{l}\text { Little to no } \\
\text { observations }\end{array}$ & \\
\hline & $\begin{array}{l}\text { Can't give } \\
\text { choice }\end{array}$ & & & & & \\
\hline
\end{tabular}

\begin{tabular}{lllll}
\hline $\begin{array}{l}\text { More } \\
\text { support }\end{array}$ & No supplies & $\begin{array}{l}\text { Teacher } \\
\text { expectations }\end{array}$ & Behavior & Choice \\
\hline $\begin{array}{l}\text { Could use } \\
\text { more } \\
\text { support staff }\end{array}$ & $\begin{array}{l}\text { Hard to find } \\
\text { materials }\end{array}$ & $\begin{array}{l}\text { Plans not } \\
\text { required to } \\
\text { be detailed }\end{array}$ & Behavior & $\begin{array}{l}\text { No math } \\
\text { choice }\end{array}$ \\
\end{tabular}

